\title{
Consensus statement on the management of pulmonary hypertension in clinical practice in the UK and Ireland
}

\author{
National Pulmonary Hypertension Centres of the UK and Ireland
}

Correspondence to:

Dr J Simon R Gibbs, National

Pulmonary Hypertension Service,

Department of Cardiology,

Hammersmith Hospital, Du Cane

Road, London W12 OHS, UK;

s.gibbs@imperial.ac.uk

\section{FOREWORD}

I am delighted to write the foreword for this consensus statement which updates the "Recommendations on the management of pulmonary hypertension in clinical practice" of 2001. The consensus statement reflects contemporary practice in the management of this uncommon, deadly but now treatable condition in the pulmonary hypertension designated centres in the UK and Ireland. It matches and complements international guidelines, which are currently under revision.

In addition to health professionals who encounter affected patients within national centres or in other fields of practice, the statement is a comprehensive but readily accessible source of information for commissioners and managers of specialised services.

Initially the evidence on which to base the care of patients with rare and deadly diseases often rests on the experience and judgement of those who deliver daily care, the collection of clinical, epidemiological and pathological data, and the assiduous construction of informative registers. This familiar discipline has enabled the advances summarised in this document.

The first challenge to health service commissioners is to ensure that all patients with pulmonary hypertension have access to appropriate therapy as quickly as possible. Delay in making the diagnosis has the same consequences as delay in those with cancer. Regrettably "postcode prescribing" and its consequences still persist.

As for other uncommon conditions, continued progress in developing effective therapies rests on specialised centres working in concert to develop and participate in well-designed clinical trials, particularly trials of combination therapy.

This statement is a testament to the major advances in therapy made over the last 10 years, progress those of us who have cared for such patients over more than 30 years could not have envisaged.

Professor Dame Carol $M$ Black DBE, MD, FRCP, MACP, FMEDSCT

\section{INTRODUCTION}

In 2001 the BCS Guidelines and Medical Practice Committee published their "Recommendations on the management of pulmonary hypertension in clinical practice" which was approved by the British Thoracic Society (BTS) and the British Society of Rheumatology (BSR).

\section{Lead clinicians}

Gerry Coghlan, Royal Free Hospital, London, UK Paul A Corris (Co-editor), Freeman Hospital, Newcastle, UK

Sean Gaine, Mater Misericordae, Dublin, Ireland Michael A Gatzoulis, Royal Brompton Hospital, London, UK

J Simon R Gibbs (Chairman and co-editor), Hammersmith Hospital, London, UK

Sheila G Haworth, Great Ormond Street Hospital for Children, London, UK

David G Kiely, Royal Hallamshire Hospital, Sheffield, UK Andrew Peacock, Western Infirmary, Glasgow, UK

Joanna Pepke-Zaba, Papworth Hospital, Papworth Everard, UK

\section{Pulmonary hypertension clinicians}

Carol Black, Royal Free Hospital, London, UK

Charlie Elliot, Royal Hallamshire Hospital, Sheffield, UK

Andrew J Fisher, Freeman Hospital, Newcastle UK

Clive Handler, Royal Free Hospital, London, UK

Luke Howard, Hammersmith Hospital, London, UK

Rodney Hughes, Royal Hallamshire Hospital, Sheffield, UK

David P Jenkins, Papworth Hospital, Papworth Everard, UK

Martin Johnson, Western Infirmary, Glasgow, UK

Jim Lordan, Freeman Hospital, Newcastle, UK

Guy MacGowan, Freeman Hospital, Newcastle UK Nick Morrell, Addenbrookes Hospital, Cambridge, UK Ingram Schulze-Neick, Great Ormond Street Hospital for Children, London, UK

Karen Sheares, Papworth Hospital, Papworth Everard, UK Martin Wilkins, Hammersmith Hospital, London, UK

John Wort, Royal Brompton Hospital, London, UK

\section{Pulmonary hypertension clinical nurse} specialists

Agnes Crozier, Western Infirmary, Glasgow, UK Clare Das, Royal Free Hospital, London, UK Julia De Soyza, Freeman Hospital, Newcastle, UK Sinead Doherty, Mater Misericordae, Dublin, Ireland Yvette Flynn, Great Ormond Street Hospital for Children, London, UK

Wendy Gin-Sing, Hammersmith Hospital, London, UK

Carl Harries, Royal Brompton Hospital, London, UK

Maureen Rootes, Papworth Hospital, Papworth Everard, UK

Invited individuals and organisations

Geoffey Carroll, Medical Director, Health Commission Wales

Pulmonary Hypertension Association (UK)

lain Armstrong, Royal Hallamshire Hospital, Sheffield, UK British Congenital Cardiac Association

John Gibbs, Leeds General Infirmary Leeds, UK

British Society of Human Genetics

Richard Trembath, Guy's Hospital, London, UK 
Subsequently the National Pulmonary Hypertension Centres of the UK and Ireland Physicians Committee was constituted to represent all of the designated centres. This statement is issued by this Committee and represents the views of healthcare professionals who provide expert management of pulmonary hypertension $(\mathrm{PH})$ in designated centres.

Major advances in the clinical management of $\mathrm{PH}$ have been made in the time which has elapsed since the 2001 publication. The purpose of this consensus statement is to update the 2001 recommendations to reflect contemporary clinical practice in designated centres routinely managing $\mathrm{PH}$ in the UK and Ireland. It is published to inform other health care professionals, commissioners and managers who are responsible for delivering healthcare.

Since 2001 formal guidelines for the management of pulmonary arterial hypertension (PAH) have been published by the European Society of Cardiology (ESC) ${ }^{2}$ and the American College of Chest Physicians (ACCP)..$^{3-6}$ Both of these guidelines are in the process of being updated for publication in 2008-2009. Furthermore the clinical nomenclature was revised ${ }^{7}$ and clinical practice recommendations made $e^{8-10}$ at the 3rd World Symposium on Pulmonary Arterial Hypertension in 2004. These will also be updated in 2008 at the 4th World Symposium.

We have not sought to replicate international guidelines and thus there is no grading of evidence or recommendations. Instead this consensus statement is intended to complement these PAH guidelines with specific emphasis on UK and Irish practice, as well as to extend them to other forms of $\mathrm{PH}$. We recognise that in such a rapidly advancing field of clinical practice there will be a need to revise this statement in due course.

\subsection{Evolution of treatment}

Patients with PAH who do not receive disease-targeted therapy have a poor quality of life ( $\mathrm{QoL})$ and high mortality at rates similar to many cancers. In 1996 the first randomised trial of drug therapy in PAH demonstrated benefit with epoprostenol, establishing this as therapy for severe idiopathic pulmonary arterial hypertension (IPAH) in World Health Organization (WHO) functional classes III and IV. ${ }^{11}$

Over the last 10 years randomised, placebo controlled trials of other prostacyclin analogues, endothelin receptor antagonists and phosphodiesterase inhibitors have shown significant benefit to patients with $\mathrm{PAH}$, with improved survival and functional class.

In the UK designated centres, the number of patients on these treatments in both clinical practice and clinical trials on 31 March was 638 in 2004, 912 in 2005, 1242 in 2006 and 1499 in 2007. This represents a total of 24.9 patients treated per million population based on the size of the UK population in mid $2005 .{ }^{12}$ It is expected that this number will increase as patients survive longer, more patients come to medical attention and the indications for disease-targeted therapy expands.

\subsection{Centres designated to manage pulmonary hypertension}

The purpose of designated centres is to provide best clinical practice, well coordinated patient care, clinical research, and advice for those who are managing patients but are not specialists in PH. Care is provided by multiprofessional teams for inpatients, day cases and outpatients with $24 \mathrm{~h}$ cover.

Centres designated to manage $\mathrm{PH}$ are shown in table 1 . There are seven hospitals in England, one in Scotland and one in

\section{Abbreviations}

ACCP: American College of Chest Physicians

ALK-1: activin receptor-like kinase 1

APAH: associated pulmonary arterial hypertension

ATS: American Thoracic Society

BCS: British Cardiovascular Society

BLT: bilateral lung transplantation

BMPRII: bone morphogenetic protein receptor type II

BNP: brain natriuretic peptide

BSR: British Society of Rheumatology

BTS: British Thoracic Society

cAMP: cyclic adenosine monophosphate

CAMPHOR: Cambridge Pulmonary Hypertension Outcome Review

CCAD: Central Cardiac Audit Database

cGMP: cyclic guanosine monophosphate

COPD: chronic obstructive pulmonary disease

CPET: cardiopulmonary exercise test

CT: computed tomography scan

CTD: connective tissue disease

CTEPH: chronic thromboembolic pulmonary hypertension

DLCO: lung diffusing capacity

ECG: electrocardiogram

ERA: endothelin receptor antagonist

ETA: endothelin A

ETB: endothelin B

ESC: European Society of Cardiology

FPAH: familial pulmonary arterial hypertension

GOSHC: Great Ormond Street Hospital for Children

GP: general practitioner

GUCH: grown-up congenital heart disease

HIV: human immunodeficiency virus

HROOL: health-related quality of life

ILD: interstitial lung disease

INR: international normalised ratio

IPAH: idiopathic pulmonary arterial hypertension

ISHLT: International Society of Heart and Lung Transplantation

IVC: inferior vena cava

LTOT: long term oxygen therapy

MCTD: mixed connective tissue disease

MR: magnetic resonance

NCG: National Commissioning Group (formerly NSCAG)

NHS: National Health Service

NO: nitric oxide

NSCAG: National Specialist Commissioning Advisory Group

NSD: National Service Division

NYHA: New York Heart Association

PAH: pulmonary arterial hypertension

PAP: pulmonary arterial pressure

PASP: pulmonary arterial systolic pressure (estimated by echocardio-

graphy)

PCH: pulmonary capillary haemangiomatosis

PCT: Primary Care Trust

PCWP: pulmonary capillary wedge pressure

PDE: phosphodiesterase

PEA: pulmonary endarterectomy

PF0: patent foramen ovale

PH: pulmonary hypertension

Pro-NT BNP: pro-N terminal brain natriuretic peptide

PVOD: pulmonary veno-occlusive disease

PVR: pulmonary vascular resistance

QoL: quality of life

SCG: Specialist Commissioning Group

SLE: systemic lupus erythematosis

SLT: single lung transplantation

SSc: scleroderma

TGF $\beta$ : transforming growth factor $\beta$

TR: tricuspid regurgitation

VIP: vasoactive intestinal polypeptide

WHO: World Health Organization 
Ireland. Wales and Northern Ireland refer patients to UK centres and may develop their own or satellite centres in the future. This directory of centres is kept current at www.thephdirectory.com.

Formal designation of centres was undertaken by the National Specialist Commissioning Advisory Group (NSCAG) of the Department of Health in England in 2001, the National Service Division (NSD) of the Scottish Parliament in Scotland in 1998, and the Health Service Executive in Ireland. NSCAG was replaced by the National Commissioning Group (NCG) in 2007. These centres are monitored by their designating bodies by regular site visits and audit against agreed Standards of Care. Audit data will become centralised in the National Health Service (NHS) in 2008 when it is collected from all designated centres by the Central Cardiac Audit Database (CCAD).

\subsection{Commissioning of pulmonary hypertension in England}

In England, $\mathrm{PH}$ is included within the list of defined specialist services issued by the Department of Health. For adults, this means that Primary Care Trusts (PCTs) are required to commission the service through formal collaborative arrangements established by the Specialist Commissioning Group (SCG) responsible for their area.

At national level specialist commissioners are working with the six designated adult centre lead clinicians to formulate service development strategies and policies aimed at ensuring a consistent and dynamic approach in the future.

Funding of expensive disease-targeted therapies is provided on an individual patient basis by PCTs to whom applications must

Table 1 Designated pulmonary hypertension centres in the UK and Ireland

\begin{tabular}{|c|c|}
\hline $\begin{array}{l}\text { Designated centre } \\
\text { location }\end{array}$ & Contact details \\
\hline Glasgow, Scotland & $\begin{array}{l}\text { Scottish Pulmonary Vascular Unit, Western Infirmary, } \\
\text { Glasgow, G11 6NT } \\
\text { Tel: } 01412116327 \text { Fax: } 01412116334 \\
\text { Website: www.spvu.co.uk }\end{array}$ \\
\hline $\begin{array}{l}\text { Newcastle-upon-Tyne, } \\
\text { England }\end{array}$ & $\begin{array}{l}\text { Northern Pulmonary Vascular Unit, Regional Cardiothoracic } \\
\text { Centre, Freeman Hospital, Newcastle upon Tyne, NE7 7DN } \\
\text { Tel: } 01912231084 \text { or } 01912448608 \\
\text { Fax: } 01912231691\end{array}$ \\
\hline Sheffield, England & $\begin{array}{l}\text { Pulmonary Vascular Unit, Royal Hallamshire Hospital, } \\
\text { Glossop Road, Sheffield, S10 2JF } \\
\text { Tel: } 01142712590 \text { Fax: } 01142711718\end{array}$ \\
\hline Cambridge, England & $\begin{array}{l}\text { Pulmonary Vascular Diseases Unit, Papworth Hospital NHS } \\
\text { Trust, Papworth Everard, Cambridge CB3 8RE } \\
\text { Tel: } 01480830541 \text { Fax: } 01480831315 \\
\text { Website: www.papworth-hospital.org.uk }\end{array}$ \\
\hline London, England & $\begin{array}{l}\text { Pulmonary Hypertension Service, Hammersmith Hospital, } \\
\text { Du Cane Road, London, W12 OHS } \\
\text { Tel: } 02083832330 \text { Fax: } 02083832331 \\
\text { Website: www.pulmonary-hypertension.org.uk }\end{array}$ \\
\hline London, England & $\begin{array}{l}\text { Royal Brompton Pulmonary Hypertension and Adult } \\
\text { Congenital Heart Centre, } \\
\text { Sydney Street, London SW3 6NP } \\
\text { Tel: } 02073518362 \text { Fax: } 02073518629 \\
\text { Website: www.rbht.nhs.uk }\end{array}$ \\
\hline London, England & $\begin{array}{l}\text { Royal Free Hospital, Pond Street, London, NW3 } 20 \text { G } \\
\text { Tel: } 02077940500 \text { ext } 8648 \text {. } \\
\text { Website: www.royalfree.nhs.uk }\end{array}$ \\
\hline London, England & $\begin{array}{l}\text { UK Pulmonary Hypertension Service for Children, Great } \\
\text { Ormond Street Hospital, } \\
\text { London, WC1N 1EH } \\
\text { Tel } 02074059200 \text { Ext.1005, 1007, } 8495\end{array}$ \\
\hline Dublin, Ireland & $\begin{array}{l}\text { Mater Misericordiae University Hospital } \\
\text { Eccles Street, Dublin } 7 \\
\text { Tel } 0035318034420 \\
\text { Website: www.mater.ie }\end{array}$ \\
\hline
\end{tabular}

be made for each patient by a designated centre. Some PCTs have formed consortia to fund the cost of treatment according to strict criteria without the need for individual applications.

For children, NCG not only designates but funds the service and drug therapies. The Pulmonary Endarterectomy (PEA) Service is separately NCG designated and centrally funded.

\subsection{Commissioning of pulmonary hypertension in Scotland}

The Scottish Pulmonary Vascular Unit is commissioned to provide services for Scotland and is centrally funded by the NSD.

\subsection{Commissioning of pulmonary hypertension in Ireland}

A single PH Unit has been commissioned to provide a service for the whole of the Republic of Ireland and is centrally funded on a yearly basis by the Health Service Executive.

\subsection{Collection of audit data}

Currently all designated centres collect audit data in local databases. In 2008 the UK data will be centralised in the CCAD, part of the National Clinical Audit Support Programme of the NHS.

\section{NOMENCLATURE}

\subsection{Clinical classification}

The clinical classification of $\mathrm{PH}$ is key to making an accurate diagnosis and guides treatment. It was updated in $2004^{7}$ (box 1).

The classification is based upon groups of diseases causing $\mathrm{PH}$ which demonstrate similarities in clinical presentation, pathophysiology and therapeutic options.

The broad influence of the clinical classification on management is seen in table 2 .

\subsection{Functional class}

The severity of $\mathrm{PH}$ is assessed according to a modification of the New York Heart Association (NYHA) functional classification ${ }^{13}$ shown in box 2. It has long been recognised that symptomatic severity is related to prognosis ${ }^{14}$ and this remains so in contemporary practice (fig 1 ) $^{15}$ emphasising the need for early referral for investigation and treatment.

\section{PATHOPHYSIOLOGY AND GENETICS OF PULMONARY ARTERIAL HYPERTENSION: LINKS TO TREATMENTS}

The pathology of PAH is characterised by luminal obliteration of small pulmonary arteries. This process of vascular remodelling involves proliferation of smooth muscle cells, fibroblasts and endothelial cells in the vessel wall. ${ }^{16-18}$ In severe forms of $\mathrm{PH}$, the formation of a neointima is observed forming concentric intimal lesions. Abnormal endothelial cell proliferation results in the formation of plexiform lesions (fig 2). The most severe forms of precapillary $\mathrm{PH}$ are usually pathologically indistinguishable.

A number of mediators and growth factors have been shown to be involved in driving the cellular changes. Increased circulating and local expression of endothelin-1 is observed in patients with PAH. ${ }^{19} 20$ As well as being a potent vasoconstrictor, endothelin stimulates smooth muscle and fibroblast proliferation via the endothelin A (ETA) and/or endothelin B (ETB) receptors, which are increased in small hypertensive pulmonary arteries. ${ }^{21}$ Circulating levels of serotonin are also elevated in $\mathrm{PAH}^{22}$ Serotonin stimulates mitogenesis of vascular cells via serotonin receptors, including $5 \mathrm{HT}_{2 \mathrm{~A}}, 5 \mathrm{HT}_{2 \mathrm{~B}}$ and $5 \mathrm{HT}_{1 \mathrm{~B}} \cdot{ }^{18}$ In human pulmonary artery smooth muscle cells, a 
Box 1: Revised clinical classification of pulmonary

hypertension (Venice 2003) following the previous Evian

classification (described in the 2001 BCS

recommendations)

1. Pulmonary arterial hypertension (PAH)

1.1. Idiopathic (IPAH)

1.2. Familial (FPAH)

1.3. Associated with (APAH):

1.3.1. Collagen vascular disease

1.3.2. Congenital systemic-to-pulmonary shunts

1.3.3. Portal hypertension

1.3.4. HIV infection

1.3.5. Drugs and toxins

1.3.6. Other (thyroid disorders, glycogen storage disease, Gaucher's disease, hereditary haemorrhagic telangiectasia, haemoglobinopathies, myeloproliferative disorders, splenectomy) 1.4. Associated with significant venous or capillary involvement

1.4.1. Pulmonary veno-occlusive disease (PVOD)

1.4.2. Pulmonary capillary haemangiomatosis $(\mathrm{PCH})$

1.5. Persistent pulmonary hypertension of the newborn

2. Pulmonary hypertension with left heart disease

2.1. Left-sided atrial or ventricular heart disease

2.2. Left-sided valvular heart disease

\section{Pulmonary hypertension associated with lung diseases} and/or hypoxaemia

3.1. Chronic obstructive pulmonary disease

3.2. Interstitial lung disease

3.3. Sleep disordered breathing

3.4. Alveolar hypoventilation disorders

3.5. Chronic exposure to high altitude

3.6. Developmental abnormalities

\section{Pulmonary hypertension due to chronic thrombotic and/or embolic disease}

4.1. Thromboembolic obstruction of proximal pulmonary arteries

4.2. Thromboembolic obstruction of distal pulmonary arteries

4.3. Non-thrombotic pulmonary embolism (tumour, parasites, foreign material)

\section{Miscellaneous}

Sarcoidosis, histiocytosis $\mathrm{X}$, lymphangiomatosis, compression of pulmonary vessels (adenopathy, tumour, fibrosing mediastinitis)

major proliferative pathway involves activation of mitogen activated protein kinases via the serotonin transporter. ${ }^{23}$ Increased expression of the transporter is found in hypertensive arteries.

A relative deficiency of vasodilator pathways is observed in severe $\mathrm{PAH}$, an imbalance which enhances the activity of mitogenic and vasoconstrictor pathways. Patients with $\mathrm{PAH}$ produce less endothelial-derived prostacyclin, and have reduced expression of nitric oxide (NO) synthase and vasoconstrictive thromboxane. ${ }^{24}$ More recent studies have also shown a deficiency of the neuropeptide vasodilator vasoactive intestinal polypeptide (VIP) in the lungs of patients with PAH. ${ }^{25}$ Many of the important vasodilator pathways also exert antiproliferative effects on vascular cells. The deficiency of these key vasodilator pathways has provided the rationale for therapies.

Other important pathways involved in the process of pulmonary vascular remodelling include changes in potassium
Table 2 Clinical classification of pulmonary hypertension (PH) as a guide to treatment

\begin{tabular}{|c|c|}
\hline Classification & Treatment \\
\hline $\begin{array}{l}\text { Pulmonary arterial } \\
\text { hypertension }\end{array}$ & $\begin{array}{l}\text { Disease-targeted therapies (but caution in veno- } \\
\text { occlusive disease) }\end{array}$ \\
\hline $\mathrm{PH}$ with left heart disease & $\begin{array}{l}\text { Medical, interventional and surgical therapies for } \\
\text { chronic heart failure, coronary artery disease, valve } \\
\text { disease and pericardial disease }\end{array}$ \\
\hline \multirow{3}{*}{$\begin{array}{l}\text { PH associated with lung } \\
\text { diseases and/or hypoxaemia }\end{array}$} & Therapy to treat the primary lung disorder \\
\hline & Oxygen \\
\hline & $\begin{array}{l}\text { Disease-targeted therapies when pulmonary } \\
\text { hypertension out of proportion to lung disease }\end{array}$ \\
\hline \multirow{2}{*}{$\begin{array}{l}\text { PH due to chronic thrombotic } \\
\text { and/or embolic disease }\end{array}$} & Pulmonary endarterectomy (PEA) for proximal disease \\
\hline & $\begin{array}{l}\text { Disease-targeted therapies for distal disease (see } \\
\text { section } 6.4 .8 .7 \text { ), significant residual post-PEA } \\
\text { pulmonary hypertension or late redevelopment of } \\
\text { symptomatic pulmonary hypertension post-PEA }\end{array}$ \\
\hline Miscellaneous & Specific to individual diseases \\
\hline
\end{tabular}

channel (Kv1.5 and 2.1) expression, activation of vascular elastases, and increased expression of inflammatory cytokines and chemokines. ${ }^{18}$

The genetics of PAH is described in section 5.3.1.

\section{OBJECTIVES AND PRIORITIES FOR INVESTIGATION}

\subsection{Definition of pulmonary hypertension}

$\mathrm{PH}$ is defined as a mean pulmonary arterial pressure (PAP) of $>25 \mathrm{~mm} \mathrm{Hg}$ at rest or $>30 \mathrm{~mm} \mathrm{Hg}$ on exercise at cardiac catheterisation. ${ }^{26} \mathrm{PAH}$ also requires a pulmonary capillary wedge pressure (PCWP) $\leqslant 15 \mathrm{~mm} \mathrm{Hg}$ and a pulmonary vascular resistance $(\mathrm{PVR}) \geqslant 240$ dynes $/ \mathrm{s} / \mathrm{cm}^{5}$.

\subsection{When to suspect pulmonary hypertension}

The principal symptoms of $\mathrm{PH}$ are non-specific and the clinical signs subtle until patients present with advanced disease. ${ }^{26}$ As a consequence the diagnosis is most readily made where a systematic approach is taken to investigation, and high risk patients are targeted with screening programmes.

\section{Box 2: Functional classification of pulmonary hypertension} modified after the New York Heart Association functional classification according to the World Health Organization 1998

- Class I: Patients with pulmonary hypertension but without resulting limitation of physical activity. Ordinary physical activity does not cause undue dyspnoea or fatigue, chest pain or near syncope.

- Class II: Patients with pulmonary hypertension resulting in slight limitation of physical activity. They are comfortable at rest. Ordinary physical activity causes undue dyspnoea or fatigue, chest pain or near syncope.

- Class III: Patients with pulmonary hypertension resulting in marked limitation of physical activity. They are comfortable at rest. Less than ordinary activity causes undue dyspnoea or fatigue, chest pain or near syncope.

- Class IV: Patients with pulmonary hypertension with inability to carry out any physical activity without symptoms. These patients manifest signs of right heart failure. Dyspnoea and/or fatigue may even be present at rest. Discomfort is increased by any physical activity. 


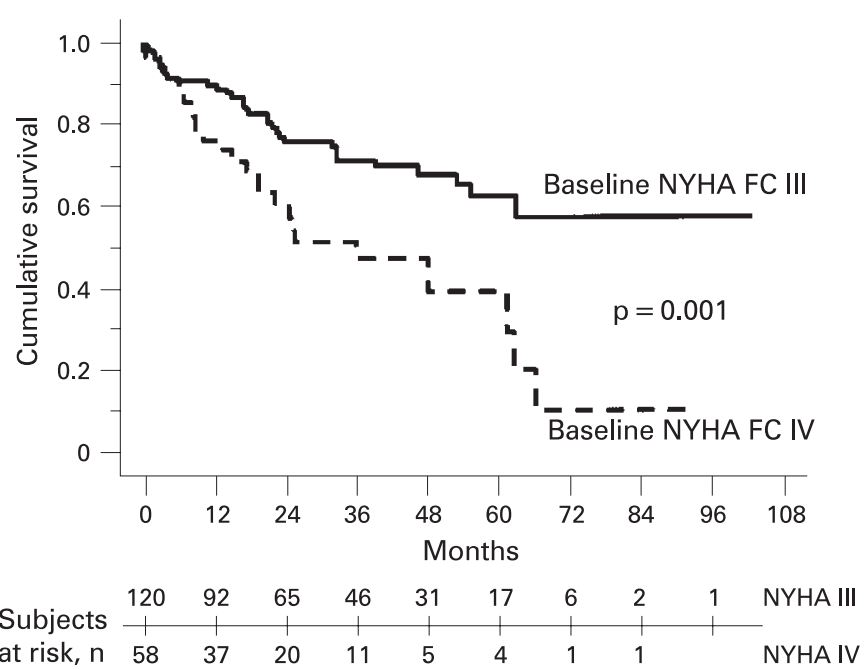

Figure 1 Survival of patients with idiopathic pulmonary arterial hypertension based upon functional class (FC) at clinical presentation. NYHA, New York Heart Association. Reproduced with permission from Sitbon 0, et al. J Am Coll Cardiol 2002;40:780-8 (fig 2, panel A only).

Clinical suspicion should arise in any patient presenting with breathlessness without overt signs of specific heart or pulmonary disease, particularly in diseases which may be associated with $\mathrm{PH}$ (box 1). While breathlessness is the most common symptom, patients may also present with chest pain, syncope, fatigue, weakness and abdominal distension. ${ }^{26}$ Frequently there is a delay of up to 3 years between first symptom and diagnosis and this interval has remained the same over the last 10 years. ${ }^{27}$

The precordial signs of $\mathrm{PH}$ include right ventricular lift, accentuated pulmonary component of the second heart sound, a pansystolic murmur of tricuspid regurgitation, a diastolic murmur of pulmonary regurgitation and a right ventricular third sound. Jugular venous distension, hepatomegaly, peripheral oedema, ascites and cold extremities characterise patients in a more advanced state with right ventricular failure at rest; central cyanosis may also be present. Ankle swelling occurs late in the natural history of the disease.

When faced with breathlessness of unknown cause, spirometry is a useful screening test to exclude common respiratory disease. A chest $x$ ray and ECG should be performed since these tests are abnormal in $80-90 \%$ of patients presenting with symptoms caused by established $\mathrm{PH} .{ }^{1}$ The ECG may demonstrate right ventricular hypertrophy and strain and right atrial dilatation. The ECG alone has inadequate sensitivity (55\%) and specificity $(70 \%)$ to be a screening tool for detecting $\mathrm{PH}^{28}$

Doppler echocardiography is the most useful non-invasive investigation and allows an estimate of pulmonary arterial systolic pressure (PASP). ${ }^{29}$ Its sensitivity and specificity in identifying $\mathrm{PH}$ depends on the population and limitations relate primarily to technical aspects of this technique. The estimated upper limit for PASP in $95 \%$ of normal subjects is $37.2 \mathrm{~mm} \mathrm{Hg} .{ }^{30}$ A PASP $>40 \mathrm{~mm} \mathrm{Hg}$ was found in $6 \%$ of those $>50$ years old and $5 \%$ of those with a body mass index (BMI) $>30 \mathrm{~kg} / \mathrm{m}$. Twenty-eight per cent of normal subjects have a PASP $>30 \mathrm{~mm} \mathrm{Hg}$, and the expected upper limit of PASP may be as high as $40 \mathrm{~mm} \mathrm{Hg}$ in older or obese subjects. Mild PH has been defined as a peak tricuspid regurgitation (TR) velocity of 2.8$3.4 \mathrm{~m} / \mathrm{s}$ with a normal right atrial pressure. ${ }^{2}$

Computed tomographic (CT) scanning also provides useful information on right ventricular and pulmonary artery size, raising the possibility of $\mathrm{PH}$ which had not otherwise been suspected.

\section{RECOMMENDATIONS}

1. $\mathrm{PH}$ should be considered in all patients presenting with breathlessness in the absence of an alternative cause of cardiorespiratory disease. The presence of progressive breathlessness associated with chest pain or syncope should particularly alert the clinician to this diagnosis.

2. While ECG and chest $x$ ray are often abnormal at presentation, the sensitivity of these investigations is such that normal appearances do not exclude $\mathrm{PH}$.

Figure 2 Pathophysiology of pulmonary arterial hypertension (PAH) and its relationship to treatment. ANP, atrial natriuretic peptide; AMP, adenosine monophosphate; ATP, adenosine triphosphate; BNP, brain natriuretic peptide; GMP, guanosine monophosphate; GTP, guanosine triphosphate; NO, nitric oxide; PDE, phosphodiesterase; VIP, vasoactive intestinal polypeptide.
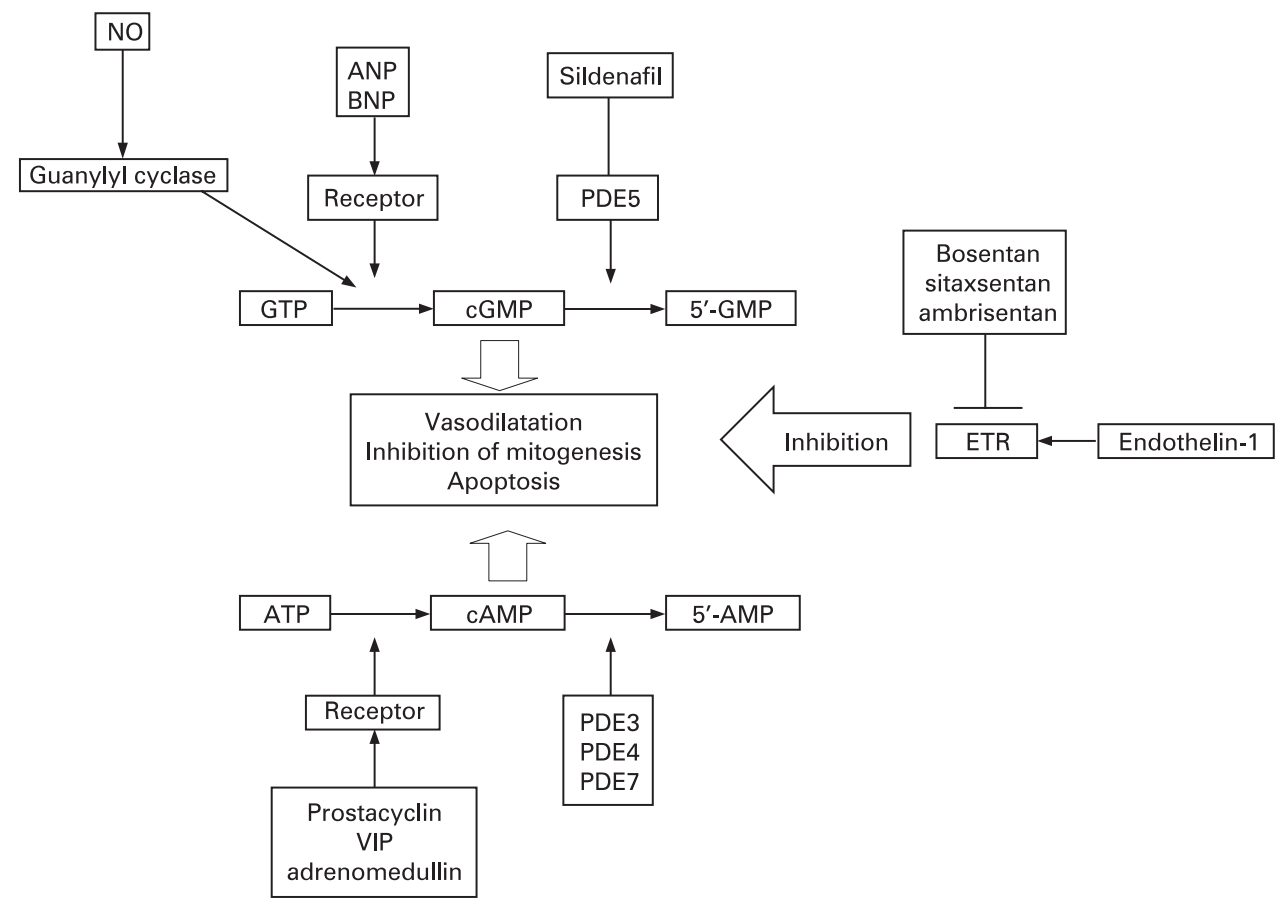
3. Spirometry should be performed to detect common respiratory diseases.

4. Doppler echocardiography is the best screening investigation for $\mathrm{PH}$.

\subsection{Screening at risk populations for pulmonary hypertension}

\subsubsection{Genetic screening for pulmonary arterial hypertension}

Incident data from specialist centres indicate the minimum frequency of recognised familial pulmonary arterial hypertension (FPAH) as $5-10 \%$ of referrals. Risk for FPAH is conferred by a heterozygous loss of function mutation of receptor members of the TGF $\beta$ superfamily, most commonly defects in the gene encoding the type II receptor, BMPRII. ${ }^{31}{ }^{32}$ Rarely, mutations of the type I receptor, $A L K-l$, have been detected in PAH subjects who may also exhibit the clinical features characteristic of hereditary haemorrhagic telangiectasia. ${ }^{33}$ A significant proportion of sporadic cases (classified as IPAH) have germline TGF $\beta$ mutations ${ }^{34}$ while the frequency of detectable mutations appears lower in childhood onset disease. ${ }^{35}$ Incidence and prevalence data for populations for FPAH/IPAH have not been reported.

An evidence base for the management of "at risk" individuals for PAH requires further research and will require modification should disease prevention or modification strategies emerge. The provision of information regarding risk and opportunities for risk resolution in monogenic disorders is a recognised function of genetic services, which should be extended to FPAH kindreds.

Indications for clinical and molecular genetic screening in IPAH remain unclear and require further research. Empirical data suggest low disease risks to first and second degree relatives in IPAH. Presentation in childhood raises specific parental concern for occurrence of disease in siblings (recurrence risk) and/or the unborn child (offspring risk) which may require referral for specialist genetic counselling. Mutation analysis has provided no insight into the clinical variability of PAH, particularly age of onset which may vary significantly within families. ${ }^{35}{ }^{36}$ The genetic basis of associated forms of $\mathrm{PAH}$ remains unclear.

\section{RECOMMENDATIONS}

5. Recognised familial cases of PAH should be offered familybased risk assessment including genetic counselling.

6. Molecular genetic testing may be indicated in FPAH following comprehensive genetic counselling for (a) resolution of individual risk and (b) family planning. Joint management of "at risk" individuals within recognised families between genetic services and specialist PAH centres is indicated. Clinical monitoring of at risk relatives is indicated for early detection of disease and management of symptoms. The frequency at which this should be conducted is unknown.

7. Close (first degree) relatives of index IPAH patients should be provided with written information of the genetic basis of the disorder, including recognition of the low $(<5 \%)$ recurrence and offspring risk. The role of clinical monitoring in this group is unknown.

8. Parental anxiety regarding recurrence and/or offspring risk following childhood onset presentation with IPAH is an indication for genetic services referral with provision for clinical assessment of "at risk" family members.

\subsubsection{Associated pulmonary arterial hypertension}

$\mathrm{PAH}$ is commonly seen in association with connective tissue disease (CTD), ${ }^{37}$ congenital heart disease, ${ }^{38}$ sickle cell disease, ${ }^{39}$ portal hypertension ${ }^{40}$ and HIV infection. ${ }^{41}$ This has resulted in a number of screening regimens to identify PAH in at risk groups ranging from investigating patients with symptoms of breathlessness to interval screening of asymptomatic individuals.

\section{RECOMMENDATIONS}

9. Screening of breathless patients should be performed in diseases where PAH is a known complication. Right heart catheterisation should be undertaken when Doppler echocardiography measures a peak TR velocity of $\geqslant 2.8 \mathrm{~m} / \mathrm{s}$ with a normal right atrial pressure (equivalent to $36 \mathrm{~mm} \mathrm{Hg}$ ).

\subsubsection{Connective tissue disease}

Pulmonary hypertension is a well known complication of CTD, particularly in limited cutaneous scleroderma (SSc) where the prevalence in this group is $12 \%{ }^{42}$ and mixed CTD (MCTD) with U1 RNP antibodies. ${ }^{43}$ PAH is recognised by an increased Doppler peak TR velocity at echocardiography and reduced lung diffusing capacity (DLCO)..$^{37} 45$

\section{RECOMMENDATIONS}

10. Screening should be performed annually in patients with limited cutaneous SSc or MCTD with U1 RNP antibodies, using echocardiography and DLCO. Right heart catheterisation should be performed in all cases with a peak TR velocity of $\geqslant 2.8 \mathrm{~m} / \mathrm{s}$ on echocardiography or a reduction in DLCO of $50 \%$ in the absence of interstitial lung disease (ILD). Patients with other CTDs are screened only in the presence of symptoms.

\subsubsection{Porto-pulmonary hypertension}

The prevalence of $\mathrm{PAH}$ in patients undergoing liver transplantation is $4.0-3.5 \%{ }^{46}$ In addition porto-systemic shunts increase the risk of developing $\mathrm{PAH}{ }^{47}$

\section{RECOMMENDATIONS}

11. All patients with portal hypertension and cirrhosis should undergo echocardiography if liver transplantation is planned.

\subsubsection{Haemolytic anaemia}

$\mathrm{PAH}$ is increasingly recognised in congenital haemolytic anaemias including sickle cell disease ${ }^{39}$ and thalassaemia. ${ }^{48} 49$ It is not yet clear whether these patients benefit from PAH disease-targeted therapies.

\section{RECOMMENDATIONS}

12. Screening for PAH is not routine in patients with haemolytic anaemia.

\subsubsection{HIV infection}

PAH is a rare complication of HIV with a cumulative incidence of $0.57 \%$ on an annual incidence of $0.1 \%{ }^{41}$

\section{RECOMMENDATIONS}

13. Screening for PAH is not routine in patients with HIV infection. 
Table 3 Imaging investigations recommended in the assessment of pulmonary hypertension (PH)

\begin{tabular}{|c|c|}
\hline Investigation & Comments \\
\hline Chest $x$ ray & $\begin{array}{l}\text { May show increase in cardiac chambers, increased } \\
\text { pulmonary artery size, hypoperfused areas of lung and } \\
\text { evidence of parenchymal lung disease }\end{array}$ \\
\hline $\begin{array}{l}\text { High resolution } \\
\text { computed tomography } \\
\text { (CT) scan of lungs }\end{array}$ & $\begin{array}{l}\text { May show parenchymal lung disease, mosaic perfusion (a } \\
\text { sign of pulmonary vascular embolism or thrombosis but for } \\
\text { which there are other causes such as air trapping), and } \\
\text { features of pulmonary venous hypertension }\end{array}$ \\
\hline $\begin{array}{l}\text { CT pulmonary } \\
\text { angiography }\end{array}$ & $\begin{array}{l}\text { Used to look for enlargement of pulmonary arteries, filling } \\
\text { defects and webs in the arteries. Detects enlarged bronchial } \\
\text { circulation }\end{array}$ \\
\hline $\begin{array}{l}\text { Ventilation perfusion } \\
\text { scanning }\end{array}$ & $\begin{array}{l}\text { More sensitive for chronic pulmonary thromboembolism } \\
\text { than CTPA but not helpful when there is underlying } \\
\text { parenchymal lung disease }\end{array}$ \\
\hline $\begin{array}{l}\text { Selective pulmonary } \\
\text { angiography by direct } \\
\text { injection of the } \\
\text { pulmonary arteries }\end{array}$ & $\begin{array}{l}\text { Gold standard for delineating chronic pulmonary } \\
\text { thromboembolism to define the location and extent of } \\
\text { disease. It may be superseded by magnetic resonance } \\
\text { angiography or multislice CT. }\end{array}$ \\
\hline Echocardiography & $\begin{array}{l}\text { Screening tool of choice for PH. Detects cardiac disease } \\
\text { (congenital, myocardial, valvular, intracavity clot or tumour, } \\
\text { pericardial). Use of contrast may be helpful to identify } \\
\text { shunts }\end{array}$ \\
\hline $\begin{array}{l}\text { Cardiac magnetic } \\
\text { resonance }\end{array}$ & $\begin{array}{l}\text { Good examination for imaging the right ventricle. Helpful in } \\
\text { delineating congenital heart defects, and the pulmonary } \\
\text { circulation by angiography }\end{array}$ \\
\hline Abdominal ultrasound & $\begin{array}{l}\text { Used for investigation of liver disease and suspected portal } \\
\text { hypertension. }\end{array}$ \\
\hline
\end{tabular}

\subsubsection{Pulmonary embolism}

Chronic thromboembolic pulmonary hypertension (CTEPH) is a complication of venous thromboembolism. Up to $4 \%$ of patients with idiopathic pulmonary embolism may develop CTEPH. ${ }^{50}$ Patients at greatest risk include those with previous episodes of venous thromboembolism, massive and sub-massive pulmonary embolism, ${ }^{51}$ an elevated PASP on admission or elevated pressure 2 months following initial presentation.

\section{RECOMMENDATIONS}

14. Patients with previous venous thromboembolism who are breathless should undergo echocardiography. Patients with massive or sub-massive pulmonary thromboembolism should undergo echocardiography 6-12 weeks following the index event. Where echocardiography is inconclusive and symptoms persist, consider contrast CT thorax.

\subsection{Criteria for referral to pulmonary hypertension centres}

Referrals are accepted at designated centres where screening investigations suggest $\mathrm{PH}$ for which there is not a cardiac or respiratory cause. Right heart catheterisation is not encouraged before referral unless individual cases are discussed with a designated centre, and the referring physician routinely undertakes right heart catheterisation with vasodilator studies.

\section{RECOMMENDATIONS}

15. Adults with confirmed or suspected PAH, CTEPH, a miscellaneous cause of $\mathrm{PH}$, or where the cause of $\mathrm{PH}$ is unclear should be referred to a designated centre. Referral should be considered in cases of $\mathrm{PH}$ in hypoxic lung disease or cardiac disease, but only if symptoms or estimated PASP at echocardiography seems excessive (>60 $\mathrm{mm} \mathrm{Hg}$ ) or the patient has another disease which may be associated with PAH.

16. Children should be referred to the UK Children's Service if they have confirmed or suspected IPAH or FPAH. The UK
Children's Service will also accept referral of and/or be available to give advice for all children with persistent neonatal $\mathrm{PH}$ beyond the first month of life, sustained, postoperative $\mathrm{PH}$, inoperable congenital heart disease with $\mathrm{PH}$, parenchymal lung disorders/disease with $\mathrm{PH}$, miscellaneous causes of $\mathrm{PH}$, or $\mathrm{PH}$ of uncertain cause.

17. All patients should have an ECG, chest $x$ ray, transthoracic echocardiogram, and spirometry in adults. If possible, all patients should be seen by a consultant in cardiology or respiratory medicine before referral to a designated centre.

18. Patients with PH may deteriorate rapidly. It is important that referrals are not delayed in order to undertake more extensive investigation if it is clear that $\mathrm{PH}$ is the dominant problem.

\subsection{Investigation at pulmonary hypertension centres}

The purpose of investigation is to confirm or exclude the diagnosis of $\mathrm{PH}$, and if present to determine the aetiology and severity of $\mathrm{PH}$ (table 3 and box 3 ).

\subsubsection{Cardiac and lung imaging}

The purpose of cardiac imaging is to determine if a cardiac cause of pulmonary hypertension is present, and assess severity. The particular advantage of non-invasive imaging is that it is safe, quick and simple to follow serially. Echocardiography can be performed at the bedside. Transoesophageal echocardiography is not routinely required but may be needed if congenital heart disease is suspected.

Lung imaging is used to detect CTEPH or parenchymal lung disease. Different techniques are used to achieve a diagnosis of $\mathrm{CTEPH}^{52}$ (fig 3). Parenchymal lung disease can be assessed on high resolution CT (table 3 ).

\section{RECOMMENDATIONS}

19. New patients require detailed investigation including cardiac and lung imaging to determine the aetiology and severity of $\mathrm{PH}$.

\subsubsection{Exercise testing}

A number of exercise test protocols have been used to assess exercise capacity although none are ideal.

The role of the 6 min walking test (6MWT) in the assessment of PH is firmly established. Guidelines describe how to perform this. ${ }^{53}$ Baseline values for distance walked correlate with functional class, pulmonary haemodynamics, cardiopulmonary exercise testing (CPET) variables and survival. ${ }^{54}$ Serial values have proven to be a useful outcome measure in the majority of drug trials in $\mathrm{PH}^{2}$ It is not an absolute change in walk distance following treatment that is predictive of survival but achieving a threshold distance. ${ }^{15}$ The sensitivity to change diminishes as the distance walked increases, particularly $>450 \mathrm{~m}$, and consequently may be less useful for patients in WHO functional classes I and II. ${ }^{55}$

Variants of the 6MWT include the shuttle test and endurance shuttle. ${ }^{5657}$

The incremental CPET is well standardised although technically more complex to perform. ${ }^{58}$ Baseline values have been shown to be predictive of disease severity and survival (including peak oxygen consumption, systolic blood pressure at peak exercise, the ventilatory equivalent for carbon dioxide and end-tidal carbon dioxide partial pressure). ${ }^{59} 60$ The test can help with differential diagnosis because patients with $\mathrm{PH}$ show characteristic changes. ${ }^{59} 61$ The significant disadvantage with the 
Box 3 Other investigations recommended in the assessment of pulmonary hypertension

- Respiratory:

- 6 min walk test

- arterial blood gases in room air

- lung function (including $\mathrm{FEV}_{1}, \mathrm{FVC}, \mathrm{TLC}, \mathrm{FRC}$, RV, TLCO, DLCO, KCO)

- nocturnal oxygen saturation monitoring

- Cardiology:

- ECG

- echocardiogram

- cardiac catheterisation (including right heart catheterisation with saturations and haemodynamics, and acute pulmonary vasoreactivity study as appropriate)

- Blood investigations include:

- routine biochemistry and haematology

- thrombophilia screen in CTEPH

- thyroid function

- autoimmune screen (including anti-centromere antibody, anti-SCL70 and U1 RNP, phospholipid antibodies)

- hepatitis serology

- serum angiotensin converting enzyme

- HIV

- Urine:

- $\beta$-HCG (women)

test is that it has not been proven useful as a serial measurement in drug trials. ${ }^{62-64}$

\section{RECOMMENDATIONS}

20. The $6 \mathrm{MWT}$ is the preferred exercise outcome measure for use in assessing patients with $\mathrm{PH}$ both at baseline and subsequent visits and should be performed according to American Thoracic Society (ATS) guidelines.

21. A baseline CPET may be useful in selected cases to confirm that exercise limitation is due to $\mathrm{PH}$ and to delineate further disease severity and prognosis.

\subsubsection{Lung function}

Comprehensive dynamic and static lung function testing is able to detect the presence of coincident obstructive or restrictive lung disease. The classical picture in PAH without coexistent lung disease is normal spirometry and lung volumes, sometimes with mild restriction, but decreased diffusing capacity. Normal lung function does not preclude $\mathrm{PH}$.

\section{RECOMMENDATIONS}

22. Lung function testing should include the measurement of spirometry, static and dynamic lung volumes and DLCO.

\subsubsection{Biomarkers}

Several biomarkers have been shown to be useful markers of heart disease. Brain natriuretic peptide (BNP) is released from ventricular myocytes in response to increased wall tension. It is recognised as a predictor of mortality, disease progression and response to therapy in PAH and CTEPH. ${ }^{65-67}$ ProBNP is the prohormone which is cleaved into active BNP and more stable $\mathrm{N}$-terminal fragment, NT-proBNP. The levels of BNP and proBNP are dependent on age, sex, glomerular filtration rate and obesity. ${ }^{66} 68-70$
Patients with unexplained pulmonary hypertension or pulmonary hypertension and a history of pulmonary embolism

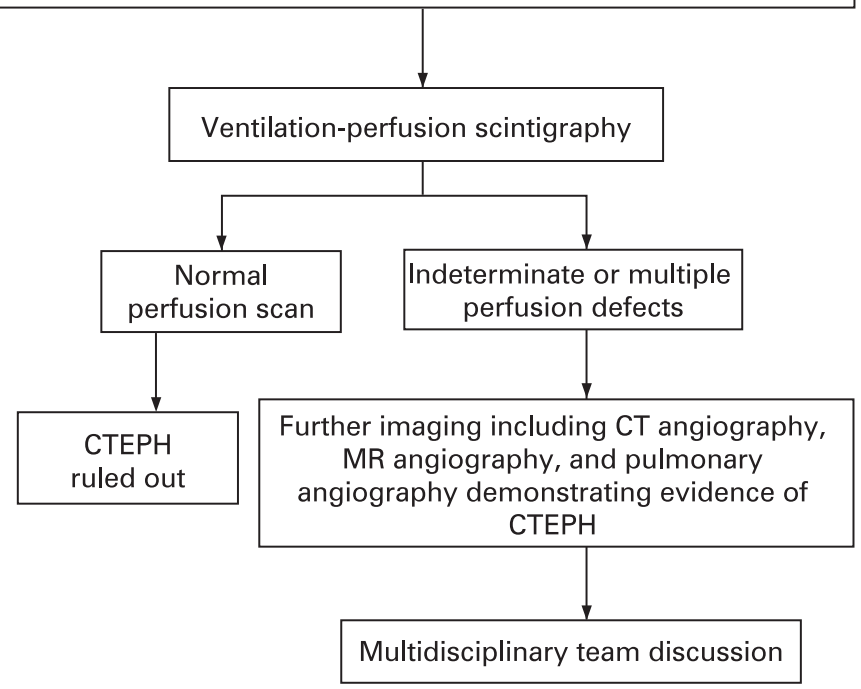

Figure 3 Diagnostic approach to chronic thromboembolic pulmonary hypertension (CTEPH). CT, computed tomography; MR magnetic resonance.

BNP and/or proBNP have been shown to be elevated in IPAH, $\mathrm{PAH}$ associated with scleroderma, systemic-to-pulmonary shunts, and PH with interstitial lung disease, chronic obstructive pulmonary disease (COPD), and CTEPH. ${ }^{66}{ }^{67}{ }^{71-75}$ Baseline and/or serial changes in BNP and NT-proBNP correlate with survival and surrogate markers such as pulmonary haemodynamics, functional class and 6MWT distance. ${ }^{65}{ }^{66}{ }^{76-78}$ Data on troponin are too limited to make any recommendations at present. $^{79}$

\section{RECOMMENDATIONS}

23. Baseline plasma NT-proBNP is a useful prognostic marker in PAH patients without significant renal or left ventricular impairment.

\subsubsection{Right heart catheterisation}

Right heart catheterisation should be undertaken in new patients after other investigation results have been reviewed in order to determine exactly which measurements are needed (box 4). It is also used to answer specific clinical questions during follow-up. Cardiac output should be measured either by thermodilution or the Fick method, the latter only when oxygen consumption is measured. Exercise haemodynamics may be helpful to evaluate borderline $\mathrm{PH}$ and left heart disease.

A vasoreactivity study is undertaken to determine suitability for high dose calcium antagonist therapy in those groups of patients who are known to benefit from such therapy. These studies are performed using inhaled NO (the agent of choice), or an infusion of intravenous epoprostenol or adenosine. ${ }^{2} \mathrm{~A}$ positive response is apparent when the mean PAP falls at least $10 \mathrm{~mm} \mathrm{Hg}$ to $<40 \mathrm{~mm} \mathrm{Hg}$ with either an increase or no change in cardiac output. A vasoreactivity study is contraindicated in $\mathrm{PAH}$ associated with significant venous or capillary involvement because of the risk of pulmonary oedema.

\section{RECOMMENDATIONS}

24. Right heart catheterisation is essential during the initial investigation of new patients. 
Box 4 Measurements typically made at right heart catheterisation

- Pressure measurements should be made in the following places:

- systemic artery

- pulmonary capillary wedge (or left ventricular enddiastolic pressure if not obtainable)

- pulmonary artery

- right ventricle

- right atrium

- (left atrium if entered via a patent foramen ovale or atrial septal defect)

- Blood samples for oximetry should be taken from:

- systemic artery

- (left atrium if entered)

- pulmonary artery (take 3 saturations and average results)

- Derived variables to be calculated:

- cardiac output and index

- pulmonary and systemic vascular resistances

25. A vasoreactivity study should be performed in patients with IPAH, FPAH, CTD APAH (excluding SSc APAH), and anorexogen-induced APAH. Only responders should be treated with high dose calcium channel blockers.

\section{OBJECTIVES AND PRIORITIES FOR TREATMENT}

\subsection{Anticoagulation}

Vascular thrombotic lesions have been identified with high prevalence at post-mortem in patients with IPAH ${ }^{80}{ }^{81}$ and other forms of $\mathrm{PAH}^{82}$ Although a relationship between thrombotic lesions, age and disease duration ${ }^{83}$ have been suggested this is not a universal finding. ${ }^{17}$ Thrombosis appears uncommon in children. Abnormalities in coagulation and fibrinolytic pathways, and platelet function have also been demonstrated. ${ }^{84-86}$ Clinical studies are limited. Two retrospective ${ }^{81}{ }^{87}$ and one small non-randomised prospective study ${ }^{88}$ have associated anticoagulation use with a survival benefit. These studies have been conducted almost exclusively in patients with IPAH. Randomised controlled trials are needed in patients with PAH associated with other diseases where the risk benefit ratio of anticoagulation is not known.

\section{RECOMMENDATIONS}

26. Anticoagulation with warfarin is recommended in patients with IPAH and CTEPH in the absence of contraindications. The international normalised ratio (INR) should be maintained between 2 and 3. For IPAH patients with a higher than normal bleeding risk an INR of 1.5 to 2.5 is suggested.

27. Anticoagulant therapy is recommended in Ssc APAH although this recommendation is purely consensus based.

\subsection{0xygen therapy}

Oxygen administered acutely has been demonstrated to reduce PVR in both hypoxic and non-hypoxic patients with PH. There are no randomised data available to suggest that long term oxygen therapy (LTOT) is beneficial in PAH. There are data showing that nocturnal oxygen therapy does not modify the natural history of advanced Eisenmenger syndrome ${ }^{89}$ (see section 6.4.8.3). This does not exclude the possibility of benefit from LTOT in other patient groups with $\mathrm{PH}$ since it is an increase in alveolar oxygen which leads to a reduction in pulmonary vascular resistance. Arterial oxygenation is not a good reflection of alveolar oxygenation in Eisenmenger physiology.

Based on the limited evidence from studies with COPD, ${ }^{90} 91$ oxygen should be prescribed in accordance with the BTS Working Group on Home Oxygen Services. ${ }^{92}$ When arterial oxygen pressure $\left(\mathrm{PaO}_{2}\right)$ is consistently at or $<8 \mathrm{kPa}$ (breathing room air) during a period of clinical stability, oxygen should or may be prescribed for at least $15 \mathrm{~h}$ a day (including night time) to achieve a $\mathrm{PaO}_{2}$ of $>8 \mathrm{kPa}$. Where daytime oxygenation is satisfactory, nocturnal oxygenation should be assessed and oxygen prescribed if mean overnight saturations are $<90 \%$ to achieve a mean saturation greater than this. There can be no recommendation for oxygen in $\mathrm{PAH}$ associated with congenital heart disease.

Arterial hypoxaemia can contribute to breathlessness on exertion through stimulation of the peripheral chemoreflex. The prescription of ambulatory oxygen should follow the recommendations of the BTS document. ${ }^{92}$ Consequently, the patient will qualify for ambulatory oxygen if there is evidence of symptomatic benefit and correctible desaturation of $>4 \%$ to $<90 \%$ on a $6 \mathrm{MWT}$.

There have been no studies using flight simulation to determine which patients require oxygen during air travel, but given the known physiological effects of hypoxia, it seems currently prudent to consider in-flight oxygen for all patients with significant pulmonary hypertension. A flow rate of $2 \mathrm{l} / \mathrm{min}$ will raise inspired $\mathrm{PO}_{2}$ to sea level values.

\section{RECOMMENDATIONS}

Except with congenital heart disease:

28. All patients should have nocturnal oxygen saturation monitoring at initial assessment and thereafter when clinically indicated.

29. Oxygen should be administered to maintain daytime and nocturnal $\mathrm{PaO}_{2}>8 \mathrm{kPa}$

30. Ambulatory oxygen can be considered in those with correctable exercise desaturation of $>4 \%$ to $<90 \%$ for symptomatic benefit.

31. In-flight supplemental oxygen should be considered for all patients in WHO functional class III and IV or those with resting oxygen saturations $<95 \%$.

\subsection{Supportive medical therapy}

Assisting patients to adapt to the uncertainty associated with chronic, life shortening disease is essential if they are to adjust successfully to the demands of their illness and its treatment. The health care team needs to be highly skilled in managing the burden and impact of this disease, and its complex and intrusive therapies at both physical and psychological levels.

Patients with $\mathrm{PH}$ often feel isolated by their diagnosis ${ }^{93}$ and many seek help from support groups for numerous reasons including learning about their illness, sharing coping strategies with others who have similar health problems, sharing their experiences, and gaining emotional support. Encouraging patients and their family members to be part of support groups can have positive effects on coping, confidence, outlook and relationships. ${ }^{94}$ Nationally the UK pulmonary hypertension patient group (The Pulmonary Hypertension Association UK, http://www.pha-uk.com) offers support to patients and their carers. Patients may also access the NHS Expert Patients Programme for people living with long term chronic ill health 
through their local GP surgery or library, and their local pulmonary hypertension support group where this exists.

\section{RECOMMENDATIONS}

32. Patients with $\mathrm{PH}$ should be managed by an experienced multiprofessional team with the required skill and expertise to meet the holistic needs of the patient and their carers. These needs include information about the disease and its prognosis, education and support in managing complex drug therapies, psychological, social and spiritual support, and access to local support in the community.

33. Patients should be encouraged to join a support group.

\subsubsection{Family planning}

Pregnancy is associated with a high risk of maternal death. The WHO identifies $\mathrm{PH}$ as a contraindication to pregnancy and advises discussing termination in the event of pregnancy.

For contraception progesterone only preparations such as medroxyprogesterone acetate and etonogestrel are highly effective. ${ }^{95}$ The Mirena coil is also effective but $5 \%$ of women may have a vasovagal reaction ${ }^{96}$ which can have potentially fatal effects in the setting of reduced cardiovascular reserve. Sterilisation is rarely used in this population due to the operative risks and higher failure rate. Bosentan is an enzyme inducer and may reduce the efficacy of hormonal contraceptive preparations (see section 6.4.7).

Some patients who become pregnant choose to continue their pregnancies even when they are informed of the high risk. Despite a variety of approaches to its management ${ }^{97-99}$ the mortality remains high. Early treatment with disease-targeted therapy ${ }^{100} 101$ may improve the chances of maternal survival. With timely admission to hospital, planned elective delivery ${ }^{102}$ and incremental regional anaesthesia with close cooperation of a PH multidisciplinary team, a successful outcome for mother and fetus may be possible although maternal mortality remains high. ${ }^{103}$

\section{RECOMMENDATION}

34. Patients with $\mathrm{PH}$ should be counselled regarding the very high risk of pregnancy ( $>30 \%$ mortality) with clear contraceptive advice. They should be offered early termination of pregnancy if the pregnancy is unwanted.

35. If a patient becomes pregnant termination of pregnancy should be discussed. When patients are fully informed and understand the risks of proceeding with pregnancy, treatment with disease-targeted therapies for $\mathrm{PAH}$ represents a realistic option and may improve the chances of maternal survival.

\subsubsection{Physical activity}

Advice regarding physical activity is empirical in $\mathrm{PH}$ and based on consensus opinion. A recent study has demonstrated an improvement in exercise capacity in patients who took part in a training programme. ${ }^{104}$

\section{RECOMMENDATIONS}

36. Patients should be encouraged to be as active as their symptoms allow. Mild breathlessness is acceptable but patients should be advised to stop exercising if they become moderately or severely breathlessness, or develop exertional dizziness or chest pain.

\subsubsection{Heart failure and arrhythmias}

Heart failure gives rise to fluid retention which is improved by diuretics, although no randomised controlled trials exist on the use of diuretics in $\mathrm{PH}$.

Digoxin has been shown to improve cardiac output acutely in IPAH ${ }^{105}$ although its efficacy is unknown when administered chronically.

Atrial flutter and other tachyarrhythmias are often poorly tolerated and may present with worsening heart failure or syncope. Treatment with an appropriate therapy after verification of the arrhythmia is recommended. Note that $\beta$-blockers are poorly tolerated in $\mathrm{PH} .{ }^{106}$

\section{RECOMMENDATIONS}

37. Diuretics are indicated to reduce fluid retention.

38. Digoxin may be beneficial in heart failure and should be considered in patients in sinus rhythm who remain symptomatic on medical therapy.

39. Acute arrhythmias require prompt management with the aim of restoring sinus rhythm and preventing recurrence of the arrhythmia.

\subsubsection{Immunisations}

Patients with $\mathrm{PH}$ are prone to infections which are often poorly tolerated because of their reduced cardiovascular reserve.

\section{RECOMMENDATION}

40. Patients should be offered immunisation against pneumococcal pneumonia and annual immunisation against influenza.

\subsection{Disease-targeted therapies for PAH}

The aim of therapy is to improve survival, symptoms and QoL. On the basis of a series of randomised trials, epoprostenol, iloprost, treprostinil, bosentan, sitaxsentan and sildenafil are available as monotherapy in some forms of PAH. These drugs offer not only improved symptom control, exercise capacity, QoL and haemodynamics, but also the prospect of extended survival. Survival is closely related to WHO functional class and exercise capacity. ${ }^{15} 107$

\subsubsection{Therapeutic classes of drugs}

Only therapies that are used in current clinical practice in the UK and Ireland have been considered. Since many reviews of drug trials in PAH have been published, we have chosen to tabulate those studies published before November 2006. For brevity these trials are not discussed further in the text. Tables 4-11 include all randomised trials and those nonrandomised trials considered by the consensus meeting to have significant impact based on the number of patients in the trial, study design and data collection. They have not been selected on the basis of a positive or negative result.

Entry criteria into the randomised trials were similar across studies: 6MWT distance $>100-150 \mathrm{~m}$ and $<450-500 \mathrm{~m}$ (except STRIDE-1 study which had no exercise limitations), mean PAP $>25 \mathrm{~mm} \mathrm{Hg}$, PCWP $\leqslant 15 \mathrm{~mm} \mathrm{Hg}$ and PVR $>240$ dynes $/ \mathrm{s} / \mathrm{cm}^{5}$.

There are no large comparative studies between the drugs and therefore our recommendations are based upon a consensus of UK and Irish specialists and the 2004 European Society of Cardiology guidelines. ${ }^{2}$

Survival has been examined up to 5 years in open label studies. In these tables, data are only reported up to $2-3$ years owing to the small number of patients beyond these time 


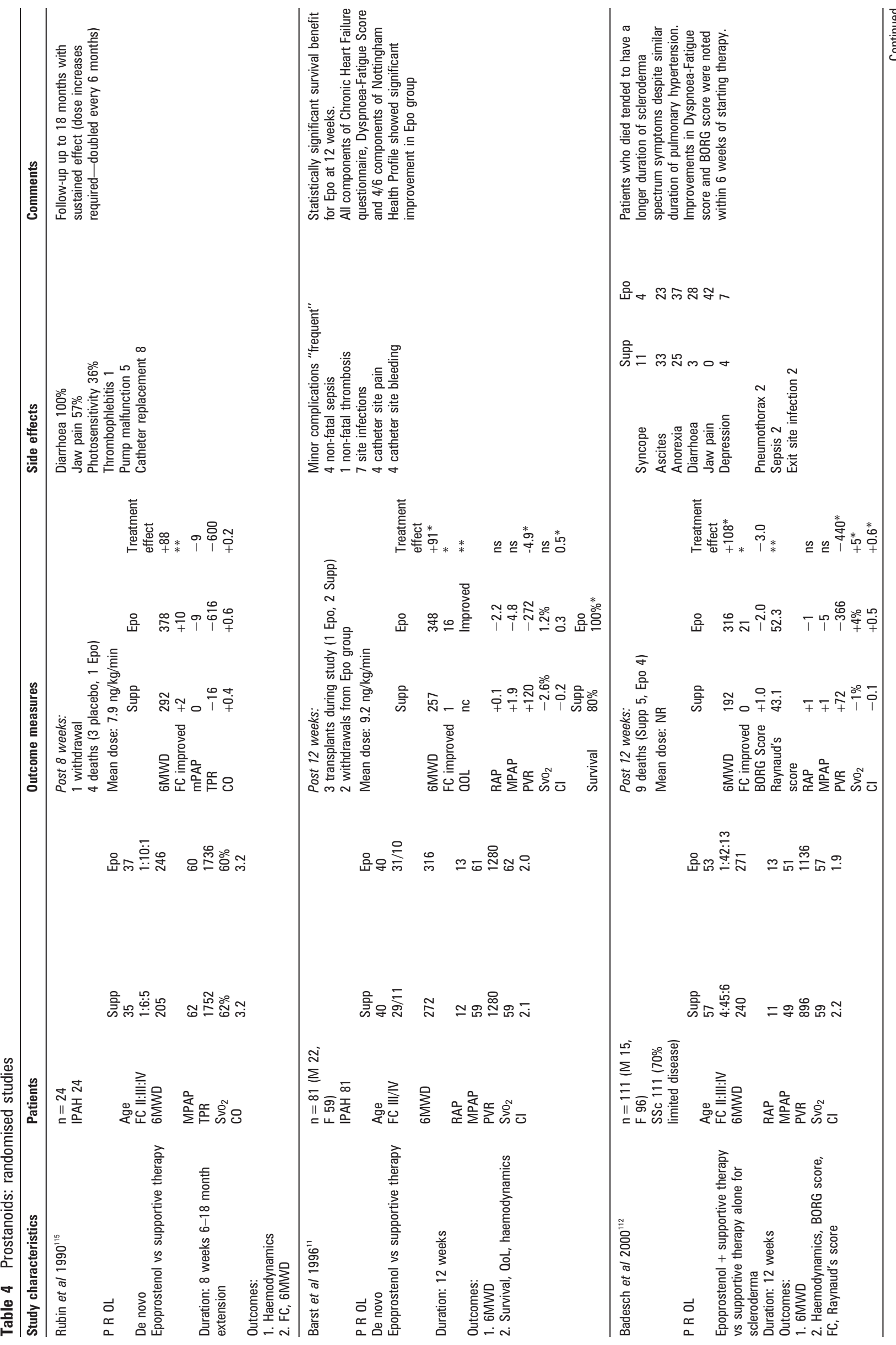




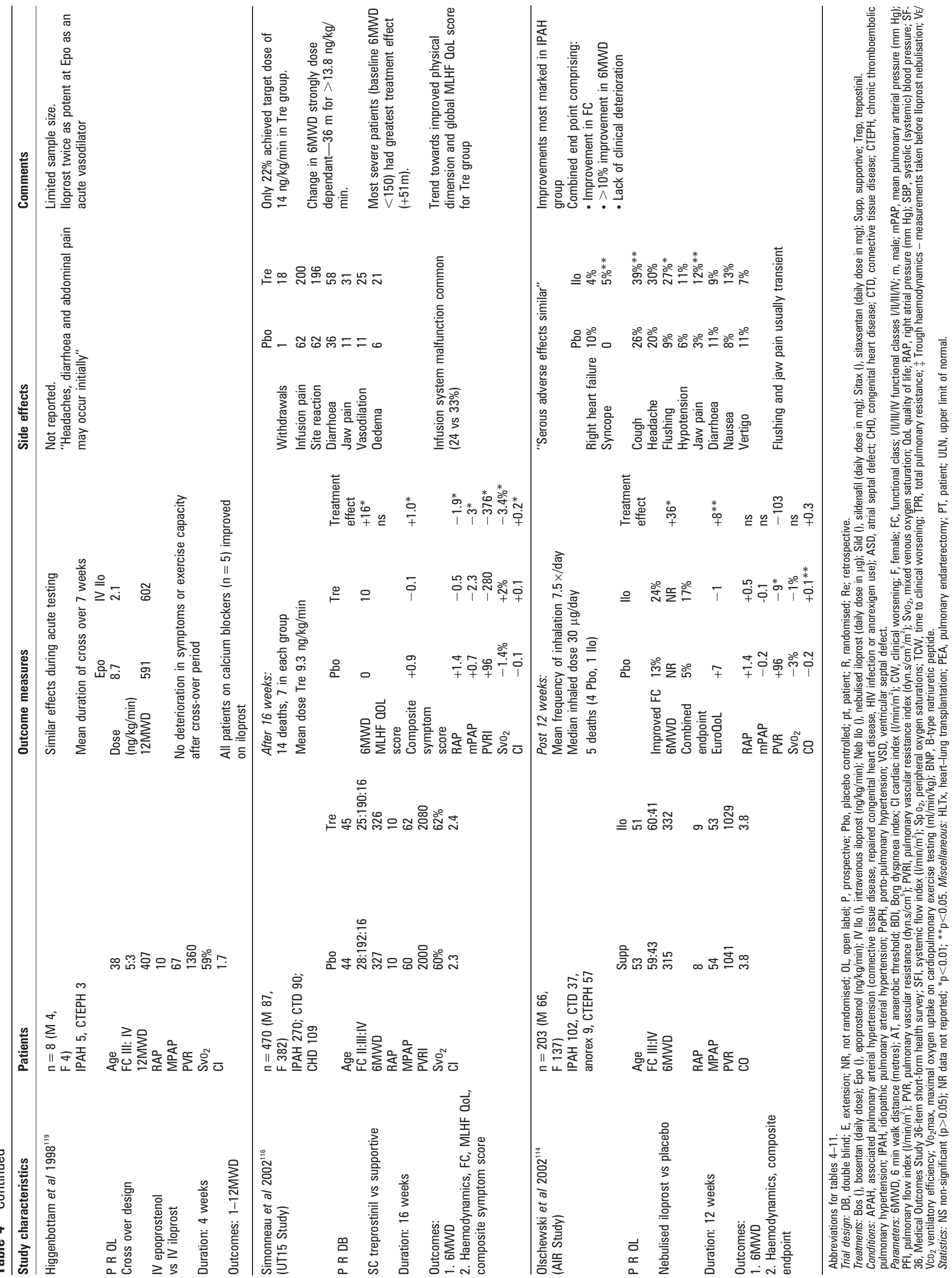




\section{Pulmonary hypertension}
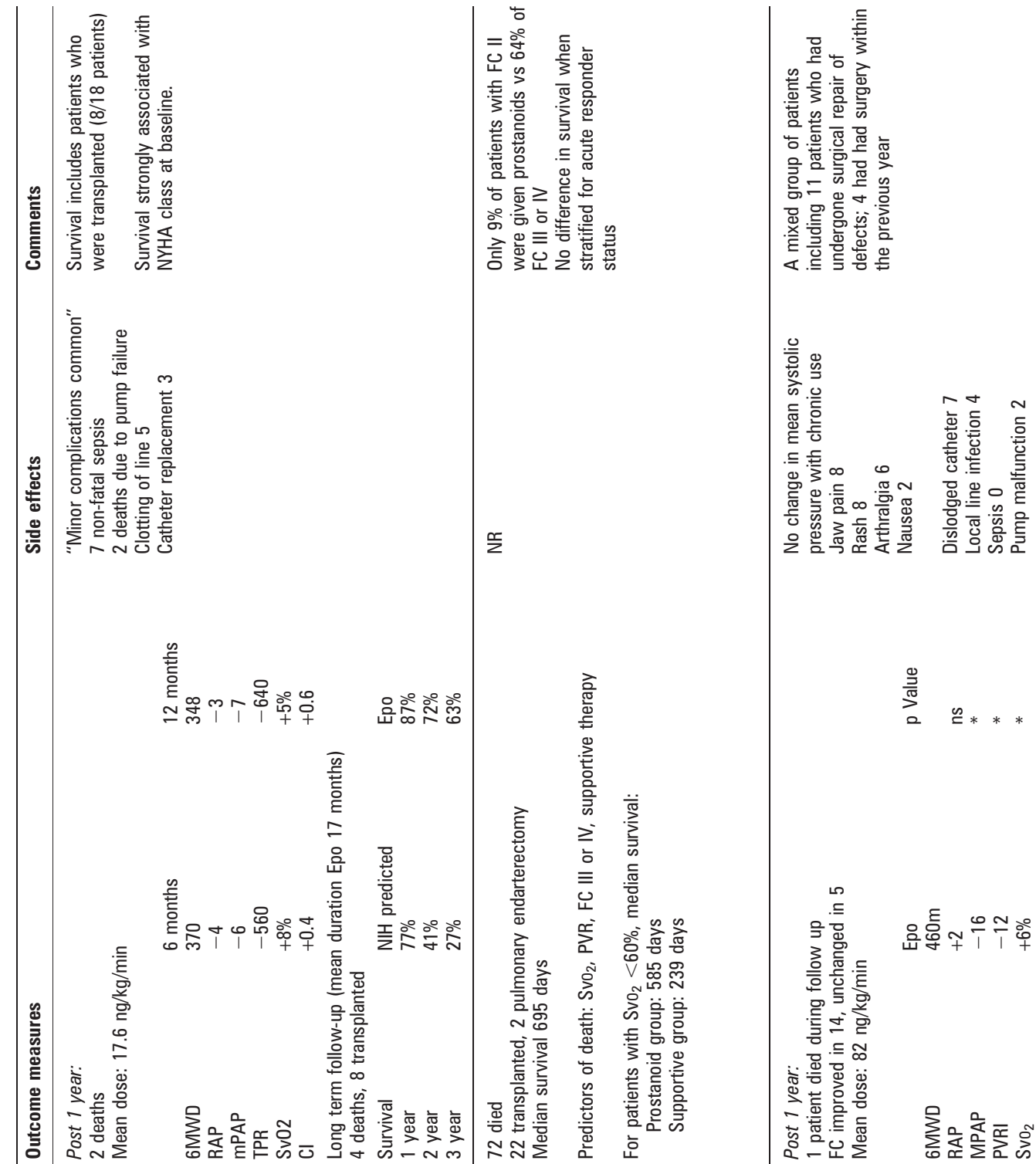

$\stackrel{\infty}{2}$
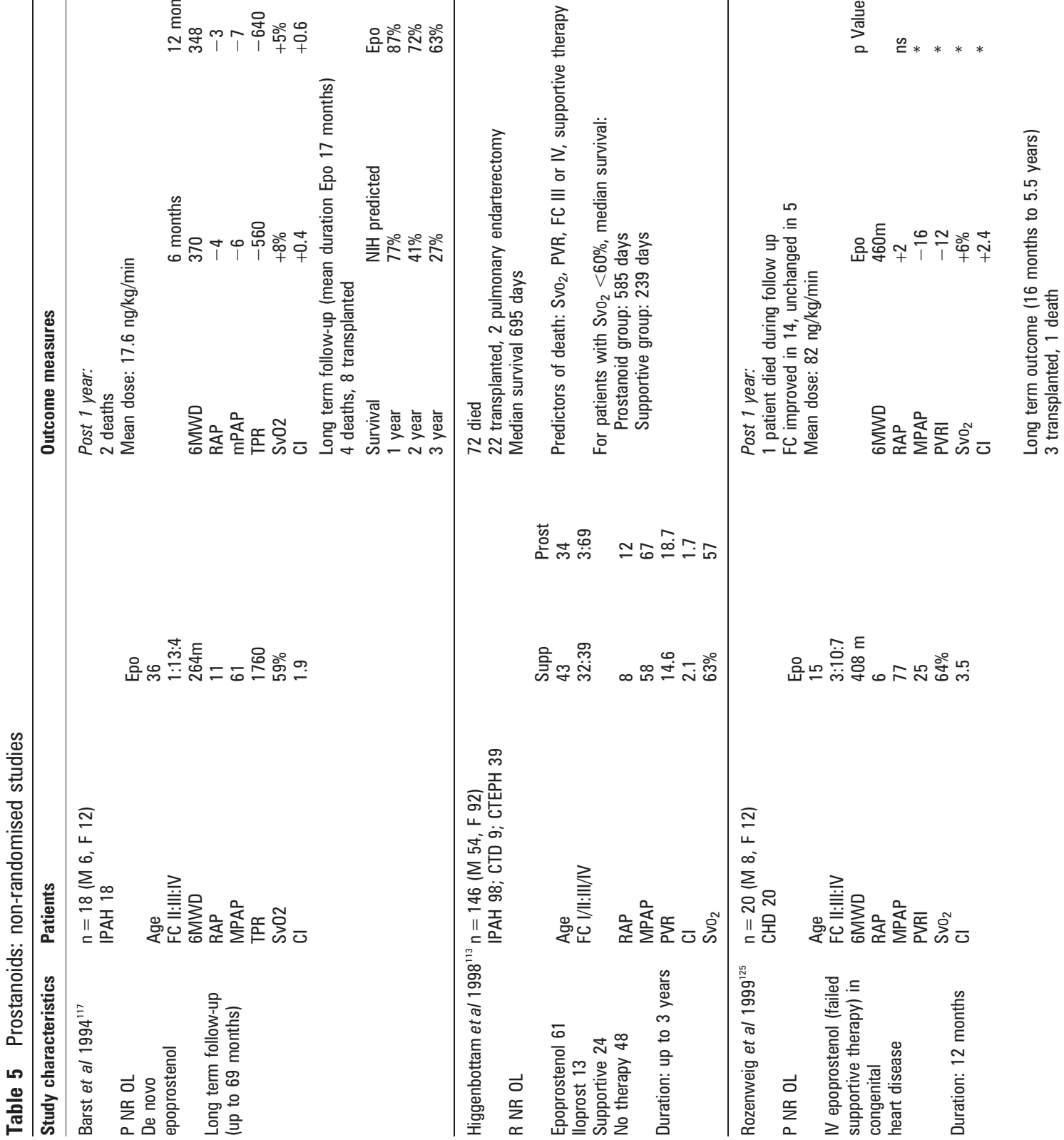

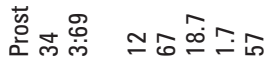

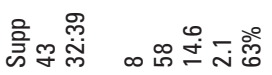

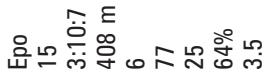

西

존른

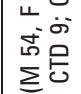

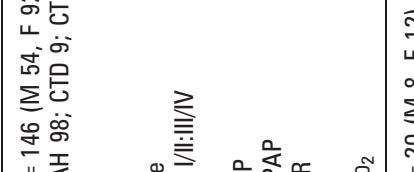

咅

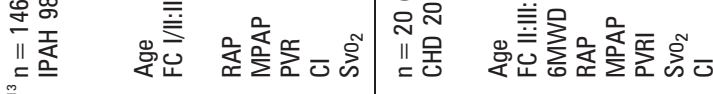

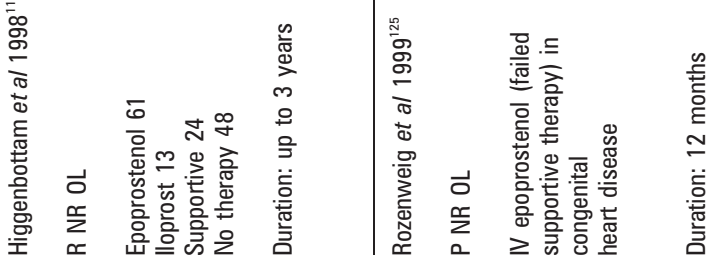



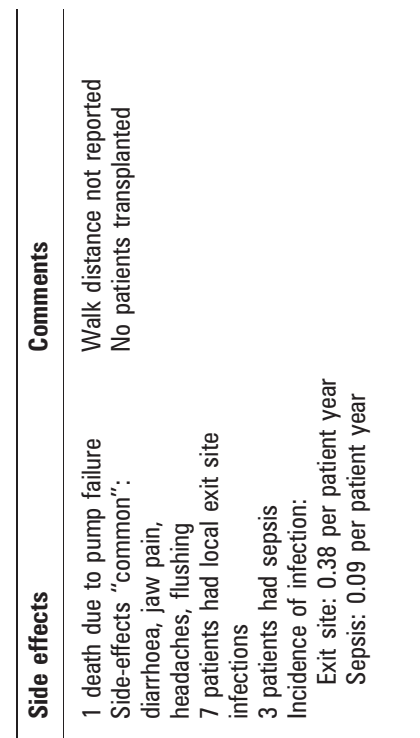
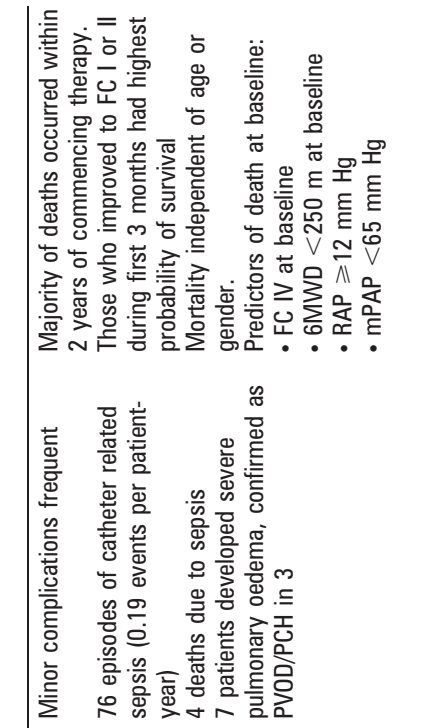

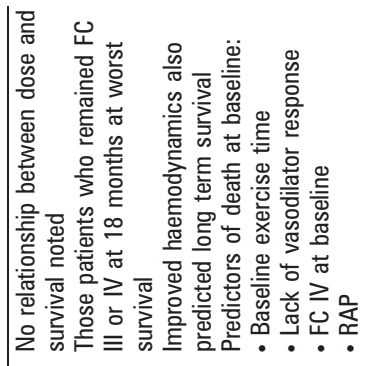

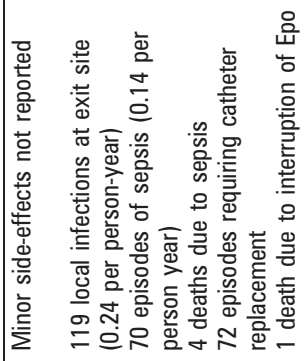

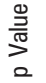

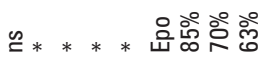

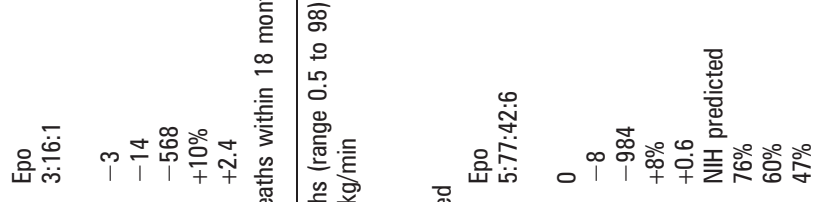

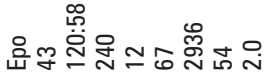

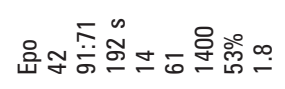

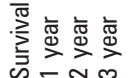




\section{Pulmonary hypertension}

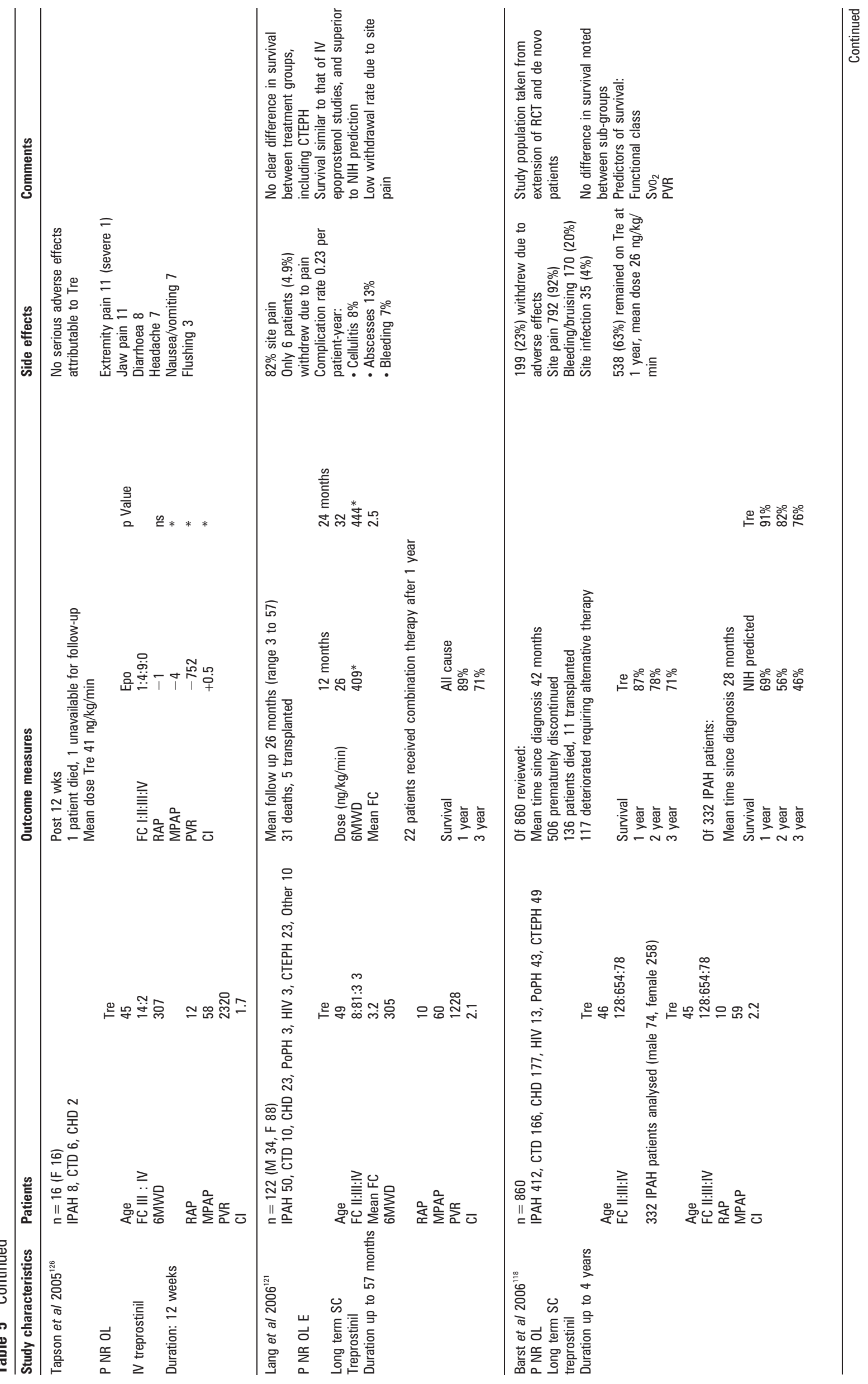




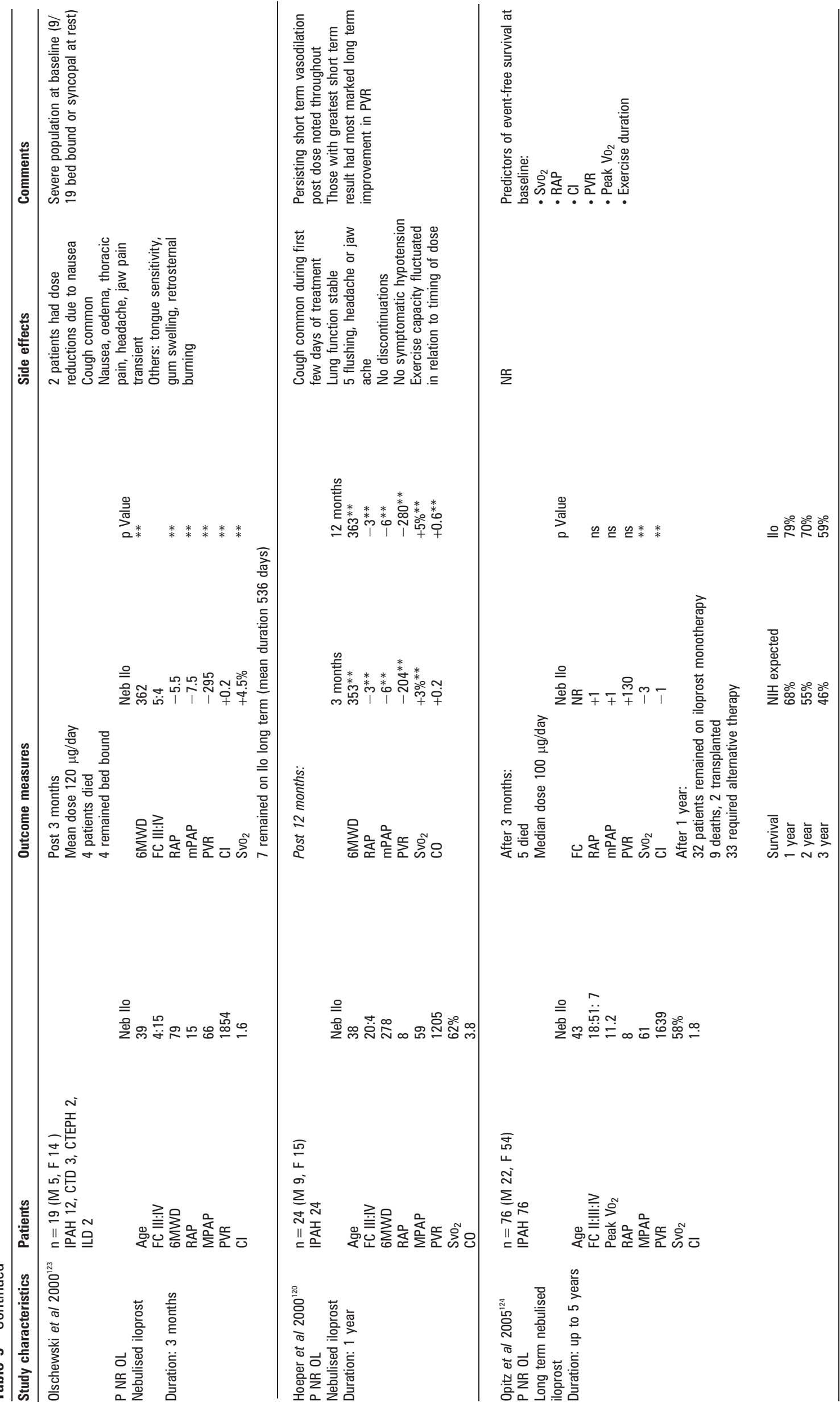




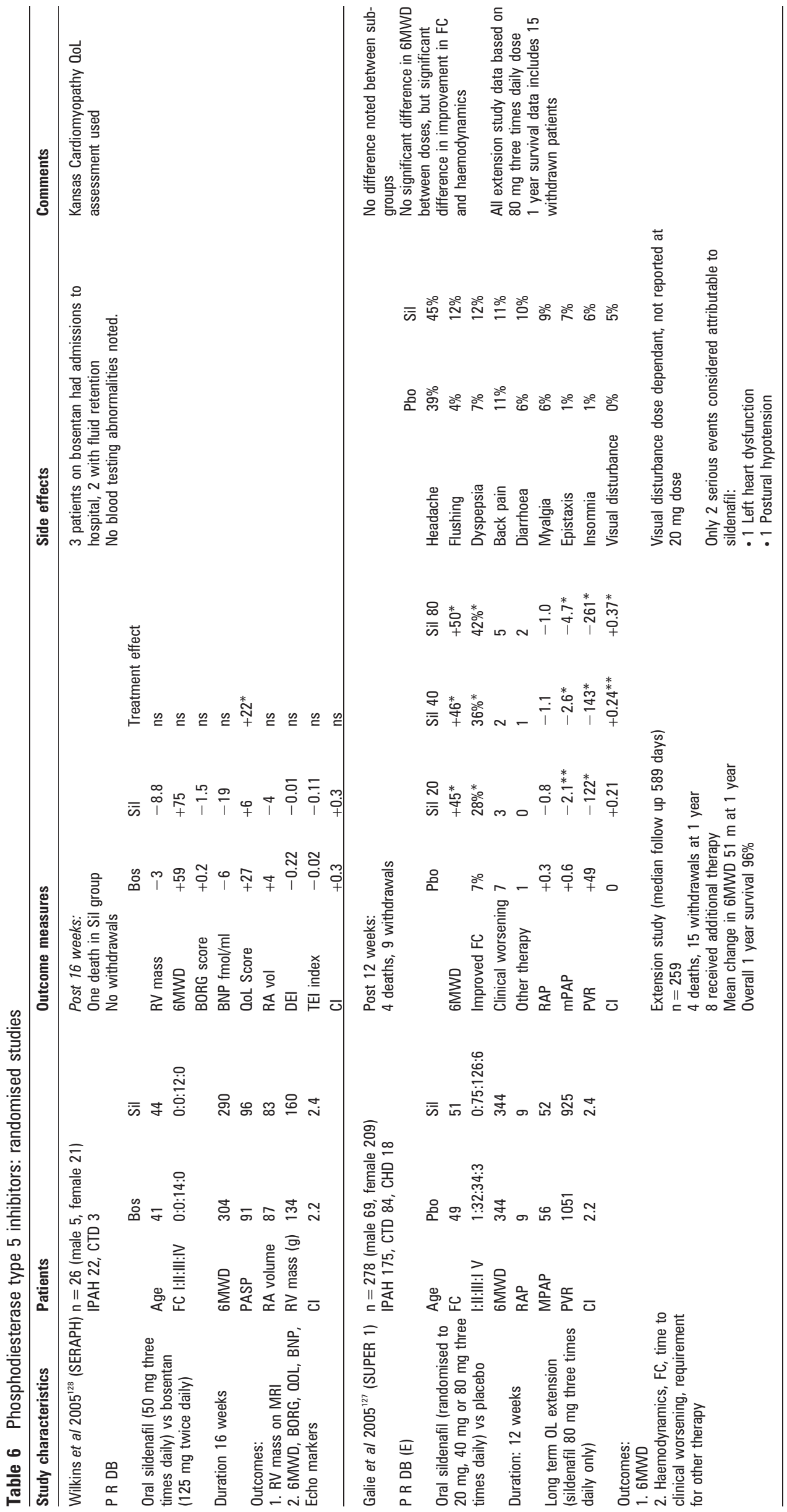


Table 7 Phosphodiesterase type 5 inhibitors: non-randomised studies

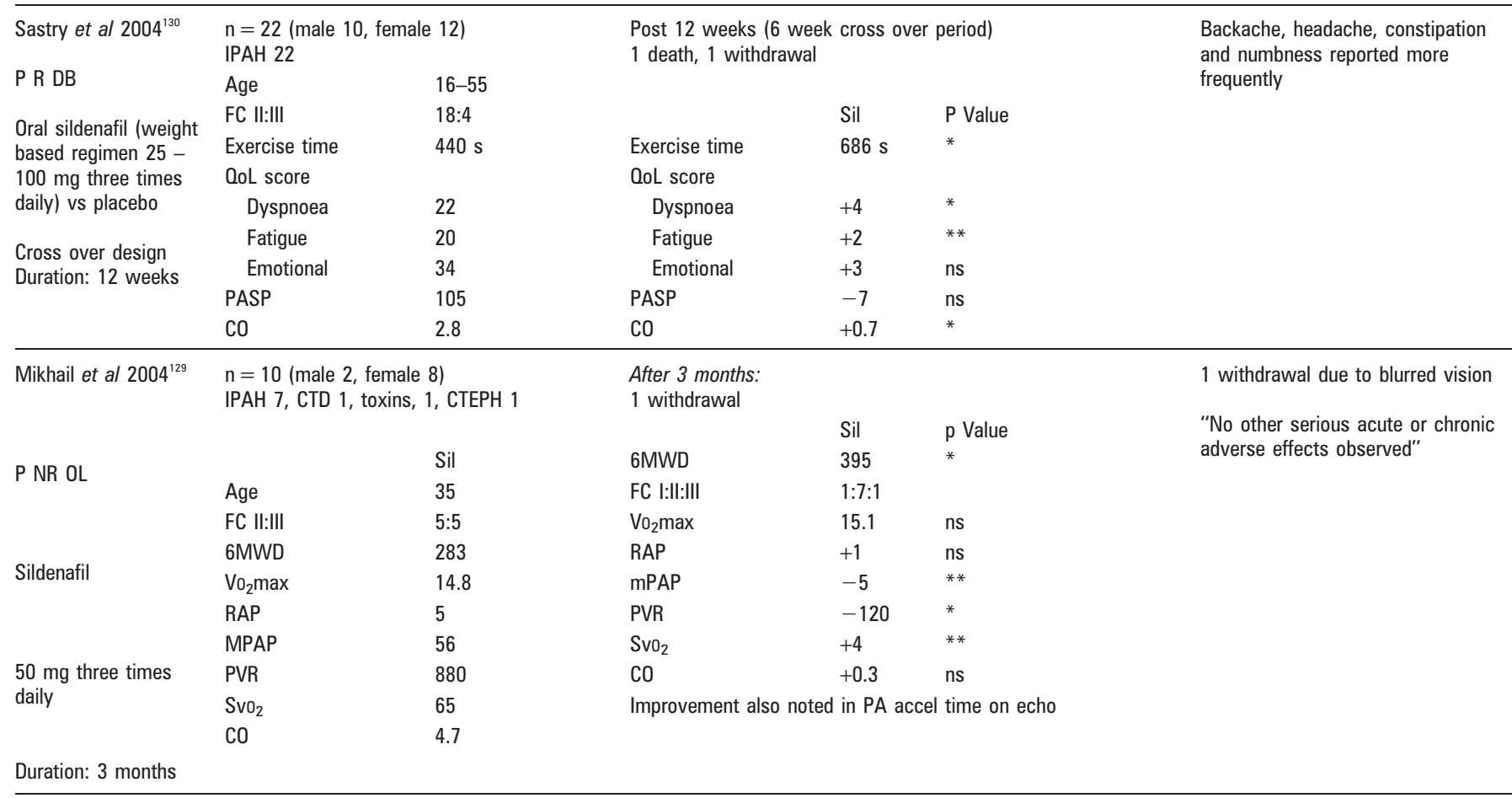

points. Some survival studies compare observed survival against $\mathrm{NIH}$ predicted survival. ${ }^{14}$ It is not clear whether this formula can accurately predict the current natural history of IPAH and its results should be interpreted with caution.

\subsubsection{Calcium channel blockers}

High dose calcium channel blockers are beneficial in a subset $(<10 \%)$ of patients with IPAH, FPAH and anorexigen APAH who demonstrate a positive vasoreactivity response at right heart catheterisation and have improved 5 year survival. $.^{88} 108-110$ In these patients treatment is started with slowly titrated high dose calcium channel blockers (for example, up to $240 \mathrm{mg}$ /day of nifedipine or up to $900 \mathrm{mg} /$ day of diltiazem). If there is no improvement after 1 month or patients are unable to achieve WHO class I or II with associated improvement in haemodynamics over 3 months, then patients should be treated as nonresponders. Only $54 \%$ of those who respond acutely will maintain a sustained response to calcium channel blockers. ${ }^{110}$ Patients who have not undergone a vasoreactivity study or those with a negative study should not be started on these agents. ${ }^{111}$

\section{RECOMMENDATIONS}

41. Patients with IPAH, FPAH and anorexigen APAH and a positive vasoreactivity response should be treated with high doses of calcium channel blockers. Since only half will respond chronically, it is important to ascertain normalisation or near-normalisation of PAP at follow-up.

42. If patients taking high dose calcium channel blockers demonstrate no clinical improvement after 1 month or are unable to achieve functional class I or II with associated improvement in haemodynamics over 3 months, then they should be treated as non-responders.

\subsubsection{Prostanoids}

Prostanoids are analogues of prostacyclin and include epoprostenol, iloprost and treprostinil. They must be given by infusion or aerosolised for inhalation. Dosing requires balancing symptom control with side effects (including headache, flushing, nausea, vomiting, loose bowel motions, jaw pain and limb pain) and needs to be managed on an individual basis. There is no prescribed upper limit to dose. In most patients the dose requires progressive uptitration over time. There is a risk of local and systemic sepsis in patients on infusions. Patients must be able to manage an infusion or frequent inhaled treatment at home.

It is not possible to draw firm conclusions about the relative efficacy of different prostanoids. The choice of therapy is determined by patient and physician choice which in turn is affected by differences in the half-life of the drugs, side effect profile, complexity of the delivery system, patient acceptability and the patient's home circumstances. In some patients nonlicensed therapies are preferred for these reasons.

The results of randomised trials ${ }^{11}{ }^{110}{ }^{112-116}$ are shown in table 4 and non-randomised trials ${ }^{15^{107117-126}}$ in table 5. Their use is described in fig 4.

\subsubsection{Phosphodiesterase 5 inhibitors}

PDE 5 inhibitors are the newest class of disease-targeted therapy in PAH and there is less long term experience than prostanoids or endothelin receptor antagonists (ERAs). Only sildenafil is available for use in PAH. While sildenafil has been licensed for use at $20 \mathrm{mg}$ three times daily, longer term survival data has been collected at $80 \mathrm{mg}$ three times daily.

The results of randomised trials ${ }^{127}{ }^{128}$ are shown in table 6 and non-randomised trials ${ }^{129} 130$ in table 7.

\subsubsection{Endothelin antagonists}

Bosentan, an ETA and ETB receptor blocker, and sitaxsentan, a selective ETA receptor blocker, are available in the UK

Patients taking ERAs require monthly liver function tests to monitor transaminases which may rise and progress to liver failure unless the dose is reduced or the drug discontinued. 


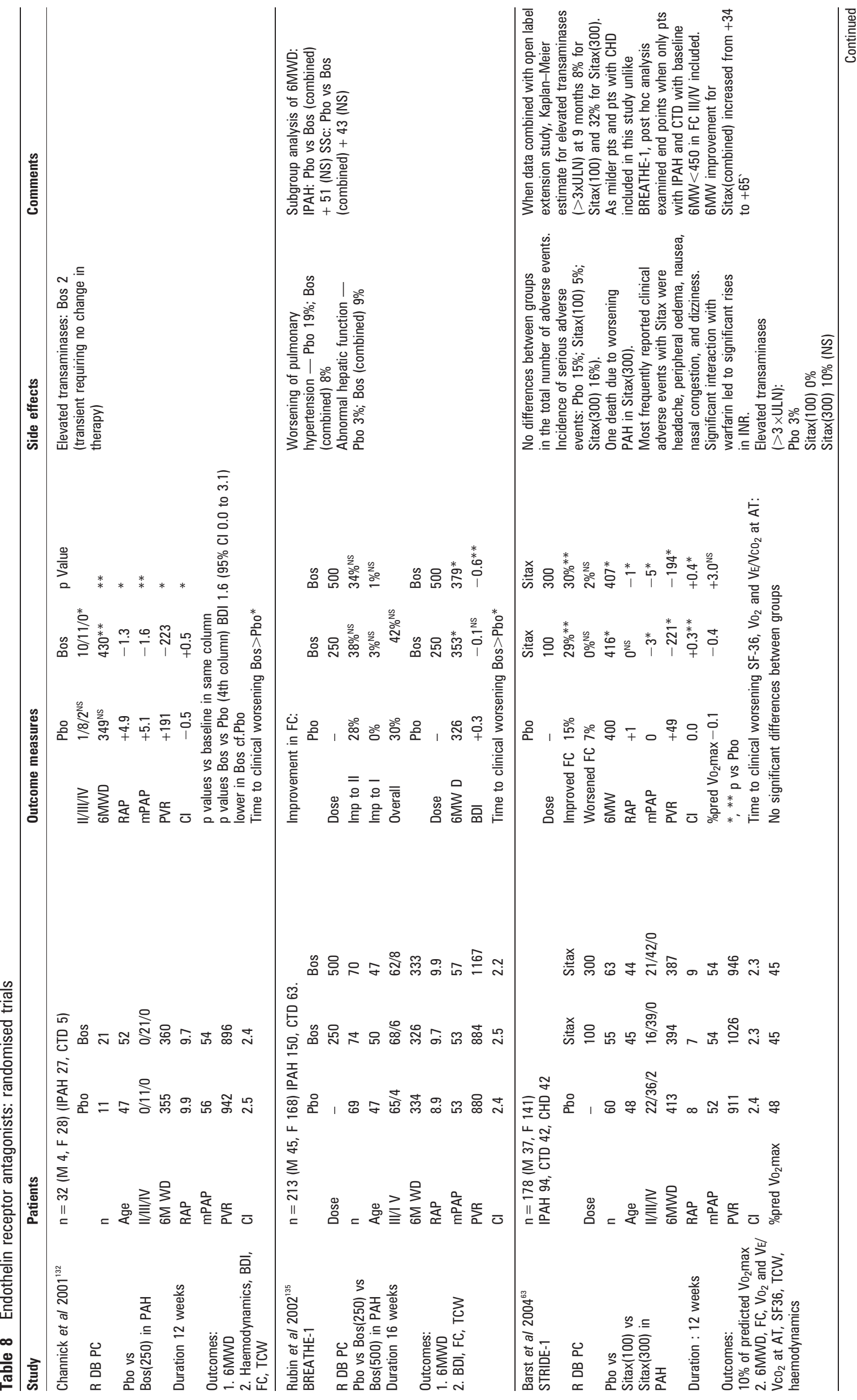




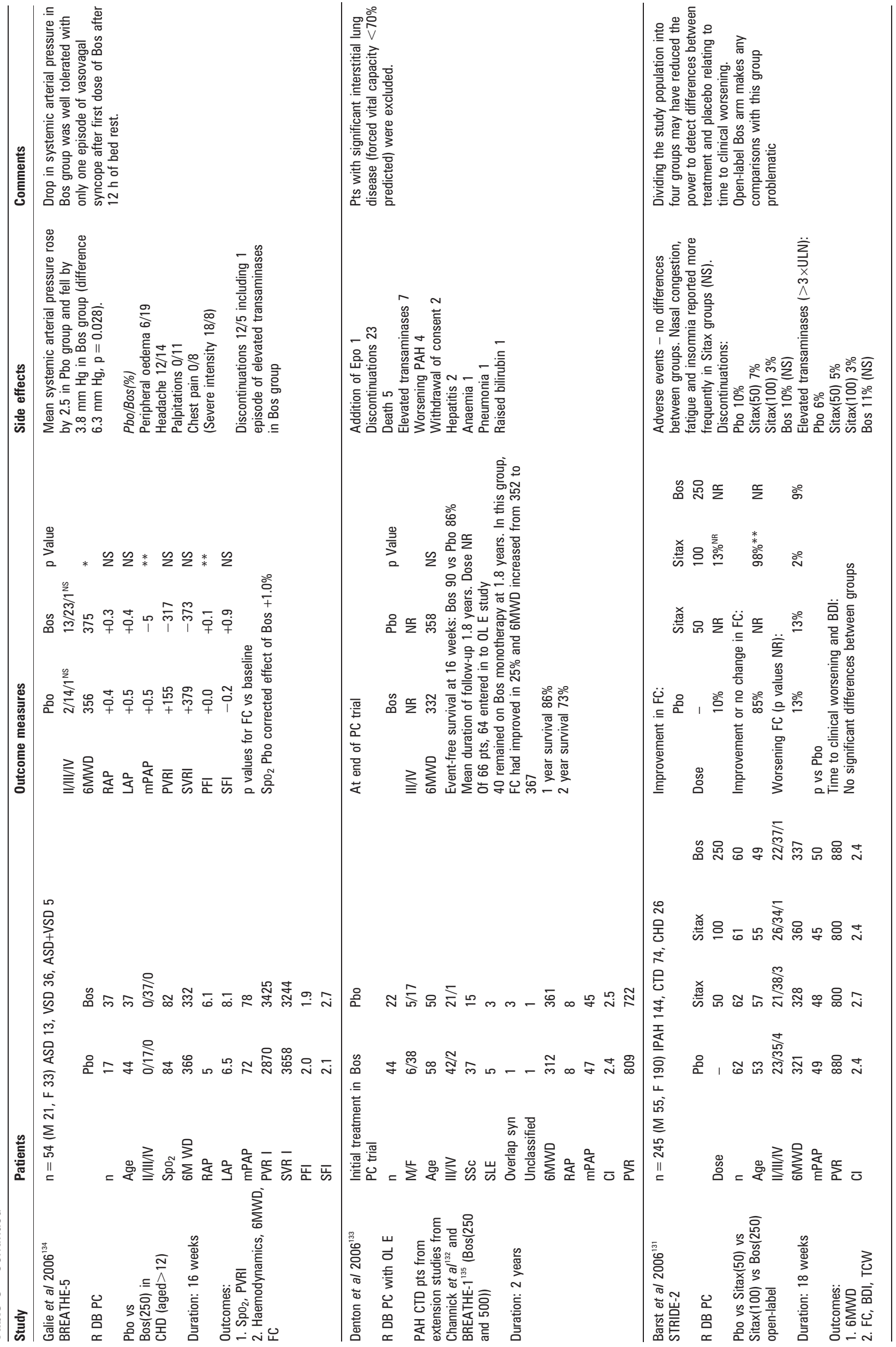




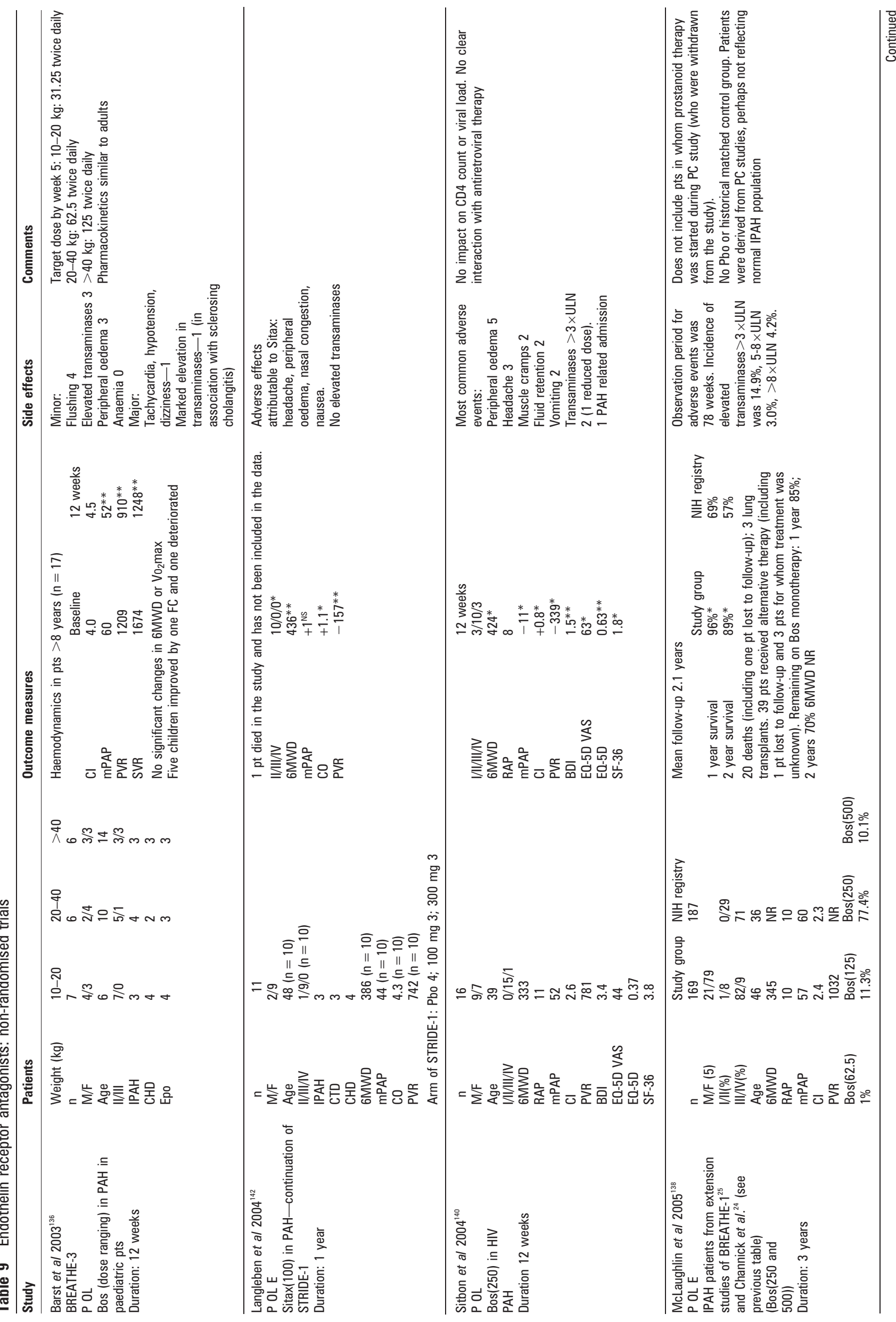




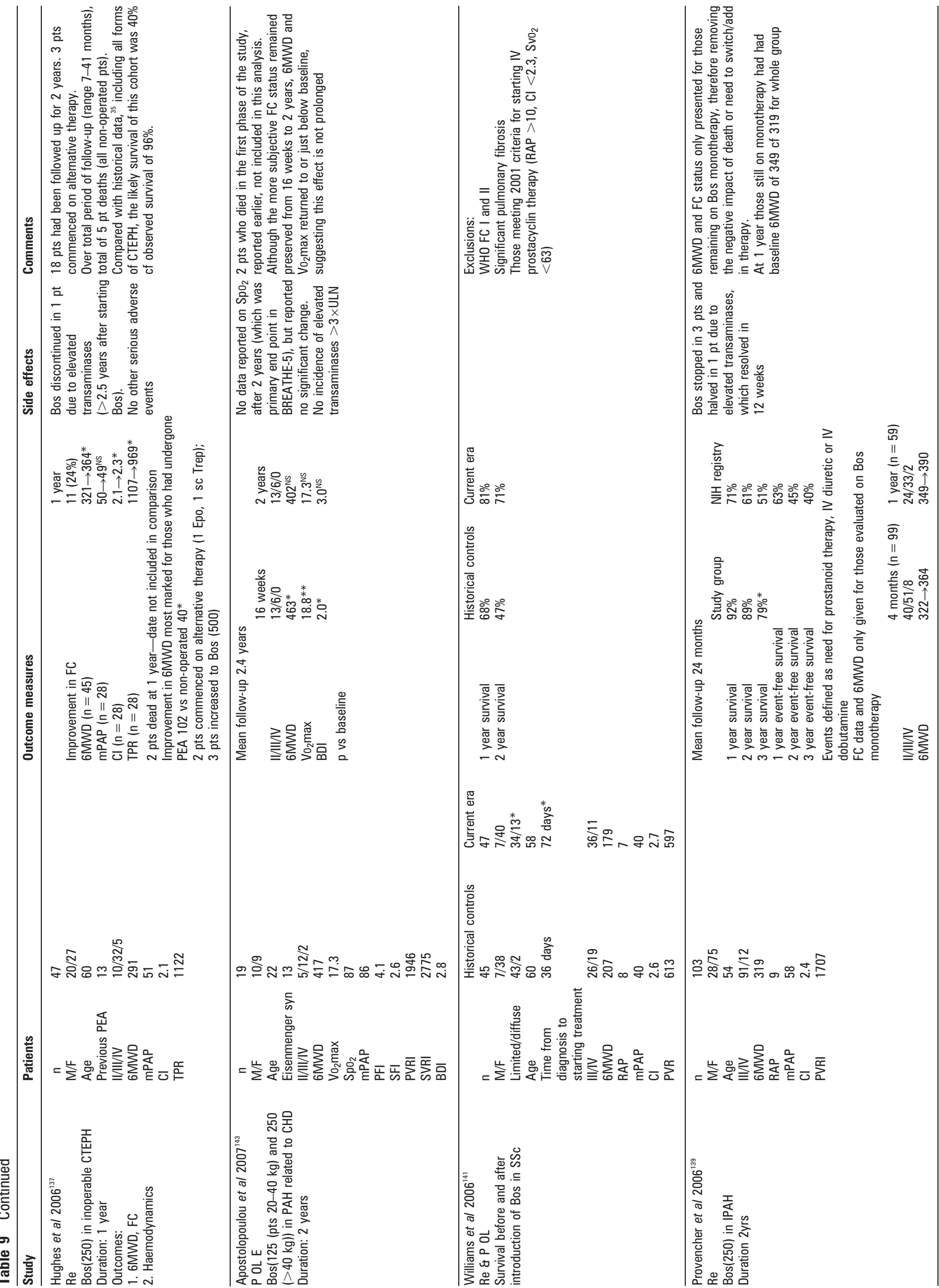



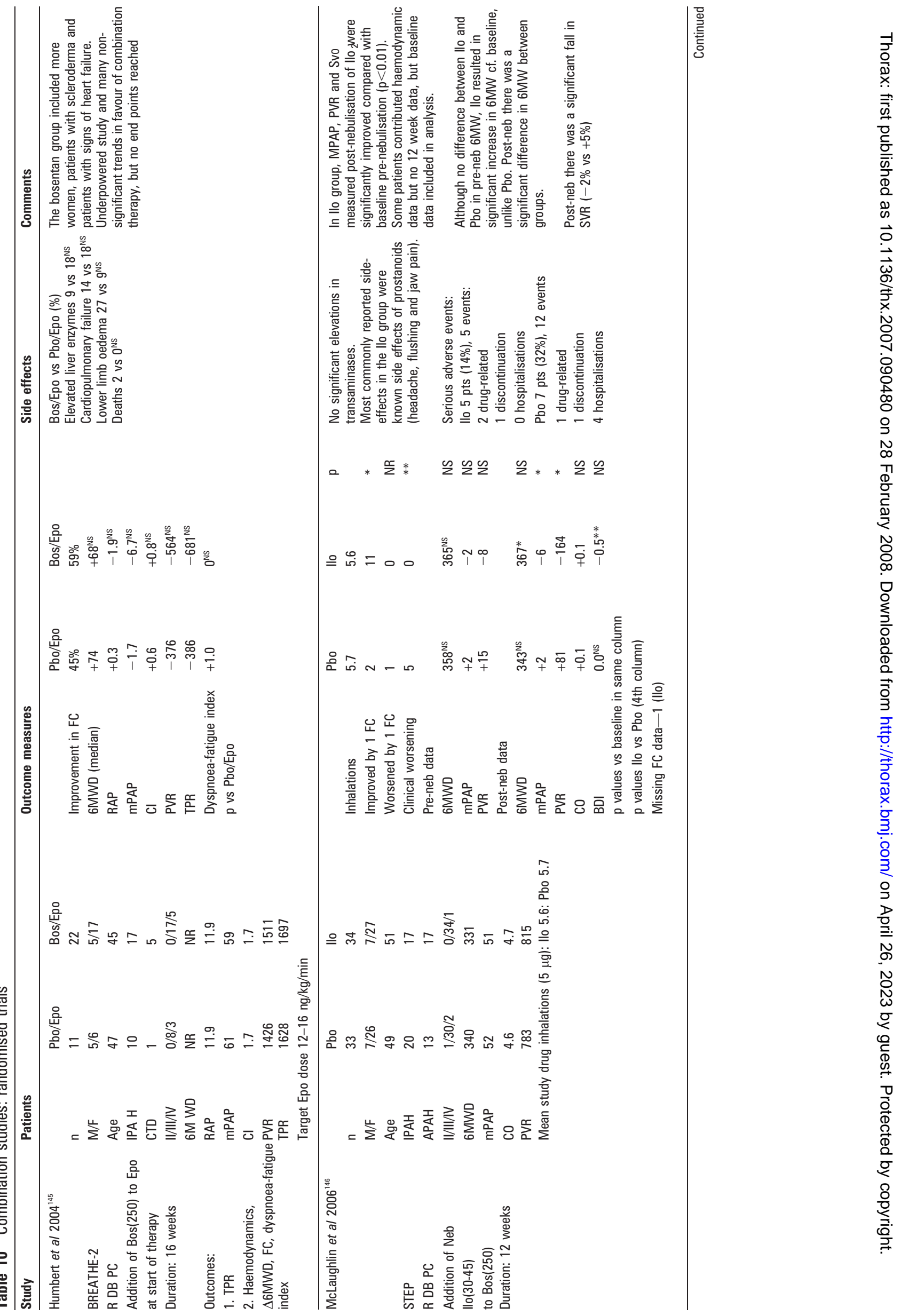


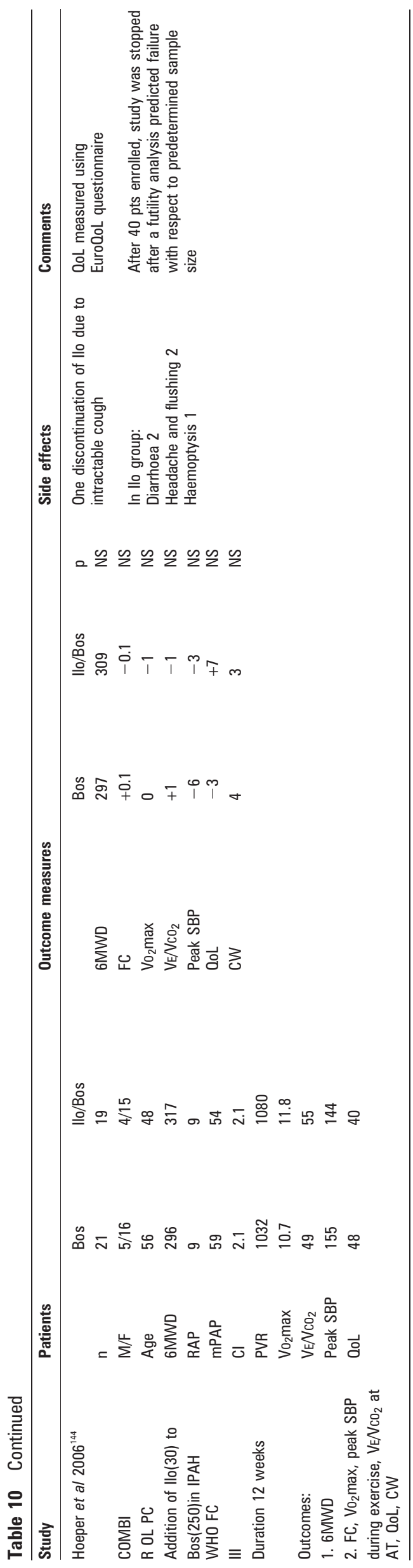

The results of randomised trials ${ }^{63}{ }^{131-135}$ are shown in table 8 and non-randomised trials ${ }^{136-143}$ in table 9.

\subsubsection{Combination therapy}

The results of randomised trials $s^{144-146}$ are shown in table 10 and non-randomised trials ${ }^{147-150}$ in table 11.

The optimal management for those patients who exhibit clinical deterioration despite targeted monotherapy remains a matter of debate. ${ }^{9}$ In the event of worsening functional status and haemodynamics, the approach of combining different agents to augment the clinical response has a strong rationale and has already been widely adopted by clinicians in most centres in Europe and the USA. ${ }^{150}$

\subsubsection{Rationale for combination therapy}

The use of combinations of drugs acting on distinctly different pathways involved in the disease in order to maximise clinical gain for patients with pulmonary hypertension is an emerging concept $^{3}{ }^{151}$ which has gained acceptance in published guidelines. ${ }^{26}$ The rationale can be summarised:

\section{Multiple pathways involved}

The notion that a unifying molecular mechanism might be critical to the development of PAH seems improbable given that there are numerous distinct clinical syndromes, environmental factors and genetic abnormalities which predispose to the disorder. ${ }^{152}$ Furthermore, a number of defects have been demonstrated in distinct pathways that have proved amenable to targeted therapies in clinical trials (that is, NO, prostacyclin and endothelin pathways). Consequently, it is unlikely that employing treatments that act on a single pathway will be consistently successful. A broad based approach targeting multiple pathways is more likely to be effective. ${ }^{153}$

\section{The precedent for combination therapy in medicine}

Combination therapy is often necessary in order to optimally control systemic hypertension, while in a variety of other diseases such as cardiac failure, cancer and HIV infection, combination therapy has become standard care supported by the highest levels of evidence. The potential for targeting multiple pathways at the time of initial diagnosis for patients with advanced disease makes intuitive sense. A treatment algorithm that includes combinations of individually successful drugs has merit even in the absence as yet of robust support from the medical literature.

\section{The lack of a durable response to monotherapy}

Many patients will have a suboptimal response or develop tolerance to an initial therapeutic regimen. ${ }^{15} 107114116127131$ Follow-up beyond the first 3 months of oral therapy shows a proportion of patients deteriorate. A well-recognised drawback of long term epoprostenol therapy is tachyphylaxis ${ }^{154}$ and repeated dose escalation is frequently hindered by the onset of disabling side effects at high doses. The lack of durable response does not indicate that monotherapy is failing to have a clinically important effect in slowing disease progression. Indeed withdrawal of the original disease-targeted therapy after addition of a second therapy may result in acute clinical deterioration even in stable patients. ${ }^{155}$ There are no formal trials of, or tested protocols for, withdrawing the original therapy. Reluctance of clinicians to withdraw the original therapy comes from the precarious clinical state of patients who are failing monotherapy as well as evidence that prostacyclin withdrawal results in 


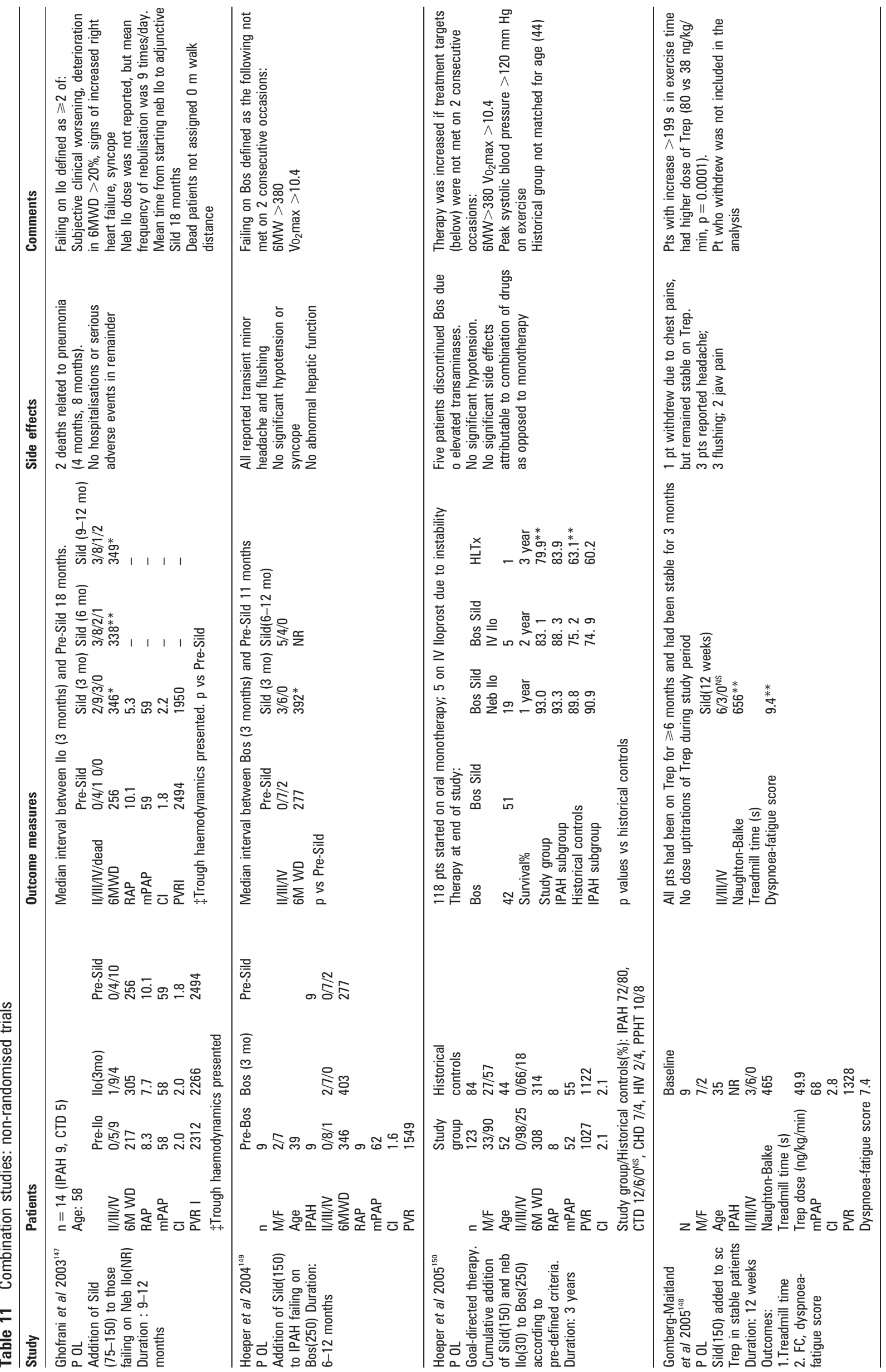




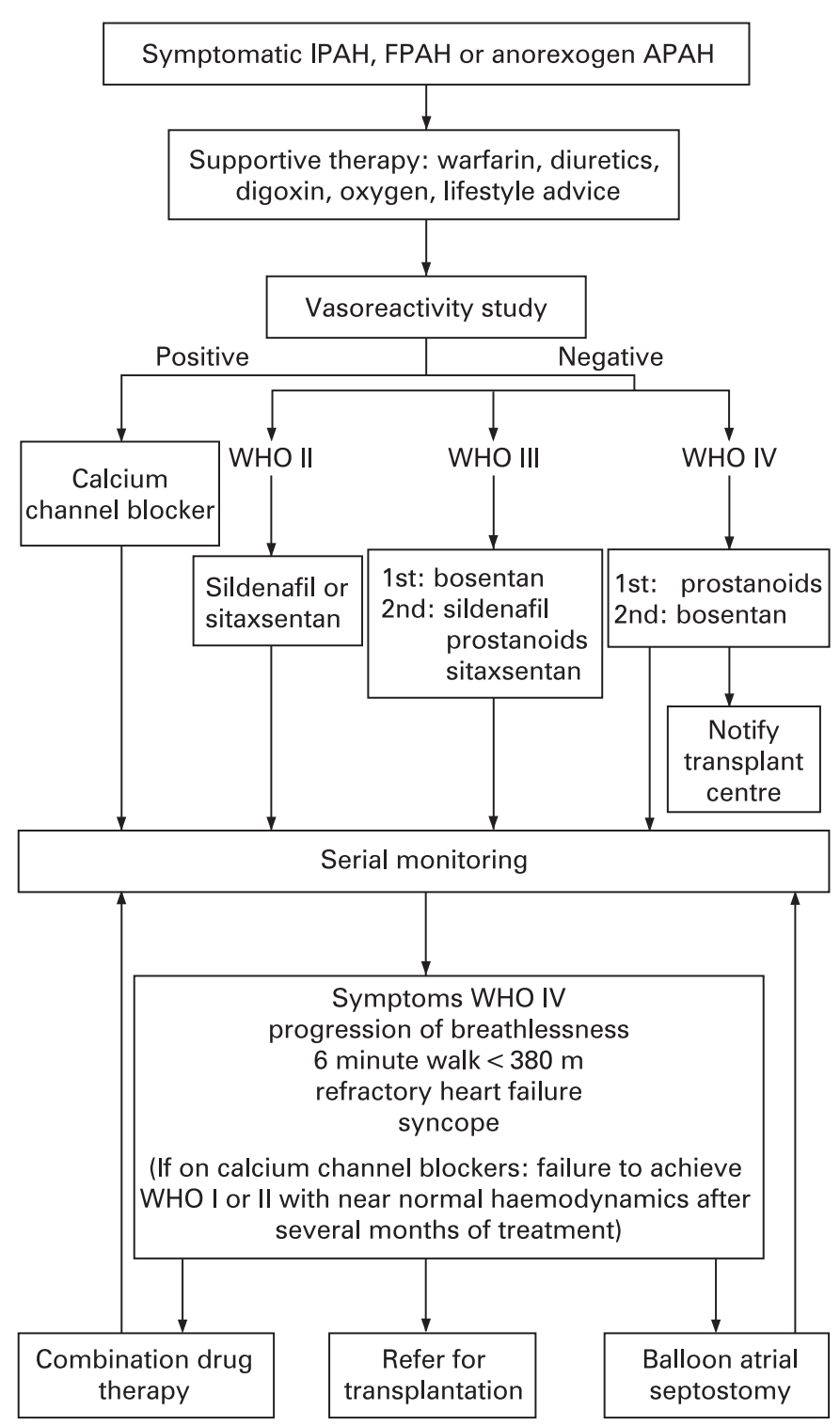

Figure 4 Algorithm for the management of idiopathic, familial and anorexogen-induced pulmonary arterial hypertension. The prefixes 1st and 2 nd indicate preferred and alternative drugs based on the quality and the weight of evidence assessed by the Consensus Meeting. APAH, associated pulmonary arterial hypertension; $\mathrm{FPAH}$, familial pulmonary arterial hypertension; IPAH, idiopathic pulmonary arterial hypertension; WHO, World Health Organization.

clinical deterioration which cannot be rescued by restarting therapy.

\section{Synergies between agents}

By exploiting molecular interrelationships between individual therapeutic targets, it may be possible to improve overall treatment efficacy and minimise risk of toxicity by using reduced dosages of individual agents. PDE inhibitors are responsible for limiting the adenylate cyclase regulated actions of epoprostenol. ${ }^{156}$ The addition of PDE inhibitors may augment and/or prolong the vasodilatory effects of prostanoids through "crosstalk" between the cyclic adenosine monophosphate (cAMP) and cyclic guanosine monophosphate (cGMP) pathways. The addition of sildenafil in patients refractory to epoprostenol is associated with enhanced levels of cAMP, an effect mediated via inhibition of PDE-3 by cGMP. ${ }^{157}$ This effect in turn causes upregulation of $\mathrm{NO}$ production and further increases in cGMP concentrations. Sildenafil, when added to aerosolised iloprost, causes a greater reduction in PVR than either drug alone. ${ }^{147} 158$ Co-treatment with sildenafil and beraprost may also result in greater increases in plasma concentrations of cAMP and cGMP than with either drug alone. ${ }^{159}$ Bosentan and sildenafil have synergistic effects on haemodynamics and mortality in animal models. ${ }^{160}$ Since endothelin suppresses NO production, ${ }^{110} 161$ ERAs upregulate $\mathrm{NO}$ production and synergise sildenafil. ${ }^{147} 162$

\subsubsection{Clinical evidence for use of combination therapy}

To date there have been relatively few prospective trials conducted to appraise the merits of combining drugs with different modes of action for the treatment of PAH. Many authors have reported successful outcomes with this approach in animal models of $\mathrm{PH}$ as well as in observational series and non-randomised studies. Most of the studies currently available are of a retrospective or observational nature, describing experiences with small numbers of heterogeneous patients (often from a single centre) without matched controls characterised. Investigators have mostly chosen to investigate IPAH, CTD APAH or anorexigen induced APAH, limiting the applicability of results to other categories of $\mathrm{PH}$. A number of well-designed studies are now underway (Appendix 1) that should help clarify the potential benefits of a variety of different combination strategies in the next $1-3$ years.

A comprehensive listing of published studies is included in this manuscript (tables 4-11). There are only four possible combinations of currently available agents: ERAs and prostanoids, ERAs and PDE 5 inhibitors, PDE 5 inhibitors and prostanoids, or all three drug types together. Because there are four types of prostanoids and two ERAs the combinations can become complex within these four groups.

\subsubsection{Approaches to combination therapy}

Given the limited amount of conclusive data pertaining to combination treatment, published guidelines have so far made no specific recommendation to guide clinicians on the next step to improve the status of their patients who fail monotherapy.

The most commonly applied combination therapy approach to date has involved the addition of a second drug where patients deteriorate (or fail to sufficiently improve) despite optimal doses of an initial therapy. The algorithms in figs 4 and 5 indicate commonly used clinical criteria for considering combination therapy. These criteria were chosen because they indicate a particularly poor prognosis and can be documented.

For patients who present in WHO functional class III the most common combination is the addition of a second oral agent (sildenafil to an ERA or an ERA to sildenafil). In the UK this accounts for $65 \%$ of combination therapy prescriptions. In small studies this approach has been shown to be effective in improving functional class, 6MWT distance and peak oxygen consumption. ${ }^{149} 163164$

The addition of a parenteral prostanoid to the original oral therapy increases the complexity of administering treatment. It is indicated in the event of rapid deterioration, especially when expected survival time is limited. The combination of a prostanoid plus sildenafil accounts for $23 \%$ of combination therapy prescriptions in the UK and confers added clinical benefits to monotherapy compared with either class of drugs alone. $^{147} 148158165$ 
Figure 5 Algorithm for the management of pulmonary arterial hypertension associated with connective tissue disease. The prefixes 1st and 2nd indicate preferred and alternative drugs based on the quality and the weight of evidence assessed by the Consensus Meeting. APAH, associated pulmonary arterial hypertension; CTD, connective tissue disease; WHO, World Health Organization.

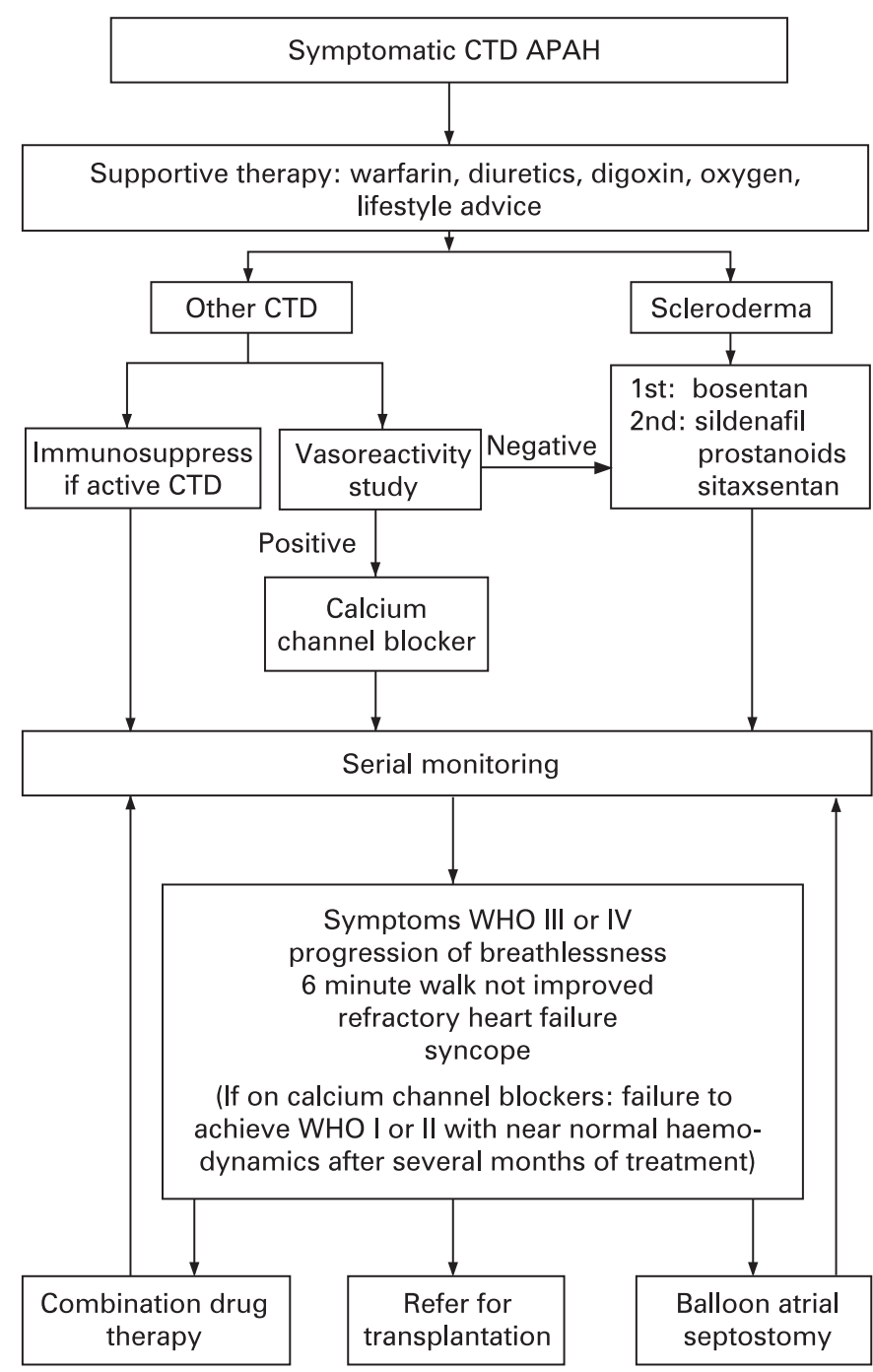

Although evidence suggests that the combination of bosentan and epoprostenol may have limited benefit, ${ }^{145}$ the addition of bosentan to treprostinil improved functional class, exercise capacity and haemodynamics, ${ }^{148}$ and the addition of inhaled iloprost to bosentan monotherapy improved exercise capacity. ${ }^{146}$ Prescription of a prostanoid plus an ERA accounts for $12 \%$ of combination therapy prescriptions in the UK.

Given the likelihood of eventual monotherapy failure, another approach is to commence two (or more) treatments simultaneously at the time of diagnosis. This approach is occasionally applied in patients in WHO functional class IV where survival without therapy is measured in months as evidenced by exercise capacity and haemodynamics.

While awaiting the results of further clinical trials a consistent approach to combination therapy is urgently required in view of the risk of fatal outcome. The trigger to consider combination therapy should be part of a goal-oriented strategy to assist timing of treatment escalation. ${ }^{150}$ Individuals who demonstrate an inadequate exercise tolerance despite monotherapy for 34 months should be considered for additional therapy as outlined in figs 4 and 5 . All patients should be offered a second agent as part of a clinical trial where possible. There are a number of trials enrolling patients with $\mathrm{PAH}$ who are on monotherapy with either bosentan or sildenafil (Appendix 1).

\section{RECOMMENDATIONS}

43. Individuals who demonstrate an inadequate response to monotherapy (see figs 4 and 5) should be considered for a combination of two or more disease-targeted therapies.

44. Where combination therapy is to be used, patients should be entered into a clinical trial where possible.

45. In the absence of a clinical trial, there is sufficient expert consensus to proceed with combination therapy while the patient's response to treatment is carefully monitored with consistent measures linked to national audit.

\subsubsection{Drug interactions of disease-targeted therapies for PAH}

There is the potential for clinically significant drug interactions from combining some therapies (table 12). In addition to pharmacokinetic interactions that alter drug concentrations and may affect efficacy and increase toxicity, pharmacodynamic interactions in the systemic vasculature may lead to hypotension and systemic side effects such as dizziness.

Bosentan is an inducer of CYP3A4, a hepatic enzyme involved in the metabolism of many drugs, as well as being a substrate for this enzyme. Co-administration of bosentan and sildenafil (a CYP3A4 substrate) in patients with PAH has been shown to reduce plasma sildenafil levels by $50 \% .{ }^{166}$ Conversely, bosentan levels are increased by about $50 \%$, presumably by competition 
Table 12 Significant drug interactions

\begin{tabular}{|c|c|c|c|}
\hline PAH drug & Mechanism & Interacting drug & Interaction \\
\hline \multirow[t]{7}{*}{ Bosentan } & CYP3A4 inducer & Sildenafil & Sildenafil levels fall $50 \%$; bosentan levels increase $50 \%$ \\
\hline & CYP3A4 substrate & Ciclosporin & $\begin{array}{l}\text { Ciclosporin levels fall } 50 \% \text {; bosentan levels increase } 4 \text {-fold. Combination } \\
\text { contraindicated }\end{array}$ \\
\hline & CYP3A4 substrate & Erythromycin & Bosentan levels increased \\
\hline & CYP3A4 substrate & Ketoconazole, itraconazole & Bosentan levels increased \\
\hline & CYP2C9 inducer & HMG $\mathrm{CoA}$ reductase inhibitors & Simvastatin levels reduced 50\%; similar effects likely with atorvastatin \\
\hline & CYP2C9 inducer & Warfarin & Increases warfarin metabolism, may need to adjust warfarin dose \\
\hline & CYP2C9 and CYP3A4 inducers & Hormonal contraceptives & Hormone levels decreased, contraception unreliable \\
\hline \multirow[t]{2}{*}{ Sitaxentan } & CYP2C9 inhibitor & Warfarin & Inhibits warfarin metabolism, warfarin dose needs to be reduced \\
\hline & ? inhibition of OATP transporter & Ciclosporin & Increases sitaxentan levels 6-fold; combination contraindicated \\
\hline \multirow[t]{7}{*}{ Sildenafil } & CYP3A4 substrate & Bosentan & Sildenafil levels fall $50 \%$; bosentan levels increase $50 \%$ \\
\hline & CYP3A4 substrate & HMG $\mathrm{Co} A$ reductase inhibitors & May increase simvastatin/atorvastatin levels through competition for metabolism \\
\hline & CYP3A4 substrate & HIV protease inhibitors & Ritonavir and saquinovir increase sildenafil levels \\
\hline & CYP3A4 substrate & Erythromycin & Sildenafil levels increased \\
\hline & CYP3A4 substrate & Ketoconazole & Sildenafil levels increased \\
\hline & CYP3A4 substrate & Cimetidine & Sildenafil levels increased \\
\hline & cGMP & Nitrates, nicorandil & Profound systemic hypotension \\
\hline
\end{tabular}

with sildenafil for metabolism. The net effect of these changes on response of patients to the combination has not been determined but the implications are: (1) the possibility of hepatic toxicity from higher plasma bosentan levels; and (2) lack of effect from low dose sildenafil (that is, $20 \mathrm{mg}$ dose regimen) when given with bosentan. Bosentan has been reported to reduce the level, and so efficacy, of other CYP3A4 substrates, such as simvastatin, oral oestrogens and ciclosporin. In contrast, CYP3A4 inhibitors, such as ketoconazole and ciclosporin, increase bosentan levels; co-administration of bosentan and ciclosporine is contraindicated. Bosentan induces CYP2C9 and increases warfarin metabolism.

Sitaxsentan is an inhibitor of this enzyme and co-prescription with warfarin requires a reduction in warfarin dose to maintain a therapeutic INR. Sitaxentan is a weak inhibitor of CYP3A4/5. It produces an increase in oestrogen levels when given with oral oestrogen contraceptives, and a small but clinically insignificant elevation of sildenafil when given with this drug.

Sitaxentan levels are increased sixfold when given with ciclosporin and co-administration of these drugs is contraindicated.

Sildenafil, as discussed above, is a CYP3A4 substrate and levels are increased by inhibitors of this enzyme, such as erythromycin, ketoconazole and several HIV protease inhibitors, such as ritonavir and saquinovir.

\subsubsection{Recommendations and strategies for the use of disease- targeted therapies}

\subsubsection{Idiopathic, familial and anorexogen-induced PAH}

While patients in WHO functional classes III and IV were included in early trials, recent trials have seen the inclusion of functional class II patients. There is no evidence to support the treatment of functional class I and this has been excluded from the algorithm (fig 4).

The benefit of identifying responders to calcium channel blockers has been covered in section 6.4.2. Most patients in WHO functional class III are commenced on oral therapy as first line treatment as distinct from functional class IV where evidence for prostanoids predominates. In some severely ill patients in functional class IV, most pulmonary hypertension specialists are unwilling to undertake an acute vasoreactivity study and would institute an intravenous epoprostenol infusion immediately.

\section{RECOMMENDATIONS}

46. Patients with IPAH, FPAH or anorexigen-induced PAH should be managed according to the algorithm in fig 4 .

\subsubsection{Connective tissue disease}

Data on the treatment of CTD APAH have been acquired from subpopulations of larger studies and are more limited than IPAH. An algorithm for CTD APAH management is shown in fig 5 .

\subsection{Supportive therapy}

Oxygen therapy may alleviate moderate hypoxia. The use of diuretics and digoxin may benefit some patients. ${ }^{167}$

\subsection{Calcium channel blockers}

The prevalence of a vasodilator response in CTD APAH is reported between 2-5\%. ${ }^{168} 169$ While reductions in PVR are common these do not appear to predict outcome in SSc. ${ }^{42}$ None of these studies has reported a clear correlation between response to calcium channel blocker therapy and vasodilator response in the setting of CTD. Tolerance of high dose calcium channel blockers is unusual in SSc APAH. ${ }^{42}$

\section{RECOMMENDATION}

47. Routine vasodilator testing in patients with SSc APAH is not mandatory since this does not identify a population who will benefit from calcium channel blockers.

\subsection{Prostanoids}

Epoprostenol improves 6MWT distance in patients with severe SSc APAH. ${ }^{112}$ There are no long term data showing improved prognosis. There was no improvement in outcome for SSc APAH, half of whom were treated with epoprostenol, ${ }^{170}$ when compared to an untreated population ${ }^{171} 10$ years earlier.

Not all prostanoids appear to be effective in SSc APAH. ${ }^{62} 114172$ Although this population were less tolerant of higher doses of treprostinil (mean $8.4 \mathrm{ng} / \mathrm{kg} / \mathrm{min}$ after 12 weeks), they exhibited haemodynamic benefit (increase of cardiac index by $0.2 \mathrm{l} /$ $\mathrm{min} / \mathrm{m}^{2}$ and reduction of indexed PVR by 320 dynes $/ \mathrm{s} / \mathrm{cm}^{5}$ ). There was a trend toward 6MWT distance improvement. ${ }^{173}$ Inhaled iloprost showed little benefit in the CTD APAH 


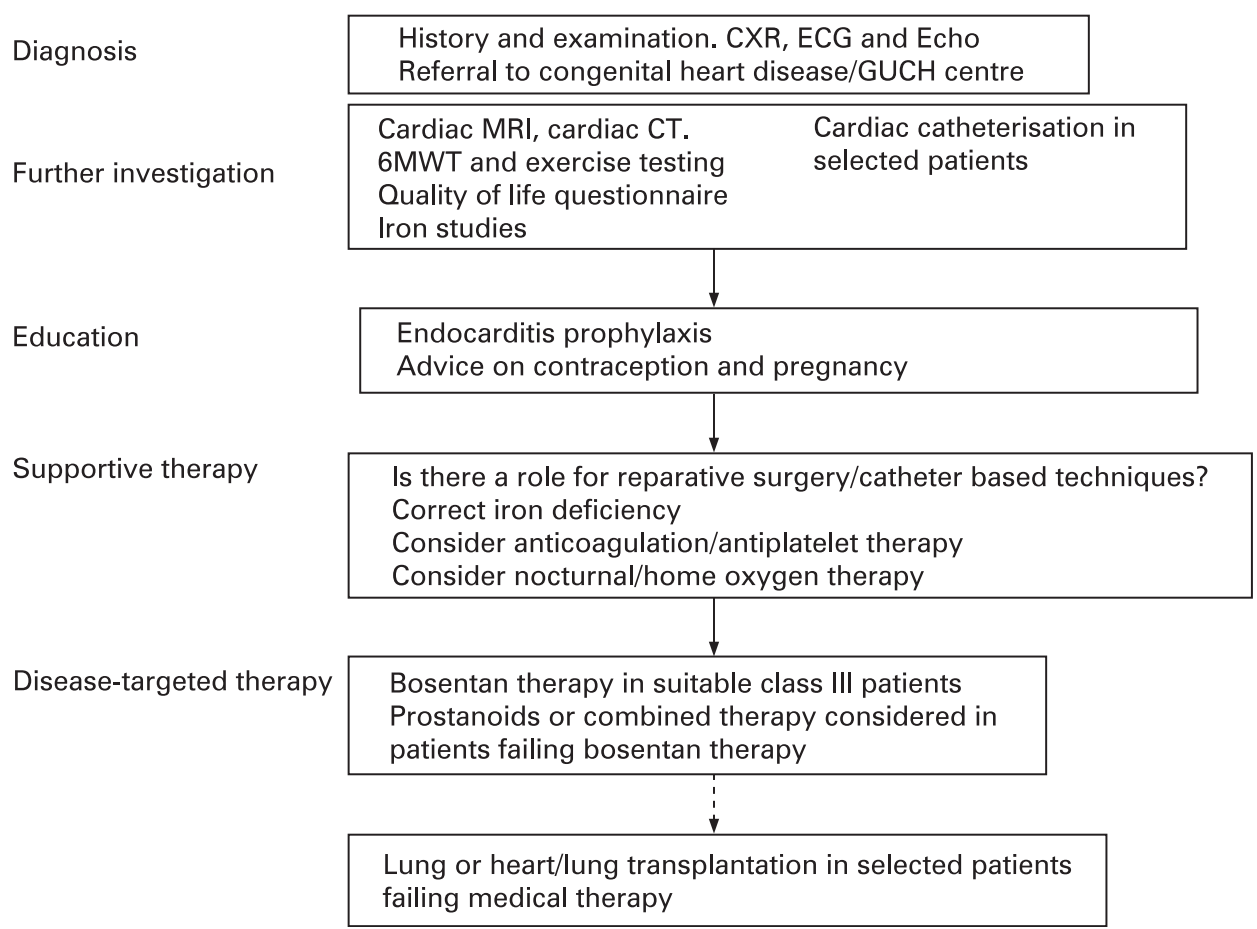

Figure 6 Algorithm for the management of adults with classical Eisenmenger syndrome. CT, computed tomography; CXR, chest $x$ ray; ECG, electrocardiogram; Echo, echocardiography; GUCH, grown-up congenital heart disease; 6MWT, 6 min walking test.

subpopulation. ${ }^{114}$ More data on SSc APAH are required to determine the future roles of these agents.

\subsection{Endothelin receptor antagonists}

Endothelin levels are elevated in the dermis and internal organs of SSc patients ${ }^{174} 175$ as well as lung tissue. ${ }^{176}$ The fundamental role of endothelin in fibrotic, mitogenic and proliferative activity, and vasoconstriction suggests that ERAs may influence the pathobiological processes underlying CTD APAH. ${ }^{177}$

In the SSc subgroup of double-blind, placebo-controlled trials, bosentan prevented a decline in functional ability seen with placebo patients. ${ }^{133}$ Bosentan improved 6MWT distance, delayed the time to clinical worsening and reduced dyspnoea. The 1 year survival at $81 \%$ was the best reported survival data at the time. In a single centre historical control registry, bosentan therapy was associated with a marked improvement in survival when compared to previously available therapy. ${ }^{141}$ The safety of this therapy has now been demonstrated in the TRAX registry which includes nearly 1500 patients with CTD APAH with an average follow up of 9 months. ${ }^{178}$

Post hoc analysis of sitaxsentan trials found 119 patients with CTD (63 SSc, 22 MCTD, 25 systemic lupus erythematosus (SLE)) APAH, 58 of whom received placebo, 61 were treated with sitaxsentan $100 \mathrm{mg}$ once daily, and small numbers who received either $50 \mathrm{mg}$ or $300 \mathrm{mg} .{ }^{179}$ For those taking the $100 \mathrm{mg}$ dose, the net improvement in 6MWT distance was $38 \mathrm{~m}$, similar to the improvement seen in IPAH $(p=0.042)$.

\subsection{Phosphodiesterase inhibition}

The SUPER-1 trial ${ }^{127}$ shows a similar magnitude of benefit with sildenafil to IPAH in the subgroup with CTD APAH. ${ }^{180}$ In this trial 84 patients had CTD APAH (including 38 SSc, 12 CREST (calcinosis, Raynaud's phenomenon, oesophageal dysmotility, sclerodactyly, and telangiectasia), 19 SLE and 8 MCTD), of whom 32 were in WHO functional class II, 51 class III and 1 class IV. The 6MWT distance decreased by $13 \mathrm{~m}$ in the placebo group, but increased by $42 \mathrm{~m}, 36 \mathrm{~m}$ and $15 \mathrm{~m}$ in the 20, 40 and $80 \mathrm{mg}$ three times daily groups, respectively. There are no long term follow data for the CTD subgroup.

\section{RECOMMENDATION}

48. ERAs should be first line therapy for patients with CTD APAH until long term data for other treatment modalities show that they have a comparable effect on survival.

\subsection{Combination therapy}

There are no data on combination therapy in the CTD PAH population. Only $10 \%$ of these patients achieve WHO functional class II, mean PAP $<35 \mathrm{~mm} \mathrm{Hg}$ and NT-proBNP $<400 \mathrm{pmol} / \mathrm{ml} .^{78}$ Most have some response, but with a first year mortality of $20 \%$, and $70 \%$ remaining in functional class III or IV, the natural history of the condition has not been sufficiently altered to deliver a satisfactory outcome. Current consensusbased clinical practice is illustrated in fig 5 and when combination therapy is used, sildenafil is added to bosentan or sitaxsentan. The next step is to either add inhaled iloprost or to switch to intravenous prostanoids.

\subsection{Transplantation}

Transplantation should be considered but is frequently not offered to patients with systemic conditions. While the results of transplantation in a very carefully selected group of patients with connective tissue disease is the same as for the population with interstitial lung disease alone, many potential candidates may not be suitable because of their associated comorbidities such as severe oesophageal dysfunction. 


\section{RECOMMENDATION}

49. Video-fluoroscopic assessment of swallowing should be undertaken as part of the assessment of transplantation in SSc APAH.

\subsubsection{Adults with classical Eisenmenger syndrome}

Eisenmenger syndrome is defined as severe $\mathrm{PAH}$ associated with a large and non-restrictive intra- or extra-cardiac shunt which with time leads to reversal of flow and cyanosis. Although annual mortality rates for Eisenmenger patients are relatively low compared to other forms of PAH, median survival is reduced by at least 20 years and is worse in patients with complex cardiac anatomy. ${ }^{38} 181182$ A more favourable clinical course than IPAH can be anticipated in Eisenmenger patients due to (a) a naturally occurring right-to-left shunt (sustaining systemic cardiac output, albeit at the expense of cyanosis) and (b) right ventricular remodelling occurring over a long time. Despite the varied and often complex underlying cardiac anatomy and physiology, pulmonary vascular histological changes are remarkably similar to other forms of $\mathrm{PAH}$, and most patients are symptomatic primarily with breathlessness. ${ }^{183} 184$

Secondary erythrocytosis is universal in patients with Eisenmenger syndrome. Haemoglobin concentration is inversely related to oxygen saturation only in iron-replete patients. ${ }^{182}$ Furthermore, iron deficiency closely correlates with venesection, often performed for "symptoms of hyperviscosity" or a haematocrit $>65 \%$, although many of these symptoms are also common in patients with iron deficiency. Patients with lower haematocrit have a lower exercise capacity and phlebotomy itself is associated with a higher and not lower incidence of cerebrovascular accidents. ${ }^{185}$ It is not justified to recommend routine phlebotomy in these patients. Iron deficiency should be promptly identified and corrected and an "upper limit" of haematocrit or haemoglobin should not be set. ${ }^{185}$

Many patients are anticoagulated with warfarin or given antiplatelet therapy to treat or prevent intravascular thrombosis which is common in these patients. ${ }^{186}$ Similarly, some patients are treated with LTOT at night on an individual basis, despite conflicting evidence as to a clinical benefit. ${ }^{89} \mathrm{NO}$, prostanoids and transplantation have been shown to be effective in improving functional class, but they are invasive and associated with problems of optimal timing and patient selection. ${ }^{125} 187188$

Bosentan has been studied in a randomised double blind placebo controlled study (BREATHE-5) and significantly improved haemodynamics and exercise capacity without adversely affecting systemic arterial oxygen saturation in WHO functional class III patients. ${ }^{134}$ Improvements in exercise capacity were maintained mid to long term in an open-label extension study. ${ }^{189}$ Figure 6 shows an algorithm for the management of patients with Eisenmenger syndrome.

\section{RECOMMENDATIONS}

In grown-up congenital heart disease:

50. Patients with Eisenmenger syndrome have a multi-organ disease and should be managed at least in part in a grownup congenital heart disease (GUCH) centre.

51. Each GUCH centre should have formal links to a designated pulmonary hypertension centre.

52. Iron deficiency should be corrected. Venesection should not be used routinely.

53. No specific recommendations can be given for general use of anticoagulation, antiplatelet or oxygen therapy, although all of them may be used on an ad hoc basis. INR monitoring requires specialist expertise and where anticoagulation is used haematology advice should be sought.

54. Patients in WHO functional class III should be considered for disease-targeted therapies for which there is evidence of efficacy and safety supporting the use of oral bosentan.

55. Transplantation should be considered for Eisenmenger patients remaining in WHO functional class IV.

\subsubsection{Veno-occlusive disease and pulmonary capillary haemangiomatosis}

The relationship between IPAH and pulmonary veno-occlusive disease (PVOD) and pulmonary capillary haemangiomatosis $(\mathrm{PCH})$ is unclear. Given reports of familial occurrences in all three conditions ${ }^{190-192}$ and the identification of a BMPR2 receptor gene mutation in a patient with PVOD, ${ }^{193}$ it has been suggested that PVOD and PCH may represent variants of IPAH in which the primary lesion affects the venous and capillary regions of the pulmonary vascular bed. ${ }^{2}$

The presentation of PVOD or PCH is often identical to IPAH, although some clinical features can be used to distinguish between them including more pronounced respiratory failure, digital clubbing and bibasal crackles. ${ }^{194}$ High resolution CT scan of the thorax is the most discriminatory non-invasive test. The presence of centrilobular ground glass opacities, septal lines and mediastinal lymphadenopathy are the most predictive features for $\mathrm{PVOD}$ or $\mathrm{PCH} .{ }^{195}$ It has also been suggested that bronchoalveolar lavage showing haemosiderin laden macrophages can be a useful discriminatory test as it demonstrates the occult alveolar haemorrhage that occurs in $\mathrm{PVOD} / \mathrm{PCH} .{ }^{196}$ Definitive diagnosis requires a surgical lung biopsy ${ }^{197} 198$ but this carries significant mortality. ${ }^{198}$

The use of disease-targeted therapies for PAH in PVOD and PCH is problematic. There are no controlled trials and there have been a number of case reports associating the use of vasodilator agents (principally calcium channel blockers and prostanoids) with worsened or even fatal pulmonary oedema. ${ }^{191} 194$ 199-202 This is particularly true with $\mathrm{PCH}^{203}$ Conversely, in PVOD there are case reports where the use of vasodilator agents has appeared to stabilise the condition. ${ }^{194204206}$ There are no published data on the use of ERAs in PVOD and there is only one reported case of the use of sildenafili, ${ }^{207}$ although unpublished experience with this agent has been promising. Antiangiogenic agents such as interferon- $\alpha 2 \mathrm{a}$ and doxycycline have been used in a small number of patients with $\mathrm{PCH}$ with variable reports of benefit. $199203208-210$

Most patients with PVOD die within 2 years. ${ }^{194}{ }^{211}$ Median survival with $\mathrm{PCH}$ is 3 years. ${ }^{203}$ Transplantation has been successful in both PVOD and $\mathrm{PCH},{ }^{203} 211$ although a recent case report suggests PVOD may recur after transplantation. ${ }^{212}$

\section{RECOMMENDATION}

56. An acute vasoreactivity study should not be performed in patients with PVOD or $\mathrm{PCH}$, although right heart catheterisation should be performed.

57. Anticoagulation may be hazardous since haemoptysis may be troublesome, particularly in $\mathrm{PCH}$.

58. Treatment results with disease-targeted therapy are anecdotal. Given the poor prognosis of the condition and the reports of temporary stabilisation in some patients, disease-targeted therapies may be attempted but must be stopped if there is any indication of worsening pulmonary oedema.

59. PCH should not currently be treated with disease-targeted drugs. Anti-angiogenic agents such as doxycycline may be 
considered in association with laboratory measurement of angiogenic factors.

60. Consider immediate referral for transplantation at time of diagnosis.

61. Atrial septostomy is a treatment option but is often precluded by hypoxaemia.

\subsubsection{Chronic thromboembolic disease \\ 6.4.8.5.1 Epidemiology}

CTEPH has emerged as one of the leading causes of severe PH. The incidence and prevalence of CTEPH are unknown. Originally it was thought that $0.1-0.5 \%$ of patients who survived an episode of acute pulmonary embolism develop CTEPH. ${ }^{213}{ }^{214}$ More recent studies suggest $3.1 \%$ of patients will develop symptomatic CTEPH at 1 year and $3.8 \%$ by 2 years post-pulmonary embolism. ${ }^{50}$ The natural history of untreated CTEPH is dismal: $<20 \%$ of patients survive 2 years if the mean PAP is $>50 \mathrm{~mm} \mathrm{Hg}$ at the time of presentation. ${ }^{215}$

\subsection{Pathophysiology}

CTEPH is characterised by intraluminal thrombus organisation and fibrous stenosis or complete obliteration of the pulmonary artery lumen. ${ }^{10}$ In the currently accepted model of CTEPH disease, acute pulmonary embolism, whether symptomatic or asymptomatic, serves as the initiating event. Following the embolism, disease progression occurs due to progressive pulmonary vascular remodelling and development of a generalised hypertensive pulmonary arteriopathy ${ }^{216}$ in those areas of the pulmonary vasculature that were spared from thromboembolic occlusion. Histopathology shows changes in the pulmonary microvasculature in CTEPH appearing similar to those seen in other forms of severe, non-thromboembolic PAH. ${ }^{216-218}$ This model explains why some CTEPH patients have severe $\mathrm{PH}$ out of proportion to the degree of vascular obstruction documented on pulmonary angiography. Patients with significant $\mathrm{PH}$ of microvascular origin but with little or no visible evidence of thromboembolic segmental vessel occlusion may not always benefit from PEA surgery. ${ }^{219} 220$

The mechanism underlying the development of CTEPH is not known. Two factors are important and should be distinguished: prevention of complete recanalisation of a pulmonary artery after pulmonary embolism, and the process of remodelling in small vessels. The normal pulmonary circulation carries a high fibrinolytic potential, but alteration in the fibrinolytic system has not been identified in patients with CTEPH. The only factors that have been linked to CTEPH are anticardiolipin antibodies $^{221}$ and elevated factor VIII. ${ }^{222}$ Other risk factors include chronic inflammatory disease, myeloproliferative syndromes, ventriculo-atrial shunt and splenectomy. ${ }^{223}$

\subsection{Clinical findings}

Patients with CTEPH usually present with symptoms and signs of chronic $\mathrm{PH}$, complaining of progressive dyspnoea on exertion and fatigue, with signs of right heart dysfunction. Others present after a single or recurrent episode of pulmonary embolism. Clinical findings are similar to other forms of $\mathrm{PH}$ with the addition of a bruit in the lung periphery in approximately $10 \%$ of patients. This is highly specific although of low sensitivity.

\subsection{Investigation and general management}

As the therapeutic approach to CTEPH is different to PAH, it is important to clarify the diagnosis by following the diagnostic algorithm in fig $3 .{ }^{224}$ Patients with CTEPH should receive lifelong anticoagulation with warfarin in the therapeutic range of

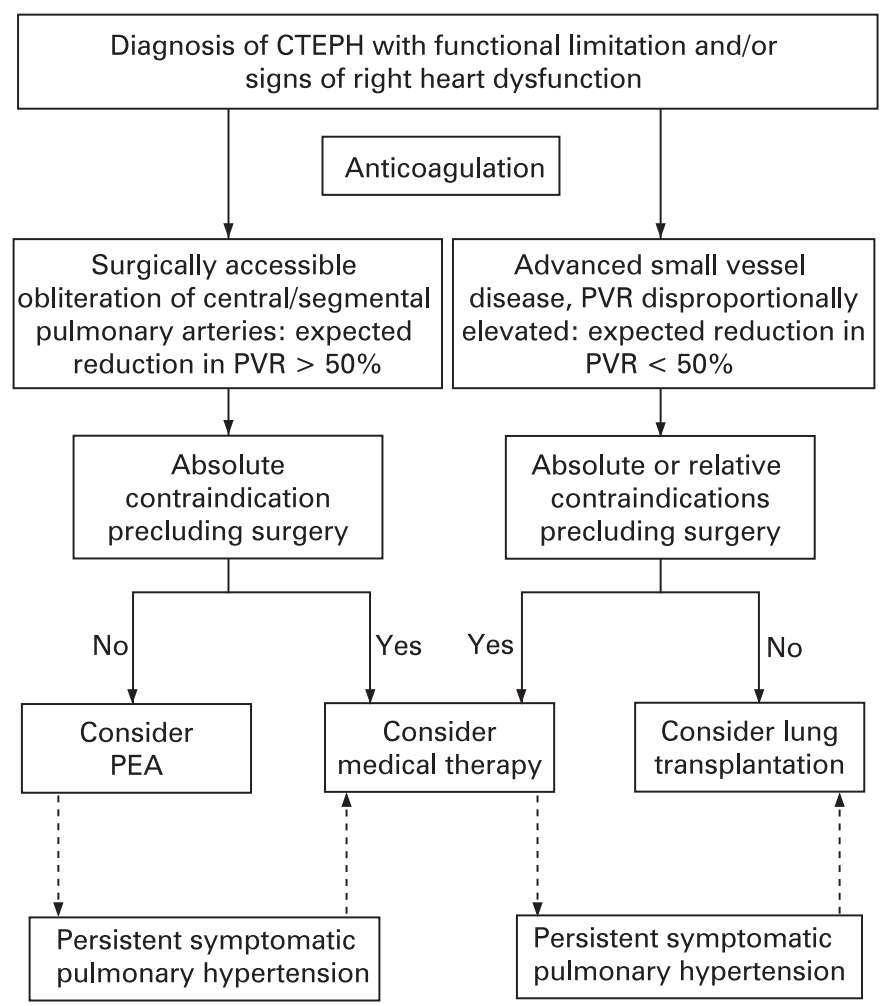

Figure 7 Algorithm for the management of patients with chronic thromboembolic pulmonary hypertension (CTEPH). PEA, pulmonary endarterectomy; PVR, pulmonary vascular resistance.

INR between 2-3.25 It is accepted worldwide practice to insert an inferior vena cava (IVC) filter in patients with CTEPH undergoing PEA surgery. There is little evidence to support this management, although there is a risk of thromboembolism in the early postoperative period until full anticoagulation is reestablished. In the UK an IVC filter is inserted in most patients and there have been no adverse consequences arising from this policy to date. In females of reproductive age the IVC filter may be removed postoperatively to avoid potential problems of IVC filters in pregnancy.

\subsection{Surgical management}

The treatment of choice for symptomatic CTEPH is PEA. ${ }^{219}$ This is the only proven treatment to offer significant symptomatic and prognostic benefit.

To identify those patients who will receive the greatest benefit from surgery, the disease has been classified into four subgroups based on the operative findings. Patients with proximal disease (types 1 and 2) have a much better risk: benefit ratio from surgery ${ }^{26}$ than more distal disease. Those with a PVR $>1200$ dyne $/ \mathrm{s} / \mathrm{cm}^{5}$ have a higher risk of mortality with attempted PEA. In particular, in patients with a PVR disproportionately higher than the segmental obstruction visible by imaging, there is less benefit from PEA and a much higher risk of mortality. Some may be considered for lung transplantation instead. Decisions regarding operability in some patients depend on the combined clinical experience of the multidisciplinary team.

Operative risk is almost totally dependent on CTEPH, and concomitant procedures (CABG, valve replacement, etc) are performed as necessary without additional risk. The only comorbidity that may influence the decision to operate is severe 
parenchymal lung disease, but there are few absolute contraindications to PEA surgery and all patients should be referred after complete investigation for consideration of surgery. Age is not a barrier to surgery, and results in patients $>80$ years are good.

\subsection{Surgical outcome}

Overall the reported operative mortality for the PEA procedure is between $5-15 \%$ in experienced centres, but is dependent on the case mix of patients.

\subsection{Medical management}

While there is no doubt that most patients with CTEPH should undergo PEA, it is uncertain how to approach those with nonsurgical distribution of the disease and those with residual $\mathrm{PH}$ post-PEA. Disease-targeted therapies for PAH are now being studied. Intravenous epoprostenol has been used as a bridge before surgery resulting in some haemodynamic stabilisation. ${ }^{227} 228$ Uncontrolled studies suggest a role for both sildenafil ${ }^{229}$ and bosentan. ${ }^{137}$ A randomised, placebo-controlled trial to establish safety and efficacy of bosentan is currently in progress. A proposed therapeutic approach to CTEPH is presented in fig $7 .{ }^{224}$ Current UK practice for medical treatment of CTEPH is to adopt the treatment algorithm as in IPAH until new evidence from randomised trials is available. Patients with significant postoperative $\mathrm{PH}$ or late recurrence of $\mathrm{PH}$ are considered for disease-targeted therapies.

\subsection{Organisation of care}

In the UK all patients with suspected CTEPH should be referred initially to their regional NCG designated PH centre who will then refer appropriate patients to the NCG designated centre for PEA surgery at Papworth Hospital.

\section{RECOMMENDATION}

62. All patients with CTEPH should be assessed for PEA unless they do not wish to undergo surgery.

63. An IVC filter should be inserted preoperatively.

64. Patients with distal CTEPH should be managed with disease-targeted therapies for PAH.

\subsection{Patient-centred outcomes}

Compared with healthy individuals, patients with $\mathrm{PH}$ suffer from limitations in their physical mobility, energy, emotional reactions and social isolation. Although measurement of HRQoL and GoL is important in this patient population, the impact of $\mathrm{PH}$ and its treatments on HRQoL or GoL has not traditionally been assessed in clinical practice.

In some clinical trials of PAH treatments HRQoL and generic measures such as the Short-Form-36, Minnesota, or the EuroQoL were assessed. ${ }^{11} 114116127172230$ The content of these is not disease-specific. A new disease-specific patient reported outcome instrument, CAMPHOR, has been developed. ${ }^{94}$ CAMPHOR correlates well with the most common surrogate end points used for assessing disease progression and is sensitive to small changes in health and QoL in this patient group. ${ }^{231}$

\section{RECOMMENDATION}

65. A QoL assessment such as CAMPHOR should be used in routine clinical practice.

\subsubsection{Follow-up and shared care}

Patients with PAH require life long follow-up since the drug treatments are not curative and the disease may break through drug treatment unpredictably. Routine follow-up should include a history and physical examination, 6MWT and CAMPHOR questionnaire. Further investigations should be performed according to the clinical status of the patient and include ECG, chest radiography, biomarkers, echocardiography, right heart catheterisation, cardiac magnetic resonance and CT.

Patients who live at a distance from a designated centre will be admitted to their local hospital in case of emergency. It is important that a local physician knows the patient. Depending on the interest of the physician and local hospital facilities shared care may be considered.

\section{RECOMMENDATION}

66. Patients with PAH, CTEPH and others treated with diseasetargeted therapy should receive life-long follow-up in an NCG designated centre.

67. Patients taking disease-targeted therapy normally require 3 monthly hospital outpatient visits.

68. Patients living at a distance from a designated centre should also be followed up by a local physician.

\subsection{Atrial septostomy}

Patients with IPAH and a patent foramen ovale (PFO) have a survival advantage over those without a $\mathrm{PFO},{ }^{232}$ supporting the concept of atrial septostomy as a treatment for IPAH. The creation of an inter-atrial right to left shunt can decompress the right ventricle, increase left ventricular preload and increase cardiac output, improving systemic oxygen transport despite arterial oxygen desaturation.

The precise role of atrial septostomy in the treatment of IPAH remains uncertain, but evidence is suggestive of benefit in patients who are in WHO functional class IV with right heart failure refractory to medical therapy or with severe syncopal symptoms. ${ }^{233-235}$

The recommended technique is graded balloon dilation atrial septostomy which produces equivalent improvements in haemodynamics and symptoms but reduced risk compared with the original blade technique. ${ }^{235} 236$ A baseline mean right atrial pressure of $>20 \mathrm{~mm} \mathrm{Hg}$ and an oxygen saturation at rest of $<80 \%$ breathing air indicates a high risk of procedure related mortality and in general atrial septostomy should be avoided. In UK practice atrial septostomy is considered only in patients who are failing medical therapies. This includes patients who are being considered for or awaiting transplantation.

Evidence suggests improvements in cardiac index following the procedure of $15-58 \%$ with improvements in 6MWT distance. ${ }^{235} 237$

Severe IPAH has been the main indication for atrial septostomy in adults, although other indications include PAH associated with surgically corrected congenital heart disease, distal CTEPH, PVOD, PCH and SSc APAH.

The impact of atrial septostomy on long term survival has not been established in prospective uncontrolled studies, but reports do support improvements in survival within the patient populations treated and late deaths are primarily due to progression of the pulmonary vascular disease which is unaffected by septostomy per se. ${ }^{235}$

\section{RECOMMENDATIONS}

69. Atrial septostomy should be regarded as a palliative or bridging procedure for patients with severe PAH failing on medical therapy. 
70. Atrial septostomy should be performed by centres with experience in the procedure of graded balloon dilation atrial septostomy, the preferred choice of procedure.

71. Patients with advanced PAH whose right atrial pressure is $>20 \mathrm{~mm} \mathrm{Hg}$ and whose oxygen saturation at rest is $<80 \%$ are at high risk of dying if the procedure is undertaken.

\subsection{Transplantation}

The advent of effective medical therapy for severe PAH has presently reduced the number of patients referred for transplantation. The long term outcomes of such patients remain uncertain and it is clear that lung or heart lung transplantation will remain an important mode of treatment both for patients failing medical treatment either following an initial period of clinical benefit or not. Transplantation guidelines have been published. ${ }^{238}$ Studies demonstrate up to $25 \%$ of patients with IPAH may fail to improve on disease-targeted therapy and the prognosis of those who remain in functional class III or IV remains poor. ${ }^{15} 107$

\subsubsection{Prognostic factors in consideration of transplant listing Aetiology}

The prognosis of $\mathrm{PAH}$ varies according to its underlying aetiology. SSc APAH has a worse prognosis than IPAH even with prostanoids. ${ }^{112} 239$ Patients with PAH associated with congenital left to right shunts have an improved survival and this has been noted in patients with advanced disease on transplant waiting lists. PVOD and $\mathrm{PCH}$ have the worst prognosis due to the lack of disease specific medical therapy.

\section{Functional studies}

In addition to WHO functional class, exercise testing correlates with survival in IPAH. A $6 \mathrm{MWT}$ distance $<332 \mathrm{~m}$ or a peak oxygen consumption $<10.4 \mathrm{ml} / \mathrm{min} / \mathrm{kg}$ is associated with a worse prognosis. ${ }^{54} 59$

\section{Haemodynamics}

Adverse predictors of poor survival include cardiac index $<2 \mathrm{l} / \mathrm{min} / \mathrm{m}^{2}$, right atrial pressure $>20 \mathrm{~mm} \mathrm{Hg}$, a mean PAP $>55 \mathrm{~mm} \mathrm{Hg}$ and a mixed venous oxygen saturation $<63 \%$. ${ }^{1}$ It is important to note that the adverse haemodynamic data do not predict a lack of potential response to medical therapy. ${ }^{240}$

\subsubsection{Choice of surgery}

For patients with PAH, choosing the transplant operation is an important facet of preoperative evaluation. Both heart lung and isolated lung transplantations have been performed for pulmonary vascular disease but heart and lung transplantation should now be reserved for patients who are not candidates for lung transplantation alone. The threshold of unrecoverable right ventricular dysfunction remains unknown and severe dysfunction has been shown to be reversible after isolated lung transplantation. While afterload is immediately reduced by lung transplantation, right ventricular dysfunction does not improve immediately and haemodynamic instability is a common problem in the early postoperative period. ${ }^{241}$ Both single lung transplantation (SLT) and bilateral lung transplantation (BLT) have been performed for PAH. While recipient survival rates have been similar after SLT and BLT for PAH, any complication in the allograft following SLT is associated with severe hypoxaemia and there has been a move towards BLT. The International Society of Heart and Lung Transplantation
(ISHLT) reported that in 2005 BLT was performed in 95\% of isolated lung transplantations for PAH.

In PAH patients with Eisenmenger syndrome the option of HLT should be carefully considered, despite the fact both SLT and BLT have been combined with repair of cardiovascular anomalies. $^{242}$

Patients with Eisenmenger syndrome due to ventricular septal defects have improved survival with HLT. ${ }^{243}$ Overall worldwide activity for HLT has dropped over the years with only 75 operations reported to the ISHLT in 2006.

\section{Outcomes}

Actuarial survival following transplantation for $\mathrm{PAH}$ has been well documented by the Registry of the ISHLT. The overall 5 year survival is $45-50 \%{ }^{244}$ Transplantation for PAH and Eisenmenger syndrome has the highest perioperative mortality among the major diagnostic categories of patients undergoing transplantation, and this is explained by the complexity of the surgery in severe PH.

\section{RECOMMENDATION}

72. Designated $\mathrm{PH}$ centres should establish a clear working relationship with a UK transplant centre to facilitate the referral process.

73. Patients should be referred if they fulfil the general international guidelines for transplantation and are functional class III or worse.

74. The potential need for transplantation should be discussed with all patients presenting in WHO functional class III. Patients in WHO functional class IV should be referred on presentation to a transplant unit if they appear to be potential candidates.

75. All candidates should be treated with disease-targeted therapy before undergoing transplantation. Transplantation should be undertaken when treatment with such therapy is failing.

76. Those patients who show significant improvements following medical therapy over the first 3 months and who in particular move to WHO class II functional status can defer further transplant assessment or listing.

\subsection{New and future therapies}

$\mathrm{PAH}$ research is currently thriving, with new drug treatments in clinical trials and several novel targets under active investigation. Interest in correcting endothelial dysfunction and increased vasomotor tone remains, but there is now greater emphasis on addressing directly the structural changes that accompany and in some cases precede the development of increased PVR. The pleotrophic effects of statins (anti-proliferation, pro-apoptosis, anti-inflammation) together with preclinical observations suggest this drug class may be beneficial in $\mathrm{PAH}$, but this remains to be demonstrated. Tyrosine kinase inhibitors such as imatinib have attracted interest following a case report, ${ }^{245}$ but the results of formal clinical studies are needed to establish safety in PAH. Other interesting pharmacological strategies include inhibition of the serotonin reuptake transporter, activation of potassium channels, inhibition of Rho kinase, and modification of mitochondrial pyruvate dehydrogenase kinase. Cell based therapy is also under investigation. Endothelial progenitor cells from patients can be expanded in culture and there is interest in using these cells to deliver gene therapy to the pulmonary vascular bed. This is at a very early 
Box 5: Types of pulmonary hypertension treated in children

1. Pulmonary arterial hypertension

1.1 IPAH

1.2 FPAH. (Children can express the same genetic mutations and deletions as adults with IPAH ${ }^{35}$ )

1.3.1 Collagen vascular disease and the vasculitides

1.3.2 Postoperative congenital heart disease (not acute postoperative pulmonary hypertension, but that sustained over many years) which can behave like IPAH

1.3.2 Congenital heart disease which has never been operable, pulmonary vascular resistance having been elevated since birth plus the classical Eisenmenger syndrome

1.4.1 Pulmonary veno-occlusive disease

1.5 Persistent pulmonary hypertension of the newborn

\section{Pulmonary hypertension with left heart disease}

2.1 Left ventricular disease caused by cardiomyopathies and congenital left heart anomalies

3. Pulmonary hypertension associated with lung diseases

3.2 Interstitial and fibrotic lung disease

\section{Thromboembolic disease is rare in childhood}

stage and further work needs to be done to establish the most appropriate cell phenotype to deploy.

$\mathrm{PAH}$ is a heterogenous condition and it is unlikely that one treatment protocol will suit all patients. Advances in our understanding of the genetic basis of FPAH have fuelled speculation that a specific corrective therapy may emerge for some patients. For many, effective treatment will lie with combination therapy. At present, the emerging strategy is to combine existing treatments (prostanoid, ERA and PDE 5 inhibitor) and new treatments will have to find their place in this hierarchy.

A challenge will be to demonstrate efficacy from novel therapies in clinical trials. Drugs which impact on vascular structure will not be expected to show acute effects on pulmonary haemodynamics. 6MWT distance has been widely used as an end point, although its limitations are widely appreciated. When looking at combination therapies and when recruiting patients with milder symptoms (WHO functional class I-II), significant increases in 6MWT distance may not be achieved due to a ceiling effect. It is clear other more sensitive tests will be required.

\section{PULMONARY HYPERTENSION IN CHILDREN}

\subsection{Introduction}

Pulmonary vascular disease may often progress while the lung is still developing and children are generally sicker than adults at presentation. The response to treatment is less predictable in children who need close monitoring and rapid escalation of therapy with any clinical deterioration. In IPAH the mean survival time without treatment is 10 months.

\subsection{Causes of pulmonary hypertension in childhood}

The Venice classification (box 1) includes all the types of $\mathrm{PH}$ encountered in childhood. The types of $\mathrm{PH}$ currently treated with disease-targeted therapy in children are shown in box 5 .

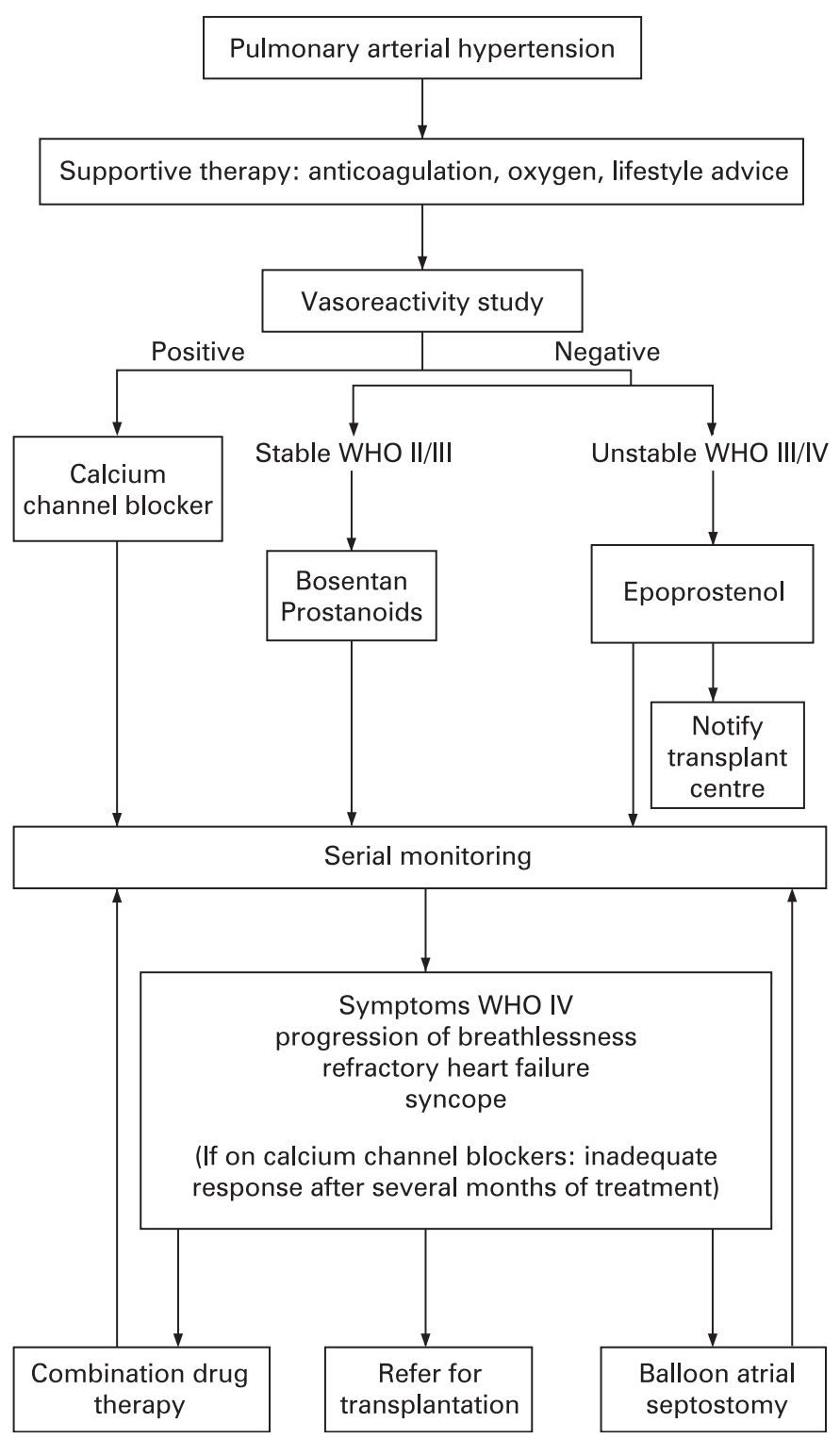

Figure 8 Algorithm for the management of pulmonary hypertension in children.

\subsection{Investigation of the pulmonary hypertensive child}

It is mandatory to make an accurate and complete diagnosis before instituting treatment. There may be an informative history of fetal or neonatal incidents, premature delivery, intrauterine growth retardation, congenital diaphragmatic hernia, or chronic lung disease. Initial investigations include an ECG, chest $x$ ray and a transthoracic echocardiogram. A $6 \mathrm{MWT}$ is performed if the child is able to cooperate. This is followed by a CT scan, and where appropriate a ventilation perfusion scan and a sleep study. Older children frequently require formal exercise testing and lung function tests. Evidence for CTD is sought. The definitive study is cardiac catheterisation following an established protocol with vasodilator testing using $\mathrm{NO}$ and a high inspired oxygen concentration.

\subsection{Medical treatment of pulmonary hypertension in children}

The treatment algorithm is a modification of the one designed for use in adults (fig 8) and has been developed from clinical experience. Children are sometimes too ill to undergo cardiac 
catheterisation $^{246}$ and treatment may have to be instituted immediately.

Only $5 \%$ of UK patients have been positive responders to vasoreactivity studies. The majority of children are therefore treated with disease-targeted therapies. These include intravenous epoprostenol ${ }^{247}$ (the only drug for children tested in a placebo-controlled trial), other prostanoids, bosentan, ${ }^{248}$ and sildenafil.

Choice of therapy is determined by WHO functional class. The age of the child is important because several drugs used to treat adults are unsuitable for young children: subcutaneous treprostinil causes site pain which is poorly tolerated; small sick children cannot reliably inhale an adequate dose of iloprost at $2-3 \mathrm{~h}$ intervals. Combination therapy is often necessary. ${ }^{107}$ Treatment regimens vary because pathogenesis, age and understanding are variable. Future therapies for children await safety data from adult studies.

Children with severe $\mathrm{PH}$ and intact atrial and ventricular septa may have syncopal attacks which require an atrial septostomy.

\subsection{Treatment outcome}

\subsubsection{Quality of life}

Every effort is made to ensure that the children have as fulfilled a life as possible and to keep the children out of hospital as much as possible. Where possible those of nursery and school age go back to school at least for some time. This includes those receiving intravenous epoprostenol.

There is currently no disease-specific quality of life assessment for children. Therefore the SF10 (QualityMetric Incorporated, Boston, USA) is used. Parents and the older children complete the form at each outpatient visit.

The results show that although physical ability is limited to approximately $50 \%$ of normal, the psychological scores are $80-90 \%$ of normal at the first and subsequent visits. ${ }^{249} 250$ Data are similar for IPAH and APAH. The quality of life score does not relate to age, time since diagnosis, PVR, type of therapy (oral, intravenous, subcutaneous, or inhaled) or cause of $\mathrm{PH}$.

\subsubsection{Survival}

Treatment with disease-targeted therapies for PAH improved survival in patients with severe pulmonary hypertension who were in WHO functional class III and IV at Great Ormond Street Hospital for Children (GOSHC). In children with IPAH the cumulative survival was $84 \%$ and $76 \%$ at 1 and 3 years, respectively. ${ }^{249} 250$ It was slightly better in those with APAH. These figures include children who died either at the onset of therapy or before therapy could be started.

\section{IPAH}

Survival is better in children given combination therapy than in those given monotherapy. ${ }^{249} 250$ According to the treatment algorithm, severely symptomatic children are given epoprostenol initially while the less symptomatic children are given bosentan. Children deteriorating on either therapy have the other drug added to their therapeutic regimen.

\section{APAH}

These children have benefited considerably from the medications used to treat patients with IPAH. The worst outcome was seen in children with postoperative pulmonary hypertension, despite being treated as aggressively as those with IPAH. Earlier recognition of pulmonary hypertension is essential in these children. Not surprisingly, the best outcome is seen in those with Eisenmenger syndrome.

\section{Benefit of atrial septostomy}

This procedure is only carried out on the severely symptomatic child with syncope, with or without right heart failure. More than 30 septostomies have been performed with no mortality. In a published series the mean age of the first 21 children treated was 8.4 years and the mean follow-up was 2.5 years. ${ }^{251}$ Atrial devices have been inserted in 10 children following which there has been no further syncope and all experienced a beneficial shift in WHO functional class.

\section{Transplantation}

Many children eventually fail medical treatment and require transplantation.

\subsection{Current service provision and education}

\subsubsection{Organisation of the clinical network}

The pulmonary hypertension team at GOSHC provides expert guidance and help to a network of paediatric cardiology centres at Leeds General Infirmary, Bristol Children's Hospital, Southampton General Hospital, Freeman Hospital Newcastle upon Tyne, Birmingham Children's Hospital, Yorkhill Hospital Glasgow and the Royal Hospital for Children, Belfast.

Each of these satellite centres has a paediatric cardiologist with a special interest in $\mathrm{PH}$. The GOSHC team hold joint clinics with local teams every 2-3 months (except Belfast), and teleclinics are interposed as needed with Belfast and Glasgow. Welsh children are seen in the Bristol clinic, with a paediatric cardiologist from the Heath Hospital Cardiff.

A genetic counselling clinic is held at GOSHC for all UK children and their families. Parents frequently demand that their other children be screened for evidence of pulmonary hypertension.

Long term support in the community is essential. This is arranged by the Clinical Nurse Specialists who have established widespread links with paediatric community nurses throughout the UK and with several hospices for children.

\section{RECOMMENDATIONS}

77. The UK Children's Service will accept referral of and/or be available to give advice for all children, even on suspicion of the diagnosis of $\mathrm{PH}$.

78. All appropriate treatment modalities that are offered to adults should be available to children including intravenous epoprostenol.

79. Close liaison with community health care professionals and schools about the pulmonary hypertensive child is essential.

\section{CLINICAL RESEARCH IMPLICATIONS}

Current therapies for PAH slow down disease progression but are not curative. New approaches to treatment will be the only means to benefit patients. As the number of clinical trials expands in such a limited patient population there are already becoming too few patients to complete all the studies which include new indications for existing therapies, investigation of benefit in diagnostic subgroups, new therapies and combinations of therapies. This demand for clinical research can only be met if the maximum number of patients is entered into trials while refining techniques used for assessing therapeutic response including imaging and biomarkers. 


\section{RECOMMENDATION}

80. Wherever possible patients with $\mathrm{PH}$ should be offered the opportunity to participate in clinical trials. This will be most efficiently achieved through designated centres which all have national and international collaborations.

Funding: The consensus meeting was sponsored by the patients' association, PHA-UK. The publication costs of this document have been met by unrestricted educational grants from Actelion Pharmaceuticals, Encysive Pharmaceuticals, GlaxoSmithKline, LungRx, Pfizer, and Bayer Schering Pharma.

Competing interests: lain Armstrong has received honoraria for lecturing and travel grants for conferences from Actelion, Schering and Encysive and is a member of the Nurse Advisory Board for Actelion. Dame Carol Black has been an advisor to Actelion, Cambridge Antibody Technology, Genzyme, and Merck \& Co. Gerry Coghlan has received financial support from Actelion for nurse specialist, audit work, consultancy service, lecturing and support for congress attendance; Lilly-Icos for consultancy service; Pfizer for lecturing; Schering for nurse specialist financial support and consultancy services. Paul Corris has been a member of advisory boards for Actelion, Encysive and Pfizer and has received honoraria for lecturing from Actelion, Pfizer and Schering. Agnes Crozier is on the Nurse Advisory board for Actelion and has received travel grants for conferences from Pfizer and Actelion. Julia De Soyza has received travel grants from Actelion, Schering and Encysive and is a member of the Nurse Advisory Board for Actelion. Charlie Elliott has received honoraria for lectures from Actelion and travel grants from Actelion and Schering. Sean Gaine has been a member of advisory boards for Actelion, GlaxoSmithKline, Encycisive and Pfizer and has received honoraria for lecturing from Actelion, GlaxoSmithKline, Encysive, and Schering. The PH Unit has received contributions to research funds from Pfizer, Schering, Actelion and GlaxoSmithKline. Michael A Gatzoulis has received honoraria for lecturing and advisory board meetings and unrestricted educational grants from Actelion and Pfizer. Simon Gibbs has been a member of advisory boards for Actelion, GlaxoSmithKline, Pfizer and Encysive and has received honoraria for lecturing from Actelion, GlaxoSmithKline and Schering. Wendy Gin-Sing is a member of the nurse advisory board for Actelion and has received grants to attend conferences from Actelion, Pfizer, Schering, Encysive, United Therapeutics and GlaxoSmithKline, and honoraria for lecturing from Actelion, Encysive and United Therapeutics. Clive Handler has received travel grants for conferences from Actelion and Encysive. Luke Howard has received travel grants and lecture fees from Actelion and GlaxoSmithKline. Sheila G Haworth has received consulting fees from Actelion, and accepting honoraria from Pfizer. The PH unit has received support for the clinical service from Actelion and GSK. Rodney Hughes has received honoraria for lecturing and travel grants from Actelion, Schering and United Therapeutics. Martin Johnson has received travel grants for conferences from Actelion, GlaxoSmithKline and Encysive. David G Kiely is a member of advisory boards for Actelion, Pfizer and Encysive Pharmaceuticals and has received honoraria for lecturing from Actelion, Schering, Pfizer and United Therapeutics. Jim Lordan has been a member of an advisory board for Encysive and has received travel grants and honoraria from Encysive. Nicholas Morrell has received honoraria for educational lectures from Actelion, United Therapeutics and GlaxoSmithKline, and has received research funding from Actelion and Novartis. Andrew Peacock is on the advisory boards for Actelion, Pfizer, GSK and Encysive, and has received lecture fees from Actelion, Pfizer, GSK and Encysive. Joanna Pepke-Zaba is a member of advisory board for Actelion and Pfizer, and has received honoraria for lecturing from Actelion and Schering. Karen Sheares has received travel grants for educational meetings/conferences from Actelion, GlaxoSmithKline and United Therapeutics. Martin Wilkins has received contributions to research funds from Pfizer and Actelion and honoraria from Pfizer, Actelion, GlaxoSmithKline and Encysive. John Wort has received contributions for research funds and travel grants from Actelion.

\section{REFERENCES}

\section{. British Cardiac Society Guidelines and Medical Practice Committee.} Recommendations on the management of pulmonary hypertension in clinical practice. Heart 2001;86(Suppl I):i1-13

2. Galie N, Torbicki A, Barst R, et al. Guidelines on diagnosis and treatment of pulmonary arterial hypertension. The Task Force on Diagnosis and Treatment of Pulmonary Arterial Hypertension of the European Society of Cardiology. Eur Heart J 2004;25:2243-78.

3. Badesch DB, Abman SH, Ahearn GS, et al. Medical therapy for pulmonary arterial hypertension: ACCP evidence-based clinical practice guidelines. Chest 2004;126 (1 Suppll:35S-62S

4. Doyle RL, McCrory D, Channick RN, et al. Surgical treatments/interventions for pulmonary arterial hypertension: ACCP evidence-based clinical practice guidelines. Chest 2004;126(1 Suppl):63S-71S.

5. McLaughlin VV, Presberg KW, Doyle RL, et al. Prognosis of pulmonary arterial hypertension: ACCP evidence-based clinical practice guidelines. Chest 2004;126(1 Suppl):78S-92S
6. Badesch DB, Abman SH, Simonneau G, et al. Medical therapy for pulmonary arterial hypertension: updated ACCP evidence-based clinical practice guidelines Chest 2007;131:1917-28.

7. Simonneau G, Galie N, Rubin LJ, et al. Clinical classification of pulmonary hypertension. J Am Coll Cardiol 2004;43(12 Suppl S):5S-12S.

8. Barst RJ, McGoon M, Torbicki A, et al. Diagnosis and differential assessment of pulmonary arterial hypertension. J Am Coll Cardiol 2004;43(12 Suppl S):40S-7S.

9. Galie N, Seeger W, Naeije R, et al. Comparative analysis of clinical trials and evidence-based treatment algorithm in pulmonary arterial hypertension. J Am Coll Cardiol 2004;43(12 Suppl S):81S-8S.

10. Klepetko W, Mayer E, Sandoval J, et al. Interventional and surgical modalities of treatment for pulmonary arterial hypertension. J Am Coll Cardiol 2004:43(12 Suppl S):73S-80S

11. Barst RJ, Rubin LJ, Long WA, et al. A comparison of continuous intravenous epoprostenol (prostacyclin) with conventional therapy for primary pulmonary hypertension. The Primary Pulmonary Hypertension Study Group. N Engl J Med 1996;334:296-302.

12. Office for National Statistics, General Register Office for Scotland, Northern Ireland Statistics \& Research Agency. http://www.statistics.gov.uk/CCl/ nugget.asp?!D = 950\&Pos $=\&$ ColRank $=2 \&$ Rank $=224$ (Accessed 3 June 2007)

13. Rich S. Executive summary from the world symposium on primary pulmonary hypertension 1998. http://www.who.int/ncd/cvd/pph.htm (Accessed 3 June 2007).

14. D'Alonzo GE, Barst RJ, Ayres SM, et al. Survival in patients with primary pulmonary hypertension. Results from a national prospective registry. Ann Intern Med 1991;115:343-9.

15. Sitbon $\mathbf{0}$, Humbert $\mathrm{M}$, Nunes $\mathrm{H}$, et al. Long-term intravenous epoprostenol infusion in primary pulmonary hypertension: prognostic factors and survival. J Am Coll Cardiol 2002; 40:780-8.

16. Jeffery TK, Morrell NW. Molecular and cellular basis of pulmonary vascular remodeling in pulmonary hypertension. Prog Cardiovasc Dis 2002;45:173-202.

17. Pietra GG, Edwards WD, Kay JM, et al. Histopathology of primary pulmonary hypertension. A qualitative and quantitative study of pulmonary blood vessels from 58 patients in the National Heart, Lung, and Blood Institute, Primary Pulmonary Hypertension Registry. Circulation 1989;80:1198-206.

18. Humbert M, Morrell NW, Archer SL, et al. Cellular and molecular pathobiology of pulmonary arterial hypertension. J Am Coll Cardiol 2004;43(12 Suppl S):13S-24S.

19. Giaid A, Yanagisawa $M$, Langleben $D$, et al. Expression of endothelin-1 in the lungs of patients with pulmonary hypertension. N Engl J Med 1993;328:1732-9.

20. Langleben D, DeMarchie M, Laporta D, et al. Endothelin-1 in acute lung injury and the adult respiratory distress syndrome. Am Rev Respir Dis 1993;148(6 Pt 1):164650 .

21. Davie N, Haleen SJ, Upton PD, et al. ET(A) and ET(B) receptors modulate the proliferation of human pulmonary artery smooth muscle cells. Am J Respir Crit Care Med 2002;165:398-405

22. Herve $\mathbf{P}$, Launay JM, Scrobohaci ML, et al. Increased plasma serotonin in primary pulmonary hypertension. Am J Med 1995;99:249-54.

23. Eddahibi $\mathbf{S}$, Humbert $\mathrm{M}$, Fadel $\mathrm{E}$, et al. Serotonin transporter overexpression is responsible for pulmonary artery smooth muscle hyperplasia in primary pulmonary hypertension. J Clin Invest 2001;108:1141-50.

24. Christman BW, McPherson CD, Newman JH, et al. An imbalance between the excretion of thromboxane and prostacyclin metabolites in pulmonary hypertension. N Engl J Med 1992;327:70-5.

25. Petkov V, Mosgoeller W, Ziesche R, et al. Vasoactive intestinal peptide as a new drug for treatment of primary pulmonary hypertension. J Clin Invest 2003;111:1339-46.

26. Rich S, Dantzker DR, Ayres SM, et al. Primary pulmonary hypertension. A national prospective study. Ann Intern Med 1987;107:216-23.

27. Abenhaim L, Moride $Y$, Brenot $F$, et al. Appetite-suppressant drugs and the risk of primary pulmonary hypertension. N Engl J Med 1996;335:609-16.

28. Ahearn GS, Tapson VF, Rebeiz A, et al. Electrocardiography to define clinical status in primary pulmonary hypertension and pulmonary arterial hypertension secondary to collagen vascular disease. Chest 2002;122:524-7.

29. Yock P, Popp R. Noninvasive estimation of right ventricular systolic pressure by Doppler ultrasound in patients with tricuspid regurgitation. Circulation 1994;70:657.

30. McQuillan BM, Picard MH, Leavitt M, et al. Clinical correlates and reference intervals for pulmonary artery systolic pressure among echocardiographically normal subjects. Circulation 2001;104:2797-802.

31. Deng Z, Morse JH, Slager SL, et al. Familial primary pulmonary hypertension (Gene PPH1) is caused by mutations in the bone morphogenetic protein receptor-II gene [In Process Citation]. Am J Hum Genet 2000;67:737-44.

32. Lane KB, Machado RD, Pauciulo MW, et al. Heterozygous germline mutations in BMPR2, encoding a TGF-beta receptor, cause familial primary pulmonary hypertension. The International PPH Consortium. Nat Genet 2000;26:81-4.

33. Trembath RC, Thomson JR, Machado RD, et al. Clinical and molecular genetic features of pulmonary hypertension in patients with hereditary hemorrhagic telangiectasia. N Engl J Med 2001;345:325-34.

34. Thomson JR, Machado RD, Pauciulo MW, et al. Sporadic primary pulmonary hypertension is associated with germline mutations of the gene encoding BMPR-II, a receptor member of the TGF-beta family. J Med Genet 2000;37:741-5.

35. Harrison RE, Berger R, Haworth SG, et al. Transforming growth factor-beta receptor mutations and pulmonary arterial hypertension in childhood. Circulation 2005:111:435-41. 
36. Machado RD, James V, Southwood M, et al. Investigation of second genetic hits at the BMPR2 locus as a modulator of disease progression in familial pulmonary arterial hypertension. Circulation 2005;111:607-13.

37. Mukerjee D, St GD, Knight C, et al. Echocardiography and pulmonary function as screening tests for pulmonary arterial hypertension in systemic sclerosis. Rheumatology (Oxford) 2004;43:461-6.

38. Daliento L, Somerville J, Presbitero P, et al. Eisenmenger syndrome. Factors relating to deterioration and death. Eur Heart J 1998;19:1845-55.

39. Gladwin MT, Sachdev V, Jison ML, et al. Pulmonary hypertension as a risk factor for death in patients with sickle cell disease. N Engl J Med 2004;350:886-95.

40. Hoeper MM, Krowka MJ, Strassburg CP. Portopulmonary hypertension and hepatopulmonary syndrome. Lancet 2004;363:1461-8.

41. Opravil M, Pechere M, Speich R, et al. HIV-associated primary pulmonary hypertension. A case control study. Swiss HIV Cohort Study. Am J Respir Crit Care Med 1997;155:990-5.

42. Mukerjee D, St GD, Coleiro B, et al. Prevalence and outcome in systemic sclerosis associated pulmonary arterial hypertension: application of a registry approach. Ann Rheum Dis 2003;62:1088-93.

43. Vegh J, Soos G, Csipo I, et al. Pulmonary arterial hypertension in mixed connective tissue disease: successful treatment with lloprost. Rheumatol Int 2006;26:264-9.

44. Hachulla $\mathbf{E}$, Gressin V, Guillevin L, et al. Early detection of pulmonary arterial hypertension in systemic sclerosis: a French nationwide prospective multicenter study. Arthritis Rheum 2005;52:3792-800.

45. Steen V, Medsger TA Jr. Predictors of isolated pulmonary hypertension in patients with systemic sclerosis and limited cutaneous involvement. Arthritis Rheum 2003:48:516-22.

46. Krowka MJ, Plevak DJ, Findlay JY, et al. Pulmonary hemodynamics and perioperative cardiopulmonary-related mortality in patients with portopulmonary hypertension undergoing liver transplantation. Liver Transp/ 2000;6:443-50.

47. Lebrec D, Capron JP, Dhumeaux D, et al. Pulmonary hypertension complicating portal hypertension. Am Rev Respir Dis 1979;120:849-56.

48. Atichartakarn V, Likittanasombat K, Chuncharunee S, et al. Pulmonary arterial hypertension in previously splenectomized patients with beta-thalassemic disorders. Int J Hematol 2003;78:139-45.

49. Hagar RW, Morris CR, Vichinsky EP. Pulmonary hypertension in thalassaemia major patients with normal left ventricular systolic function. Br J Haematol 2006;133:4335 .

50. Pengo V, Lensing AW, Prins $\mathrm{MH}$, et al. Incidence of chronic thromboembolic pulmonary hypertension after pulmonary embolism. N Engl J Med 2004;350:225764.

51. Ribeiro A, Lindmarker $P$, Johnsson $H$, et al. Pulmonary embolism: one-year followup with echocardiography Doppler and five-year survival analysis. Circulation 1999:99:1325-30.

52. Tunariu N, Gibbs SJ, Win Z, et al. Ventilation-perfusion scintigraphy is more sensitive than multidetector CTPA in detecting chronic thromboembolic pulmonary disease as a treatable cause of pulmonary hypertension. J Nucl Med 2007;48:6804.

53. American Thoracic Society. ATS statement: guidelines for the six-minute walk test. Am J Respir Crit Care Med 2002;166:111-7.

54. Miyamoto S, Nagaya N, Satoh T, et al. Clinical correlates and prognostic significance of six-minute walk test in patients with primary pulmonary hypertension. Comparison with cardiopulmonary exercise testing. Am J Respir Crit Care Med 2000;161(2 Pt 1):487-92.

55. Frost AE, Langleben D, Oudiz R, et al. The 6-min walk test (6MW) as an efficacy endpoint in pulmonary arterial hypertension clinical trials: demonstration of a ceiling effect. Vascul Pharmacol 2005;43:36-9.

56. Singh SJ, Morgan MD, Scott S, et al. Development of a shuttle walking test of disability in patients with chronic airways obstruction. Thorax 1992;47:1019-24.

57. Singh SJ, Morgan MD, Hardman AE, et al. Comparison of oxygen uptake during a conventional treadmill test and the shuttle walking test in chronic airflow limitation. Eur Respir J 1994;7:2016-20.

58. ATS/ACCP. Statement on cardiopulmonary exercise testing. Am J Respir Crit Care Med 2003;167:211-77.

59. Wensel R, Opitz CF, Anker SD, et al. Assessment of survival in patients with primary pulmonary hypertension: importance of cardiopulmonary exercise testing. Circulation 2002;106:319-24.

60. Yasunobu Y, Oudiz RJ, Sun XG, et al. End-tidal PCO2 abnormality and exercise limitation in patients with primary pulmonary hypertension. Chest 2005:127:163746.

61. Sun XG, Hansen JE, Oudiz RJ, et al. Exercise pathophysiology in patients with primary pulmonary hypertension. Circulation 2001;104:429-35.

62. Barst RJ, McGoon M, McLaughlin V, et al. Beraprost therapy for pulmonary arterial hypertension. J Am Coll Cardiol 2003;41:2119-25.

63. Barst RJ, Langleben D, Frost A, et al. Sitaxsentan therapy for pulmonary arterial hypertension. Am J Respir Crit Care Med 2004;169:441-7

64. Oudiz RJ, Barst RJ, Hansen JE, et al. Cardiopulmonary exercise testing and sixminute walk correlations in pulmonary arterial hypertension. Am J Cardiol 2006;97:123-6.

65. Fijalkowska A, Kurzyna M, Torbicki A, et al. Serum N-terminal brain natriuretic peptide as a prognostic parameter in patients with pulmonary hypertension. Chest 2006;129:1313-21.
66. Nagaya N, Nishikimi T, Uematsu M, et al. Plasma brain natriuretic peptide as a prognostic indicator in patients with primary pulmonary hypertension. Circulation 2000; 102:865-70.

67. Nagaya N, Ando M, Oya H, et al. Plasma brain natriuretic peptide as a noninvasive marker for efficacy of pulmonary thromboendarterectomy. Ann Thorac Surg 2002; 74:180-4

68. Daniels LB, Clopton P, Bhalla V, et al. How obesity affects the cut-points for B-type natriuretic peptide in the diagnosis of acute heart failure. Results from the Breathing Not Properly Multinational Study. Am Heart J 2006;151:999-1005.

69. McCullough PA, Sandberg KR. B-type natriuretic peptide and renal disease. Heart Fail Rev 2003;8:355-8.

70. Redfield MM, Rodeheffer RJ, Jacobsen SJ, et al. Plasma brain natriuretic peptide concentration: impact of age and gender. J Am Coll Cardiol 2002;40:976-82.

71. Allanore $\mathbf{Y}$, Borderie $\mathrm{D}$, Meune $\mathrm{C}$, et al. N-terminal pro-brain natriuretic peptide as a diagnostic marker of early pulmonary artery hypertension in patients with systemic sclerosis and effects of calcium-channel blockers. Arthritis Rheum 2003;48:3503-8.

72. Ishii J, Nomura M, Ito M, et al. Plasma concentration of brain natriuretic peptide as a biochemical marker for the evaluation of right ventricular overload and mortality in chronic respiratory disease. Clin Chim Acta 2000;301(1-2):19-30.

73. Leuchte $\mathbf{H H}$, Baumgartner RA, Nounou ME, et al. Brain natriuretic peptide is a prognostic parameter in chronic lung disease. Am J Respir Crit Care Med 2006;173:744-50

74. Mukerjee D, Yap LB, Holmes AM, et al. Significance of plasma N-terminal pro-brain natriuretic peptide in patients with systemic sclerosis-related pulmonary arterial hypertension. Respir Med 2003;97:1230-6.

75. Nagaya N, Nishikimi T, Uematsu $M$, et al. Secretion patterns of brain natriuretic peptide and atrial natriuretic peptide in patients with or without pulmonary hypertension complicating atrial septal defect. Am Heart J 1998;136:297-301.

76. Andreassen AK, Wergeland R, Simonsen S, et al. N-terminal pro-B-type natriuretic peptide as an indicator of disease severity in a heterogeneous group of patients with chronic precapillary pulmonary hypertension. Am J Cardiol 2006;98:525-9.

77. Leuchte HH, Holzapfel M, Baumgartner RA, et al. Characterization of brain natriuretic peptide in long-term follow-up of pulmonary arterial hypertension. Chest 2005;128:2368-74.

78. Williams $\mathbf{M H}$, Handler CE, Akram R, et al. Role of N-terminal brain natriuretic peptide (N-TproBNP) in scleroderma-associated pulmonary arterial hypertension. Eur Heart J 2006;27:1485-94.

79. Torbicki A, Kurzyna M, Kuca P, et al. Detectable serum cardiac troponin $\mathrm{T}$ as a marker of poor prognosis among patients with chronic precapillary pulmonary hypertension. Circulation 2003;108:844-8.

80. Bjornsson J, Edwards WD. Primary pulmonary hypertension: a histopathologic study of 80 cases. Mayo Clin Proc 1985;60:16-25.

81. Fuster V, Steele PM, Edwards WD, et al. Primary pulmonary hypertension: natural history and the importance of thrombosis. Circulation 1984;70:580-7.

82. Edwards BS, Weir EK, Edwards WD, et al. Coexistent pulmonary and portal hypertension: morphologic and clinical features. J Am Coll Cardiol 1987;10:1233-8.

83. Wagenvoort CA, Mulder PG. Thrombotic lesions in primary plexogenic arteriopathy. Similar pathogenesis or complication?. Chest 1993;103:844-9.

84. Herve $\mathbf{P}$, Humbert M, Sitbon 0 , et al. Pathobiology of pulmonary hypertension. The role of platelets and thrombosis. Clin Chest Med 2001;22:451-8.

85. Hoeper MM, Sosada M, Fabel H. Plasma coagulation profiles in patients with severe primary pulmonary hypertension. Eur Respir J 1998;12:1446-9.

86. Huber $\mathbf{K}$, Beckmann R, Frank $\mathrm{H}$, et al. Fibrinogen, t-PA, and PAl-1 plasma levels in patients with pulmonary hypertension. Am J Respir Crit Care Med 1994;150:92933.

87. Kawut SM, Horn EM, Berekashvili KK, et al. New predictors of outcome in idiopathic pulmonary arterial hypertension. Am J Cardiol 2005;95:199-203.

88. Rich S, Kaufmann E, Levy PS. The effect of high doses of calcium-channel blockers on survival in primary pulmonary hypertension. N Engl J Med 1992;327:76-81.

89. Sandoval J, Aguirre JS, Pulido T, et al. Nocturnal oxygen therapy in patients with the Eisenmenger syndrome. Am J Respir Crit Care Med 2001;164:1682-7.

90. Medical Research Council. Long term domiciliary oxygen therapy in chronic hypoxic cor pulmonale complicating chronic bronchitis and emphysema. Report of the Medical Research Council Working Party. Lancet 1981;i:681-6.

91. Weitzenblum E, Sautegeau A, Ehrhart M, et al. Long-term oxygen therapy can reverse the progression of pulmonary hypertension in patients with chronic obstructive pulmonary disease. Am Rev Respir Dis 1985;131:493-8.

92. British Thoracic Society. British Thoracic Society Working Group on Home Oxygen Services. BTS, 2006.

93. Lowe B, Grafe K, Ufer C, et al. Anxiety and depression in patients with pulmonary hypertension. Psychosom Med 2004;66:831-6.

94. McKenna SP, Doughty N, Meads DM, et al. The Cambridge Pulmonary Hypertension Outcome Review (CAMPHOR): a measure of health-related quality of life and quality of life for patients with pulmonary hypertension. Qual Life Res 2006;15:103-15.

95. Trussell J. Contraceptive efficacy. In: Trussell J, Hatcher R, Stewart F, eds. Contraceptive technology, 18th ed. New York: Ardent Media, 2004.

96. Thorne S, Nelson-Piercy C, MacGregor A, et al. Pregnancy and contraception in heart disease and pulmonary arterial hypertension. J Fam Plann Reprod Health Care 2006;32:75-81.

97. O'Hare R, McLoughlin C, Milligan K, et al. Anaesthesia for caesarean section in the presence of severe primary pulmonary hypertension. Br J Anaesth 1998;81:790-2. 
98. Smedstad KG, Cramb R, Morison DH. Pulmonary hypertension and pregnancy: a series of eight cases. Can J Anaesth 1994;41:502-12.

99. Weiss BM, Hess OM. Pulmonary vascular disease and pregnancy: current controversies, management strategies, and perspectives. Eur Heart J 2000;21:10415

100. Bendayan D, Hod M, Oron G, et al. Pregnancy outcome in patients with pulmonary arterial hypertension receiving prostacyclin therapy. Obstet Gynecol 2005;106(5 Pt 2):1206-10.

101. Elliot CA, Stewart P, Webster VJ, et al. The use of iloprost in early pregnancy in patients with pulmonary arterial hypertension. Eur Respir J 2005;26:168-73.

102. Kiely DG, Elliot CA, Webster VJ, et al. Pregnancy and pulmonary hypertension: new approaches to the management of a life threatening condition. In: Steer PJ, Gatzoulis MA, Baker P, eds. Heart disease and pregnancy. London: Royal College of Obstetricians Press, 2006.

103. Bonnin M, Mercier FJ, Sitbon 0, et al. Severe pulmonary hypertension during pregnancy: mode of delivery and anesthetic management of 15 consecutive cases. Anesthesiology 2005;102:1133-7.

104. Mereles D, Ehlken N, Kreuscher S, et al. Exercise and respiratory training improve exercise capacity and quality of life in patients with severe chronic pulmonary hypertension. Circulation 2006;114:1482-9.

105. Rich S, Seidlitz M, Dodin E, et al. The short-term effects of digoxin in patients with right ventricular dysfunction from pulmonary hypertension. Chest 1998;114:787-92.

106. Provencher S, Herve $P$, Jais $X$, et al. Deleterious effects of beta-blockers on exercise capacity and hemodynamics in patients with portopulmonary hypertension. Gastroenterology 2006;130:120-6.

107. McLaughlin VV, Shillington A, Rich S. Survival in primary pulmonary hypertension: the impact of epoprostenol therapy. Circulation 2002;106:1477-82.

108. Rich S, Brundage BH. High-dose calcium channel-blocking therapy for primary pulmonary hypertension: evidence for long-term reduction in pulmonary arterial pressure and regression of right ventricular hypertrophy. Circulation 1987;76:13541.

109. Rich S, Kaufmann E. High dose titration of calcium channel blocking agents for primary pulmonary hypertension: guidelines for short-term drug testing. J Am Coll Cardiol 1991;18:1323-7.

110. Sitbon 0, Humbert M, Jais X, et al. Long-term response to calcium channel blockers in idiopathic pulmonary arterial hypertension. Circulation 2005;111:310511.

111. Sitbon 0, Humbert $\mathrm{M}$, Jagot $\mathrm{JL}$, et al. Inhaled nitric oxide as a screening agent for safely identifying responders to oral calcium-channel blockers in primary pulmonary hypertension. Eur Respir J 1998;12:265-70.

112. Badesch DB, Tapson VF, McGoon MD, et al. Continuous intravenous epoprostenol for pulmonary hypertension due to the scleroderma spectrum of disease. A randomized, controlled trial. Ann Intern Med 2000;132:425-34.

113. Higenbottam T, Butt AY, McMahon A, et al. Long-term intravenous prostaglandin (epoprostenol or iloprost) for treatment of severe pulmonary hypertension. Heart 1998;80:151-5.

114. Olschewski H, Simonneau G, Galie N, et al. Inhaled iloprost for severe pulmonary hypertension. N Engl J Med 2002;347:322-9.

115. Rubin LJ, Mendoza J, Hood M, et al. Treatment of primary pulmonary hypertension with continuous intravenous prostacyclin (epoprostenol). Results of a randomized trial. Ann Intern Med 1990;112:485-91.

116. Simonneau G, Barst RJ, Galie N, et al. Continuous subcutaneous infusion of treprostinil, a prostacyclin analogue, in patients with pulmonary arterial hypertension: a double-blind, randomized, placebo-controlled trial. Am J Respir Crit Care Med 2002;165:800-4

117. Barst RJ, Rubin LJ, McGoon MD, et al. Survival in primary pulmonary hypertension with long-term continuous intravenous prostacyclin. Ann Intern Med 1994;121:40915

118. Barst RJ, Galie N, Naeije R, et al. Long-term outcome in pulmonary arterial hypertension patients treated with subcutaneous treprostinil. Eur Respir $J$ 2006;28:1195-203.

119. Higenbottam TW, Butt AY, Dinh XA, et al. Treatment of pulmonary hypertension with the continuous infusion of a prostacyclin analogue, iloprost. Heart 1998;79:175-9.

120. Hoeper MM, Schwarze M, Ehlerding S, et al. Long-term treatment of primary pulmonary hypertension with aerosolized iloprost, a prostacyclin analogue. N Engl J Med 2000;342:1866-70

121. Lang I, Gomez-Sanchez M, Kneussl M, et al. Efficacy of long-term subcutaneous treprostinil sodium therapy in pulmonary hypertension. Chest 2006;129:1636-43.

122. McLaughlin VV, Genthner DE, Panella MM, et al. Compassionate use of continuous prostacyclin in the management of secondary pulmonary hypertension: a case series. Ann Intern Med 1999;130:740-3

123. Olschewski H, Ghofrani HA, Schmehl T, et al. Inhaled iloprost to treat severe pulmonary hypertension. An uncontrolled trial. German PPH Study Group. Ann Intern Med 2000;132:435-43.

124. Opitz CF, Wensel R, Winkler J, et al. Clinical efficacy and survival with first-line inhaled iloprost therapy in patients with idiopathic pulmonary arterial hypertension. Eur Heart J 2005;26:1895-902.

125. Rosenzweig EB, Kerstein D, Barst RJ. Long-term prostacyclin for pulmonary hypertension with associated congenital heart defects. Circulation 1999;99:185865.
126. Tapson VF, Gomberg-Maitland M, McLaughlin VV, et al. Safety and efficacy of IV treprostinil for pulmonary arterial hypertension: a prospective, multicenter, openlabel, 12-week trial. Chest 2006;129:683-8

127. Galie N, Ghofrani HA, Torbicki A, et al. Sildenafil citrate therapy for pulmonary arterial hypertension. N Engl J Med 2005;353:2148-57.

128. Wilkins MR, Paul GA, Strange JW, et al. Sildenafil versus Endothelin Receptor Antagonist for Pulmonary Hypertension (SERAPH) study. Am J Respir Crit Care Med 2005; 171:1292-7

129. Mikhail GW, Prasad SK, Li W, et al. Clinical and haemodynamic effects of sildenafil in pulmonary hypertension: acute and mid-term effects. Eur Heart J 2004;25:431-6.

130. Sastry BK, Narasimhan C, Reddy NK, et al. Clinical efficacy of sildenafil in primary pulmonary hypertension: a randomized, placebo-controlled, double-blind, crossover study. J Am Coll Cardiol 2004;43:1149-53.

131. Barst RJ, Langleben D, Badesch D, et al. Treatment of pulmonary arterial hypertension with the selective endothelin-A receptor antagonist sitaxsentan. J Am Coll Cardiol 2006; 47:2049-56.

132. Channick RN, Simonneau G, Sitbon 0, et al. Effects of the dual endothelin-receptor antagonist bosentan in patients with pulmonary hypertension: a randomised placebo-controlled study. Lancet 2001;358:1119-23.

133. Denton CP, Humbert M, Rubin L, et al. Bosentan treatment for pulmonary arterial hypertension related to connective tissue disease: a subgroup analysis of the pivotal clinical trials and their open-label extensions. Ann Rheum Dis 2006;65:1336-40.

134. Galie N, Beghetti M, Gatzoulis MA et al. Bosentan therapy in patients with Eisenmenger syndrome: a multicenter, double-blind, randomized, placebo-controlled study. Circulation 2006;114:48-54

135. Rubin LJ, Badesch DB, Barst RJ, et al. Bosentan therapy for pulmonary arterial hypertension. N Engl J Med 2002;346:896-903.

136. Barst RJ, Ivy D, Dingemanse J, et al. Pharmacokinetics, safety, and efficacy of bosentan in pediatric patients with pulmonary arterial hypertension. Clin Pharmacol Ther 2003; 73:372-82.

137. Hughes RJ, Jais X, Bonderman D, et al. The efficacy of bosentan in inoperable chronic thromboembolic pulmonary hypertension: a 1-year follow-up study. Eur Respir J 2006;28:138-43.

138. McLaughlin VV, Sitbon 0, Badesch DB, et al. Survival with first-line bosentan in patients with primary pulmonary hypertension. Eur Respir J 2005;25:244-9.

139. Provencher S, Sitbon O, Humbert M, et al. Long-term outcome with first-line bosentan therapy in idiopathic pulmonary arterial hypertension. Eur Heart $J$ 2006;27:589-95.

140. Sitbon 0, Gressin V, Speich R, et al. Bosentan for the treatment of human immunodeficiency virus-associated pulmonary arterial hypertension. Am J Respir Crit Care Med 2004;170:1212-7

141. Williams MH, Das C, Handler CE, et al. Systemic sclerosis associated pulmonary hypertension: improved survival in the current era. Heart 2006;92:926-32.

142. Langleben D, Hirsch AM, Shalit E, et al. Sustained symptomatic, functional, and hemodynamic benefit with the selective endothelin-A receptor antagonist, sitaxsentan, in patients with pulmonary arterial hypertension: a 1-year follow-up study. Chest 2004;126:1377-81.

143. Apostolopoulou SC, Manginas A, Cokkinos DV, et al. Long-term oral bosentan treatment in patients with pulmonary arterial hypertension related to congenita heart disease: a 2-year study. Heart 2007:93:350-4.

144. Hoeper MM, Leuchte $\mathrm{H}$, Halank M, et al. Combining inhaled iloprost with bosentan in patients with idiopathic pulmonary arterial hypertension. Eur Respir $\mathrm{J}$ 2006;28:691-4.

145. Humbert M, Barst RJ, Robbins IM, et al. Combination of bosentan with epoprostenol in pulmonary arterial hypertension: BREATHE-2. Eur Respir $J$ 2004:24:353-9.

146. McLaughlin VV, Oudiz RJ, Frost A, et al. Randomized study of adding inhaled iloprost to existing bosentan in pulmonary arterial hypertension. Am J Respir Crit Care Med 2006;174:1257-63.

147. Ghofrani HA, Rose F, Schermuly RT, et al. Oral sildenafil as long-term adjunct therapy to inhaled iloprost in severe pulmonary arterial hypertension. J Am Coll Cardiol 2003;42:158-64.

148. Gomberg-Maitland M, McLaughlin V, Gulati M, et al. Efficacy and safety of sildenafil added to treprostinil in pulmonary hypertension. Am J Cardiol 2005;96:1334-6

149. Hoeper MM, Faulenbach C, Golpon H, et al. Combination therapy with bosentan and sildenafil in idiopathic pulmonary arterial hypertension. Eur Respir $\mathrm{J}$ 2004;24:1007-10

150. Hoeper MM, Markevych I, Spiekerkoetter E, et al. Goal-oriented treatment and combination therapy for pulmonary arterial hypertension. Eur Respir J 2005;26:85863.

151. Humbert M, Sitbon O, Simonneau G. Novel therapeutic perspectives in pulmonary arterial hypertension. Eur Respir J 2003;22:193-4

152. Farber HW, Loscalzo J. Pulmonary arterial hypertension. N Engl J Med 2004:351:1655-65.

153. Rubin LJ, Galie N. Pulmonary arterial hypertension: a look to the future. J Am Coll Cardiol 2004:43(12 Suppl S):89S-90S.

154. Hoeper MM, Spiekerkoetter E, Westerkamp V, et al. Intravenous iloprost for treatment failure of aerosolised iloprost in pulmonary arterial hypertension. Eur Respir J 2002;20:339-43.

155. Steiner MK, Preston IR, Klinger JR, et al. Conversion to bosentan from prostacyclin infusion therapy in pulmonary arterial hypertension: a pilot study. Chest 2006:130:1471-80. 
156. Rabe KF, Tenor H, Dent G, et al. Identification of PDE isozymes in human pulmonary artery and effect of selective PDE inhibitors. Am J Physiol 1994;266(5 Pt 1):L53643.

157. Beavo JA. Cyclic nucleotide phosphodiesterases: functional implications of multiple isoforms. Physiol Rev 1995;75:725-48.

158. Ghofrani HA, Wiedemann R, Rose F, et al. Combination therapy with oral sildenafil and inhaled iloprost for severe pulmonary hypertension. Ann Intern Med 2002; 136:515-22.

159. Ono F, Nagaya N, Kyotani S, et al. Hemodynamic and hormonal effects of beraprost sodium, an orally active prostacyclin analogue, in patients with secondary precapillary pulmonary hypertension. Circ J 2003;67:375-8.

160. Clozel M, Hess P, Rey M, et al. Bosentan, sildenafil, and their combination in the monocrotaline model of pulmonary hypertension in rats. Exp Biol Med (Maywood) 2006;231:967-73

161. Wedgwood S, Black SM. Endothelin-1 decreases endothelial NOS expression and activity through ETA receptor-mediated generation of hydrogen peroxide. Am J Physiol Lung Cell Mol Physiol 2005;288:L480-7.

162. Girgis RE, Champion HC, Diette GB, et al. Decreased exhaled nitric oxide in pulmonary arterial hypertension: response to bosentan therapy. Am J Respir Crit Care Med 2005;172:352-7.

163. Lunze K, Gilbert N, Mebus S, et al. First experience with an oral combination therapy using bosentan and sildenafil for pulmonary arterial hypertension. Eur J Clin Invest 2006;36(Suppl 3):32-8

164. Mathai SC, Girgis RE, Fisher MR, et al. Addition of sildenafil to bosentan monotherapy in pulmonary arterial hypertension. Eur Respir J 2007;29:469-75.

165. Wilkens H, Guth A, Konig J, et al. Effect of inhaled iloprost plus oral sildenafil in patients with primary pulmonary hypertension. Circulation 2001;104:1218-22.

166. Paul GA, Gibbs JS, Boobis AR, et al. Bosentan decreases the plasma concentration of sildenafil when coprescribed in pulmonary hypertension. Br J Clin Pharmacol 2005;60:107-12.

167. Sanchez $\mathbf{0}$, Humbert $\mathrm{M}$, Sitbon 0 , et al. Treatment of pulmonary hypertension secondary to connective tissue diseases. Thorax 1999;54:273-7.

168. Huffman M, Montgomery D, Seibold JR. Vasodilator response in sclerodermarelated pulmonary arterial hypertension. Am J Respir Crit Care Med 2006;173:A59.

169. Sitbon 0, Humbert M, Jais X. Acute vasodilator response to calcium channe blockers in different forms of pulmonary arterial hypertension. Am J Respir Crit Care Med 2004:169:A210.

170. Kawut SM, Taichman DB, Archer-Chicko CL, et al. Hemodynamics and survival in patients with pulmonary arterial hypertension related to systemic sclerosis. Chest 2003;123:344-50

171. Koh ET, Lee P, Gladman DD, et al. Pulmonary hypertension in systemic sclerosis: an analysis of 17 patients. Br J Rheumatol 1996;35:989-93.

172. Galie N, Humbert M, Vachiery JL, et al. Effects of beraprost sodium, an oral prostacyclin analogue, in patients with pulmonary arterial hypertension: a randomized, double-blind, placebo-controlled trial. J Am Coll Cardiol 2002;39:1496502.

173. Oudiz RJ, Schilz RJ, Barst RJ, et al. Treprostinil, a prostacyclin analogue, in pulmonary arterial hypertension associated with connective tissue disease. Chest 2004;126:420-7.

174. Vancheeswaran R, Azam A, Black C, et al. Localization of endothelin-1 and its binding sites in scleroderma skin. J Rheumatol 1994;21:1268-76.

175. Yamane K, Miyauchi T, Suzuki N, et al. Significance of plasma endothelin-1 levels in patients with systemic sclerosis. J Rheumatol 1992:19:1566-71.

176. Shi-Wen X, Rodriguez-Pascual F, Lamas S, et al. Constitutive ALK5-independent cJun $\mathrm{N}$-terminal kinase activation contributes to endothelin-1 overexpression in pulmonary fibrosis: evidence of an autocrine endothelin loop operating through the endothelin A and B receptors. Mol Cell Biol 2006;26:5518-27.

177. Kim NH, Rubin LJ. Endothelin in health and disease: endothelin receptor antagonists in the management of pulmonary artery hypertension. $J$ Cardiovasc Pharmacol Ther 2002; 7:9-19

178. Humbert M, Segal ES, Kiely DG, et al. Results of European post-marketing surveillance of bosentan in pulmonary hypertension. Eur Respir J 2007;30:338-44.

179. Seibold JR, Langleben D, Badesch D. Sitaxsentan, a selective endothelin receptor A antagonist, improves exercise capacity in PAH associated with CTD. EULAR 2006;:SAT0233.

180. Simoneau G, Burgess G, Parpia T. Sildenafil improves exercise ability and haemodynamics in patients with pulmonary arterial hypertension associated with connective tissue disease. Ann Rheum Dis 2005;64(Suppl III):109.

181. Cantor WJ, Harrison DA, Moussadji JS, et al. Determinants of survival and length of survival in adults with Eisenmenger syndrome. Am J Cardiol 1999;84:677-81.

182. Diller GP, Dimopoulos K, Broberg CS, et al. Presentation, survival prospects, and predictors of death in Eisenmenger syndrome: a combined retrospective and casecontrol study. Eur Heart J 2006;27:1737-42.

183. Diller GP, Dimopoulos K, Okonko D, et al. Exercise intolerance in adult congenital heart disease: comparative severity, correlates, and prognostic implication. Circulation 2005;112:828-35.

184. Dimopoulos K, Okonko DO, Diller GP, et al. Abnormal ventilatory response to exercise in adults with congenital heart disease relates to cyanosis and predicts survival. Circulation 2006;113:2796-802.

185. Broberg CS, Bax BE, Okonko DO, et al. Blood viscosity and its relationship to iron deficiency, symptoms, and exercise capacity in adults with cyanotic congenital heart disease. J Am Coll Cardiol 2006:48:356-65.
186. Broberg C, Ujita M, Babu-Narayan S, et al. Massive pulmonary artery thrombosis with haemoptysis in adults with Eisenmenger's syndrome: a clinical dilemma. Heart 2004;90:e63.

187. Post MC, Janssens S, Van de WF, et al. Responsiveness to inhaled nitric oxide is a predictor for mid-term survival in adult patients with congenital heart defects and pulmonary arterial hypertension. Eur Heart J 2004;25:1651-6.

188. Stoica SC, McNeil KD, Perreas K, et al. Heart-lung transplantation for Eisenmenger syndrome: early and long-term results. Ann Thorac Surg 2001;72:1887-91.

189. Diller GP, Dimopoulos K, Kaya MG, et al. Long-term safety, tolerability and efficacy of bosentan in adults with pulmonary arterial hypertension associated with congenital heart disease. Heart 2007:93:974-6.

190. Davies P, Reid L. Pulmonary veno-occlusive disease in siblings: case reports and morphometric study. Hum Pathol 1982;13:911-5.

191. Langleben D, Heneghan JM, Batten AP, et al. Familial pulmonary capillary hemangiomatosis resulting in primary pulmonary hypertension. Ann Intern Med 1988; 109:106-9.

192. Langleben D, Heneghan JM, Batten AP, et al. Familial pulmonary capillary hemangiomatosis resulting in primary pulmonary hypertension [erratum appears in Ann Intern Med 1988;109:439]. Ann Intern Med 1988;109:106-9.

193. Runo JR, Vnencak-Jones CL, Prince M, et al. Pulmonary veno-occlusive disease caused by an inherited mutation in bone morphogenetic protein receptor II. Am J Respir Crit Care Med 2003;167:889-94.

194. Holcomb BW Jr, Loyd JE, Ely EW, et al. Pulmonary veno-occlusive disease: a case series and new observations. Chest 2000:118:1671-9.

195. Resten A, Maitre S, Humbert M, et al. Pulmonary hypertension: CT of the chest in pulmonary venoocclusive disease. AJR Am J Roentgenol 2004;183:65-70.

196. Rabiller A, Jais X, Hamid A, et al. Occult alveolar haemorrhage in pulmonary venoocclusive disease. Eur Respir J 2006;27:108-13.

197. Wagenvoort CA, Wagenvoort N. The pathology of pulmonary veno-occlusive disease. Virchows Arch A Pathol Anat Histol 1974;364:69-79.

198. Wagenvoort CA, Beetstra A, Spijker J. Capillary haemangiomatosis of the lungs Histopathology 1978;2:401-6.

199. Gugnani MK, Pierson C, Vanderheide R, et al. Pulmonary edema complicating prostacyclin therapy in pulmonary hypertension associated with scleroderma: a case of pulmonary capillary hemangiomatosis. Arthritis Rheum 2000;43:699-703.

200. Humbert M, Maitre S, Capron F, et al. Pulmonary edema complicating continuous intravenous prostacyclin in pulmonary capillary hemangiomatosis. Am J Respir Crit Care Med 1998;157(5 Pt 1):1681-5

201. Palmer SM, Robinson LJ, Wang A, et al. Massive pulmonary edema and death after prostacyclin infusion in a patient with pulmonary veno-occlusive disease. Chest 1998:113:237-40.

202. Resten A, Maitre S, Humbert M, et al. Pulmonary arterial hypertension: thin-section CT predictors of epoprostenol therapy failure. Radiology 2002;222:782-8.

203. Almagro P, Julia J, Sanjaume M, et al. Pulmonary capillary hemangiomatosis associated with primary pulmonary hypertension: report of 2 new cases and review of 35 cases from the literature. Medicine (Baltimore) 2002:81:417-24.

204. Okumura H, Nagaya N, Kyotani S, et al. Effects of continuous IV prostacyclin in a patient with pulmonary veno-occlusive disease. Chest 2002;122:1096-8.

205. Palevsky HI, Pietra GG, Fishman AP. Pulmonary veno-occlusive disease and its response to vasodilator agents. Am Rev Respir Dis 1990;142:426-9.

206. Salzman D, Adkins DR, Craig F, et al. Malignancy-associated pulmonary venoocclusive disease: report of a case following autologous bone marrow transplantation and review. Bone Marrow Transplant 1996;18:755-60.

207. Barreto AC, Franchi SM, Castro CR, et al. One-year follow-up of the effects of sildenafil on pulmonary arterial hypertension and veno-occlusive disease. Braz J Med Biol Res 2005;38:185-95.

208. Ginns LC, Roberts DH, Mark EJ, et al. Pulmonary capillary hemangiomatosis with atypical endotheliomatosis: successful antiangiogenic therapy with doxycycline. Chest 2003;124:2017-22

209. White CW, Sondheimer HM, Crouch EC, et al. Treatment of pulmonary hemangiomatosis with recombinant interferon alfa-2a. N Engl J Med 1989;320:1197-200.

210. Anon. Case records of the Massachusetts General Hospital. Weekly clinicopathological exercises. Case 48-1993. A 27-year-old woman with mediastina lymphadenopathy and relentless cor pulmonale. N Engl J Med 1993;329:1720-8.

211. Mandel J, Mark EJ, Hales CA. Pulmonary veno-occlusive disease. Am J Respir Crit Care Med 2000;162:1964-73

212. Izbicki G, Shitrit D, Schechtman I, et al. Recurrence of pulmonary veno-occlusive disease after heart-lung transplantation. J Heart Lung Transplant 2005;24:635-7.

213. Fedullo PF, Auger WR, Kerr KM, et al. Chronic thromboembolic pulmonary hypertension. N Engl J Med 2001;345:1465-72.

214. Moser KM, Auger WR, Fedullo PF. Chronic major-vessel thromboembolic pulmonary hypertension. Circulation 1990:81:1735-43.

215. Riedel M, Stanek V, Widimsky J, et al. Longterm follow-up of patients with pulmonary thromboembolism. Late prognosis and evolution of hemodynamic and respiratory data. Chest 1982:81:151-8.

216. Dartevelle $\mathbf{P}$, Fadel $\mathrm{E}$, Mussot $\mathrm{S}$, et al. Chronic thromboembolic pulmonary hypertension. Eur Respir J 2004:23:637-48.

217. Arbustini E, Morbini P, D'Armini AM, et al. Plaque composition in plexogenic and thromboembolic pulmonary hypertension: the critical role of thrombotic material in pultaceous core formation. Heart 2002:88:177-82. 
218. Moser KM, Bloor CM. Pulmonary vascular lesions occurring in patients with chronic major vessel thromboembolic pulmonary hypertension. Chest 1993;103:685-92.

219. Jamieson SW, Kapelanski DP, Sakakibara N, et al. Pulmonary endarterectomy: experience and lessons learned in 1,500 cases. Ann Thorac Surg 2003;76: 1457-62.

220. Kim NH, Fesler P, Channick RN, et al. Preoperative partitioning of pulmonary vascular resistance correlates with early outcome after thromboendarterectomy for chronic thromboembolic pulmonary hypertension. Circulation 2004:109:18-22.

221. Wolf M, Boyer-Neumann C, Parent F, et al. Thrombotic risk factors in pulmonary hypertension. Eur Respir J 2000;15:395-9.

222. Bonderman D, Turecek PL, Jakowitsch J, et al. High prevalence of elevated clotting factor VIII in chronic thromboembolic pulmonary hypertension. Thromb Haemost 2003;90:372-6.

223. Bonderman D, Jakowitsch J, Adlbrecht C, et al. Medical conditions increasing the risk of chronic thromboembolic pulmonary hypertension. Thromb Haemost 2005;93:512-6.

224. Hoeper MM, Mayer E, Simonneau G, et al. Chronic thromboembolic pulmonary hypertension. Circulation 2006:113:2011-20.

225. Baglin TP, Keeling DM, Watson HG. Guidelines on oral anticoagulation (warfarin): third edition-2005 update. Br J Haematol 2006:132:277-85.

226. Thistlethwaite PA, Mo M, Madani MM, et al. Operative classification of thromboembolic disease determines outcome after pulmonary endarterectomy. J Thorac Cardiovasc Surg 2002:124:1203-11.

227. Bresser P, Fedullo PF, Auger WR, et al. Continuous intravenous epoprostenol for chronic thromboembolic pulmonary hypertension. Eur Respir J 2004:23:595-600.

228. Kerr KM, Rubin LJ. Epoprostenol therapy as a bridge to pulmonary thromboendarterectomy for chronic thromboembolic pulmonary hypertension. Chest 2003:123:319-20.

229. Ghofrani HA, Schermuly RT, Rose F, et al. Sildenafil for long-term treatment of nonoperable chronic thromboembolic pulmonary hypertension. Am J Respir Crit Care Med 2003;167:1139-41.

230. Cenedese E, Speich R, Dorschner L, et al. Measurement of quality of life in pulmonary hypertension and its significance. Eur Respir J 2006:28:808-15.

231. Doughty N, McKenna SP, Meads DM, et al. The CAMPHOR: correlation of objective measures of severity of pulmonary hypertension. Proceedings of the American Thoracic Society 2005;2:A801.

232. Glanville AR, Burke CM, Theodore J, et al. Primary pulmonary hypertension. Length of survival in patients referred for heart-lung transplantation. Chest 1987;91:675-81.

233. Kothari SS, Yusuf A, Juneja R, et al. Graded balloon atrial septostomy in severe pulmonary hypertension. Indian Heart J 2002;54:164-9.

234. Nihill MR, O'Laughlin MP, Mullins CE. Effects of atrial septostomy in patients with terminal cor pulmonale due to pulmonary vascular disease. Cathet Cardiovasc Diagn 1991;24:166-72.
235. Sandoval J, Gaspar J, Pulido T, et al. Graded balloon dilation atrial septostomy in severe primary pulmonary hypertension. A therapeutic alternative for patients nonresponsive to vasodilator treatment. J Am Coll Cardiol 1998;32:297-304.

236. Rothman A, Sklansky MS, Lucas VW, et al. Atrial septostomy as a bridge to lung transplantation in patients with severe pulmonary hypertension. Am J Cardiol 1999;84:682-6.

237. Kerstein D, Levy PS, Hsu DT, et al. Blade balloon atrial septostomy in patients with severe primary pulmonary hypertension. Circulation 1995;91:2028-35.

238. Orens JB, Estenne M, Arcasoy S, et al. International guidelines for the selection of lung transplant candidates: 2006 update - a consensus report from the Pulmonary Scientific Council of the International Society for Heart and Lung Transplantation. $J$ Heart Lung Transplant 2006;25:745-55.

239. Humbert M, Sanchez O, Fartoukh M, et al. Treatment of severe pulmonary hypertension secondary to connective tissue diseases with continuous IV epoprostenol (prostacyclin). Chest 1998;114(1 Suppl):80S-2S.

240. Rich S, Levy PS. Characteristics of surviving and nonsurviving patients with primary pulmonary hypertension. Am J Med 1984;76:573-8.

241. Boujoukos AJ, Martich GD, Vega JD, et al. Reperfusion injury in single-lung transplant recipients with pulmonary hypertension and emphysema. J Heart Lung Transplant 1997:16:439-48.

242. Bando K, Armitage JM, Paradis IL, et al. Indications for and results of single, bilateral, and heart-lung transplantation for pulmonary hypertension. J Thorac Cardiovasc Surg 1994;108:1056-65.

243. Waddell TK, Bennett L, Kennedy R, et al. Heart-lung or lung transplantation for Eisenmenger syndrome. J Heart Lung Transplant 2002;21:731-7.

244. Trulock EP, Edwards LB, Taylor DO, et al. Registry of the International Society for Heart and Lung Transplantation: twenty-third official adult lung and heart-lung transplantation report-2006. J Heart Lung Transplant 2006;25:880-92.

245. Ghofrani HA, Seeger W, Grimminger F. Imatinib for the treatment of pulmonary arterial hypertension. N Engl J Med 2005;353:1412-3.

246. Taylor CJ, Derrick G, McEwan A, et al. Risk of cardiac catheterization under anaesthesia in children with pulmonary hypertension. Br J Anaesth 2007:98:657-61.

247. Lammers $\mathbf{A E}$, Hislop $A A$, Flynn $Y$, et al. Epoprostenol treatment in children with severe pulmonary hypertension. Heart 2007;93:739-43.

248. Maiya S, Hislop AA, Flynn $Y$, et al. Response to bosentan in children with pulmonary hypertension. Heart 2006;92:664-70.

249. Haworth S, Flynn Y, Hislop AA. Survival and quality of life in children with severe pulmonary hypertension. Heart 2006:92(Suppl II):A14.

250. Hislop AA, Flynn Y, Haworth SG. Summary of the experiences of the UK pulmonary hypertension service for children 2001-2005. Proceedings of the American Thoracic Society 2006;3:A57.

251. Micheletti A, Hislop AA, Lammers A, et al. Role of atrial septostomy in the treatment of children with pulmonary arterial hypertension. Heart 2006;:92:969-72 


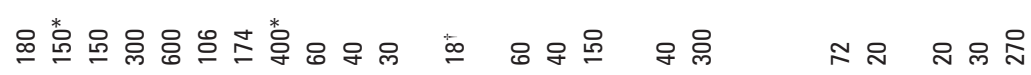

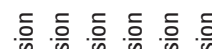

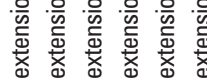

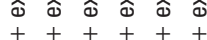

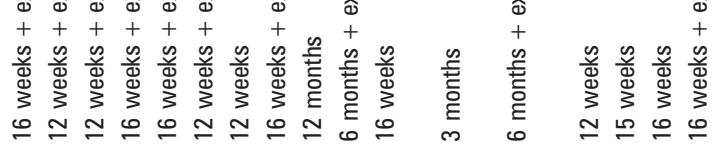

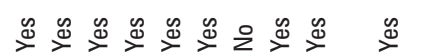

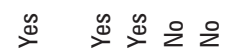

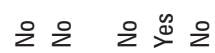

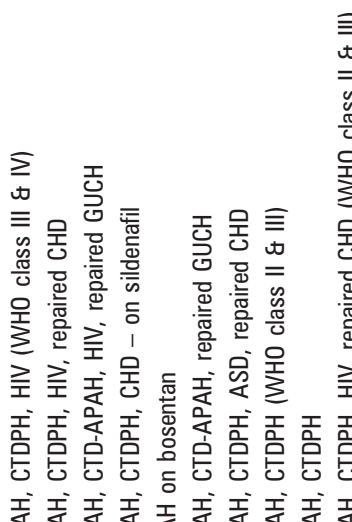

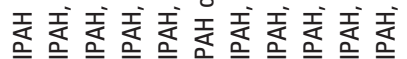

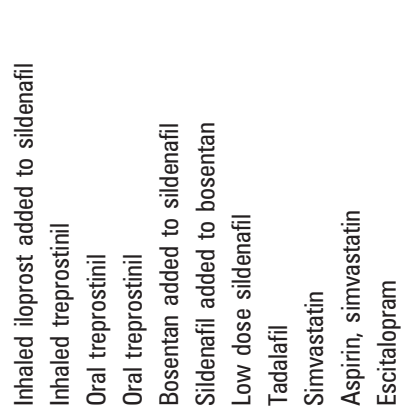

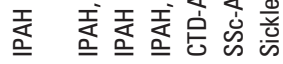
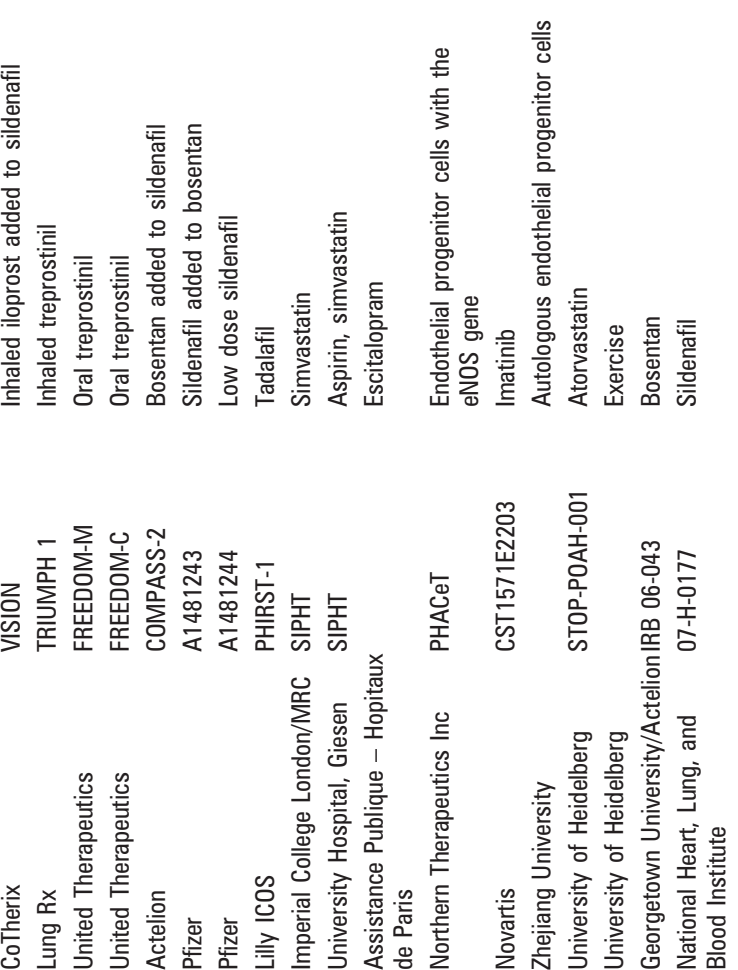